KITest: Um arcabouço de conhecimento e melhoria de processo de teste

\author{
Erika Nina Höhn
}





\title{
KITest: Um arcabouço de conhecimento e melhoria de processo de teste
}

\author{
Erika Nina Höhn
}

Orientador: Prof. Dr. José Carlos Maldonado

Tese apresentada ao Instituto de Ciências Matemáticas e de Computação - ICMC-USP, como parte dos requisitos para obtenção do título de Doutor em Ciências - Ciências de Computação e Matemática Computacional. EXEMPLAR DE DEFESA.

\section{USP - São Carlos}

Junho de 2011 
Ficha catalográfica elaborada pela Biblioteca Prof. Achille Bassi e Seção Técnica de Informática, ICMC/USP, com os dados fornecidos pelo(a) autor(a)

\begin{tabular}{|c|c|}
\hline \multirow[t]{3}{*}{$\mathrm{H} 717 \mathrm{k}$} & $\begin{array}{l}\text { Höhn, Erika } \\
\text { KITest: Um arcabouço de conhecimento e melhoria de } \\
\text { processo de teste / Erika Höhn; orientador José } \\
\text { Carlos Maldonado -- São Carlos, } 2011 . \\
\quad 93 \text { p. }\end{array}$ \\
\hline & $\begin{array}{l}\text { Tese (Doutorado - Programa de Pós-Graduação em } \\
\text { Ciências de Computação e Matemática Computacional) -- } \\
\text { Instituto de Ciências Matemáticas e de Computação, } \\
\text { Universidade de São Paulo, } 2011 .\end{array}$ \\
\hline & $\begin{array}{l}\text { 1. Teste de software. 2. Gestão de conhecimento. } \\
\text { 3. Melhoria de processo. I. Maldonado, José Carlos, } \\
\text { orient. II. Título. }\end{array}$ \\
\hline
\end{tabular}




\section{Agradecimentos}

A Deus, por todas as chances e coisas que aconteceram em minha vida. Tudo teve seu propósito e sua ordem necessária de acontecimento.

Aos meus pais, Ivo Anselmo Höhn (in memorian) e Maria do Socorro Nina Höhn, por todo incentivo, dedicação e oportunidades dadas aos meus estudos. Mamãe que mesmo coma distância sempre incentivando, tentando animar e passar confiança e fé.

Aos meus irmãos Ivo e Hans, por todo apoio - tanto a mim, quanto aos de casa em São Luís. Às irmãs Nina, Maria do Socorro (mamãe) e Maria da Graça, pelo exemplo de força e fé, que apesar dos momentos difíceis, sempre conseguem manter a serenidade - sem esquecer das boas risadas que damos também. E à minha avó Mami (in memorian), de quem elas herdaram tudo isso. Aos meus sobrinhos Letícia e Thomaz, as alegrias e orgulhos da tia! Enfim, a toda minha família.

Ao meu marido Bira, por todo amor, amizade, diversão, serenidade, equilíbrio, carinho, cuidados, incentivo, compreensão, apoio, companheirismo, suporte computacional, curativos...

Ao meu orientador Prof. Dr. José Carlos Maldonado pela confiança, oportunidade e orientação do trabalho de doutorado.

À Profa. Dra. Sandra Camargo Pinto Ferraz Fabbri pelo papel, mesmo que não oficial, de co-orientação, pelo apoio constante, incentivo, amizade e acolhida.

A la profa. Dra. Natalia Juristo, de la Universidad Politécnica de Madrid por la acogida y atención durante mi estancia como becaria en la Facultad de Informática. Y a todos los alumnos que me recibieron con mucho cariño y atención.

A todos os amigos do laboratório LABES e da USP São Carlos pela convivência, apoio, estudos e descontração. Por serem muitos, devido a tanto tempo de convívio, e por ter pouco espaço, irei representá-los em nome de Marco Aurélio e Fabiano Ferrari que muito estiveram presentes nas etapas finais do meu doutorado. Também a Simone Domingues pela convivência, risadas e desabafos em nossa república. E a AMIGA, Tati Sugeta, pela amizade mesmo à distância.

Aos amigos do LAPES UFSCar, pela acolhida, apoio, incentivo e alegria.

Aos amigos de corrida pelos momentos de distração, aperfeiçoamento de técnicas fotográficas e exemplo de dedicação e perseverança.

Ao Banco Santander, pelo apoio financeiro no Programa de Mobilidade Internacional.

Ao CNPq, pelo apoio financeiro. 


\section{Resumo}

Contexto: Apesar de existirem muitas informações sobre a área de teste de software, elas se encontram de forma dispersa e sem conexão, o que aumenta a já existente dificuldade por parte de usuários em compreender os conceitos e as tecnologias dessa área e, conseqüentemente, em tomar a decisão de onde e quando usálas. Objetivo: O objetivo deste trabalho foi criar o arcabouço KITest (Knowledge and Improvement on Test) capaz de agregar o conhecimento em teste e disponibilizá-lo para a comunidade com a intenção de facilitar a sua transferência, a definição e a melhoria de processos de teste, com mais qualidade. Metodologia: Para facilitar a transferência de conhecimento modelou-se o conhecimento em teste por meio de um processo genérico de teste organizado em um mapa mental (KITMap). Para contemplar a questão de qualidade estabeleceu-se como base as práticas do modelo TMMi, distribuídas no processo de teste genérico. Para permitir que a comunidade interaja com essa base de conhecimento em teste criou-se uma ferramenta (KITTool) que permita acesso a essas informações, faça diagnóstico do processo de teste vigente e sugira melhorias. Para gerenciar toda essa estrutura utilizou-se uma estratégia de melhoria para que essa estrutura esteja sempre em evolução com base na realimentação da comunidade que a utiliza. Resultados e Conclusões: os resultados e as conclusões sobre a aplicação do arcabouço KITest estão apresentados no relatório técnico anexo a esta tese. 


\begin{abstract}
Background: Although there is much information about the software testing area, they are dispersed and disconnected, thus hardening the understanding of concepts and technologies within this area. Consequently, this increases the difficulty on making decisions on where and when to use such testing-related information. Objective: The objective of this work was to create the KITest framework (Knowledge and Improvement on Test) aiming at aggregating knowledge of software testing and making it available to the community. The purpose of KITest is facilitating the knowledge transfer and supporting the definition and improvement of testing processes with respect to its quality. Methodology: Aiming to facilitate the knowledge transfer, the testingrelated knowledge was modeled through a generic testing process organized as a mental map (KITMap). TMMi was chosen as the underlying model to address the intended quality issues. The TMMi practices were distributed into the general testing process. To allow the community's interaction with the testing knowledge base, we created a tool named KITTool. The tool allows the access to the testing-related information, supports the diagnosis of the current testing process and the suggestion of improvements to it. To manage all this structure, an improvement strategy is used to maintain a continuous evolution based on the community's feedback. Results and Conclusions: The results and conclusions on the implementation of the KITest framework are described in the technical report that is attached to this dissertation.
\end{abstract}




\section{Índice de Figuras}

Figura 2.1: Processo de teste alinhado ao processo de desenvolvimento (Crespo et al,

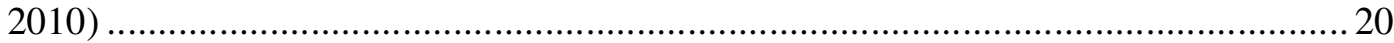

Figura 2.2 Componentes do modelo TMMi (TMMi Foundation, 2009) ....................... 24

Figura 2.3: Estratégia ColabSPI (adaptado de Malheiros, 2010) .................................26

Figura 2.4: Arquitetura da infraestrutura da ColabSPI (Malheiros, 2010) .................... 28

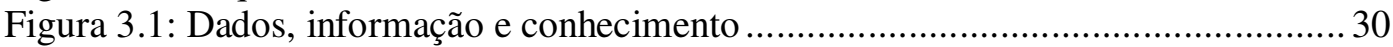

Figura 3.2: Etapas da geração de conhecimento......................................................... 30

Figura 3.3: Modelo de compartilhamento do conhecimento (Shull et al., 2004) ............ 32

Figura 3.4: Modelo de gestão do conhecimento (Rossato, 2003) ................................ 33

Figura 3.5: Objetivos da gestão de conhecimento (Dumont et al, 2006)....................... 36

Figura 3.6: Exemplo de mapa mental (Diba et al, 2004) ......................................... 38

Figura 4.1: Arcabouço KITest e gestão de conhecimento. ....................................... 40

Figura 4.2: Arcabouço KITest: KITMap, KITTool e estratégia de gestão de melhorias

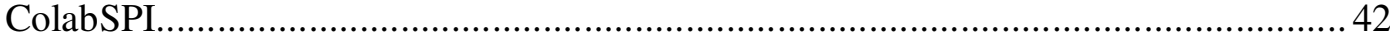

Figura 4.3: Primeiro nível do mapa mental de processo de teste. .............................. 45

Figura 4.4: Componentes do TMMi distribuídos nas fases do processo de teste........... 46

Figura 4.5: Nós com os objetivos específicos das áreas de processo ..........................46

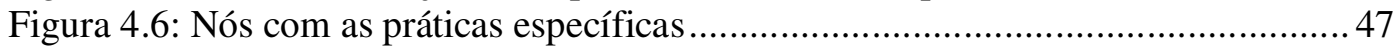

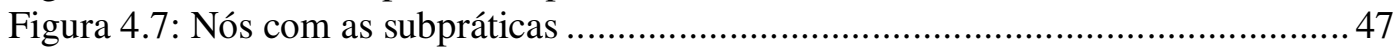

Figura 4.8: Representação da Relação do KITMap com seus usuários ......................... 48

Figura 4.9: Etapas do ciclo de melhoria do KITMap............................................ 49

Figura 4.10: Fluxo de tratamento para as propostas de melhoria ................................ 51

Figura 4.11: Diagrama de estados das propostas de melhoria................................... 52

Figura 4.12: Adaptação da arquitetura da infraestrutura da ColabSPI para gestão e

evolução do mapa mental de teste. ........................................................................ 54

Figura 5.1: Arquitetura da ferramenta KITTool...................................................5 58

Figura 5.2: Diagrama de casos de uso: Principais funcionalidades da KITTool............59

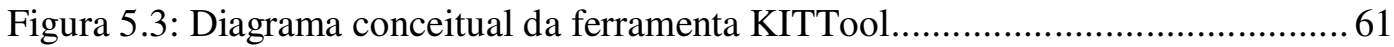

Figura 5.4: Diagrama de atividades: Avaliação por objetivos ................................... 62

Figura 5.5: Diagrama de atividades: Avaliação por práticas......................................... 63

Figura 5.6: Diagrama Entidade-Relacionamento da ferramenta KITTool...................6 65

Figura 5.7: TMMi visualizado na ferramenta SeEd-Visual ......................................6 68

Figura 5.8: Fluxograma do processo baseado em visualização para leitura estruturada de

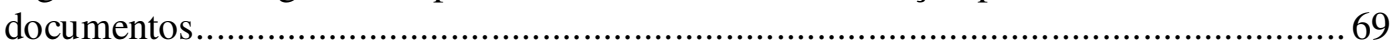

Figura 5.9: O texto de duas práticas selecionadas a partir da visualização tree-map por

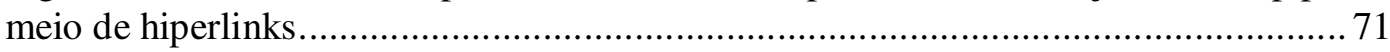

Figura 5.10: Telas iniciais da ferramenta KITTool ............................................... 72

Figura 5.11: Tela para definição das dependências ....................................................73

Figura 5.12: Tela de visualização das dependências ............................................... 74

Figura 5.13: Tela de criação de um novo projeto ..................................................... 74

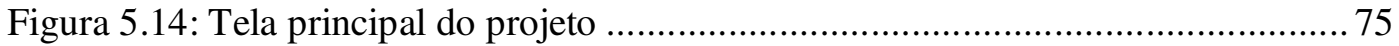

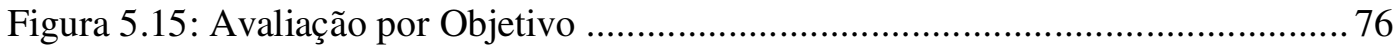

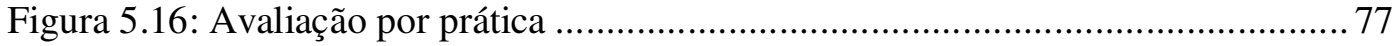

Figura 5.17: Tela de visualização de resultados da avaliação por objetivos .................. 78

Figura 5.18: Gráfico radar (Spider Web) para visualização, por área de processo, do

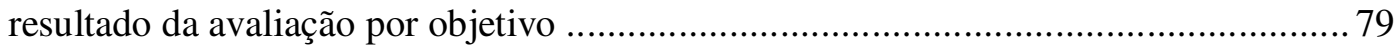


Figura 5.19: Gráfico radar para visualização do resultado da avaliação por objetivo .... 79

Figura 5.20: Tela de visualização de resultados da avaliação por objetivos .................. 80 Figura 5.21: Gráfico radar para visualização, por área de processo, do resultado da

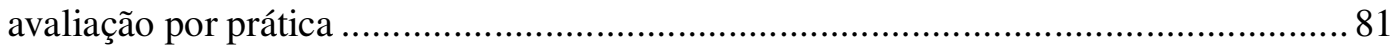
Figura 5.22: Gráfico radar para visualização, por objetivo, do resultado da avaliação por

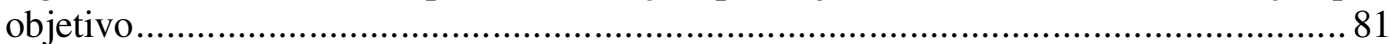

Figura 5.23: Gráfico pilha (Stacked) para visualização das áreas de processo.............. 82 Figura 5.24: Diretrizes para próximas atividades: área de processo menos completa para

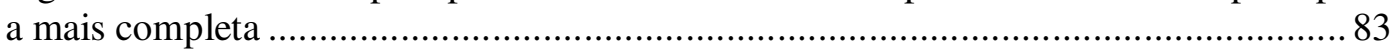
Figura 5.25: Diretrizes para próximas atividades: área de processo mais completa para a

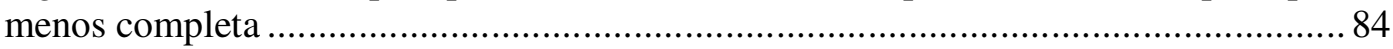

Figura 5.26: Filtro para seleção de áreas de processo............................................ 85

Figura 5.27: Filtro aplicado para áreas de processo escolhidas.................................... 85 


\section{Sumário}

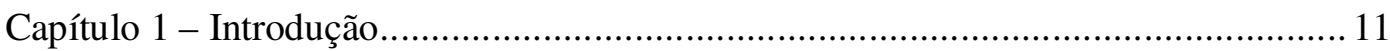

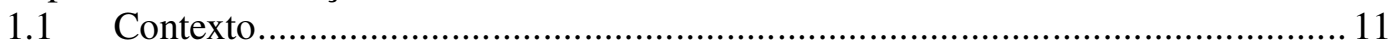

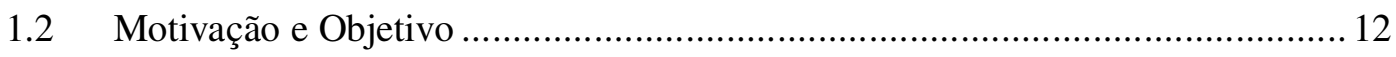

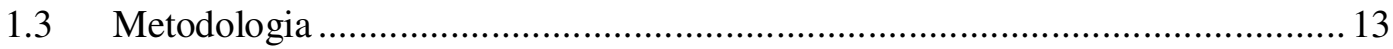

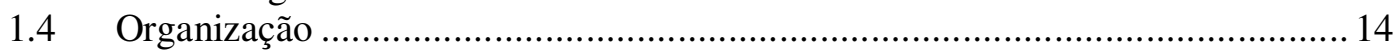

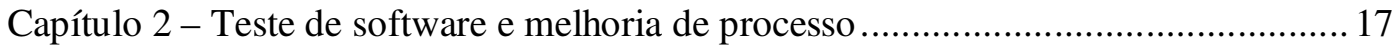

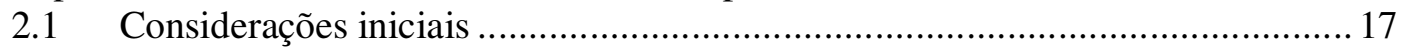

2.2 Processo de teste de software....................................................................... 17

2.3 A visão de teste nos modelos de qualidade para melhoria de processo .............. 21

2.4 Modelo de maturidade para processo de teste TMMi (Test Maturity Model

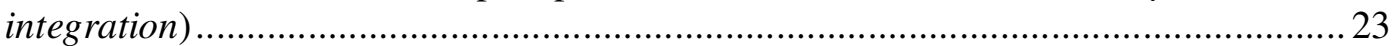

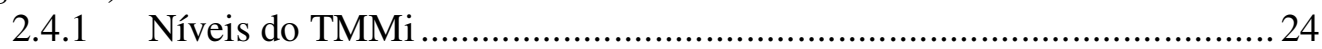

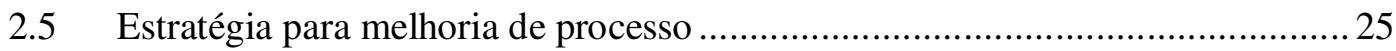

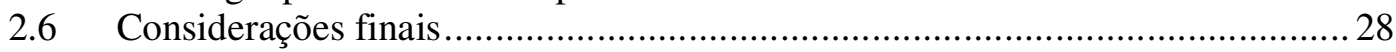

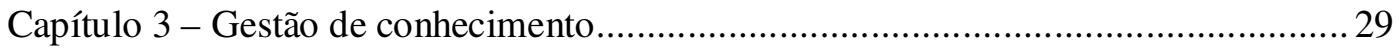

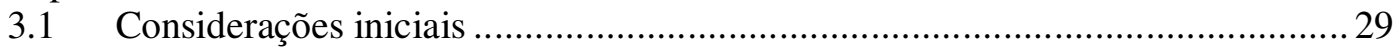

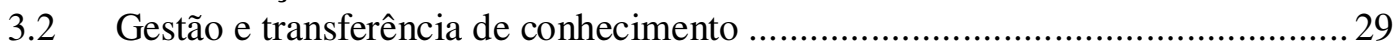

3.2.1 Conhecimento e gestão do conhecimento ........................................... 29

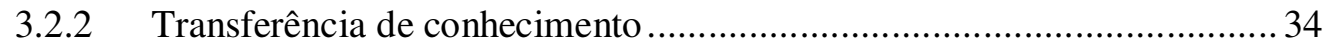

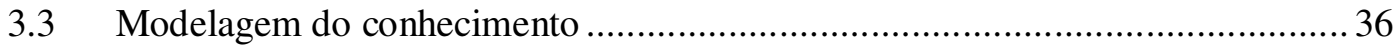

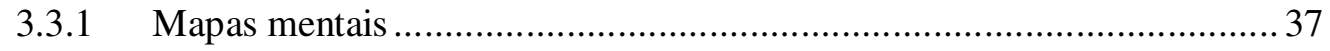

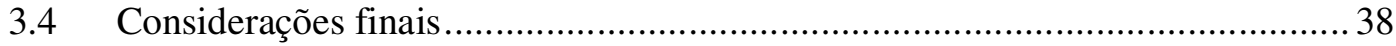

Capítulo 4 - Um arcabouço de conhecimento e melhoria de processo de teste KITest. 39

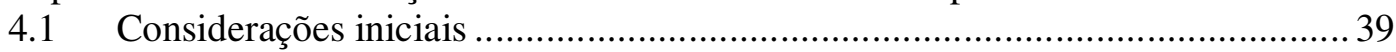

4.2 KITest - Knowledge and Improvement on Test......................................... 40

4.3 Base de conhecimento em teste - KITMap ................................................ 43

4.3.1 Construção do KITMap ................................................................. 44

4.3.2 Gestão e evolução da base de conhecimento ..................................... 47

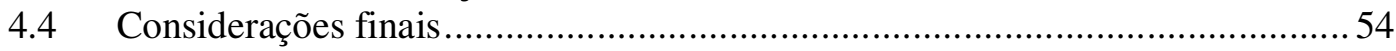

Capítulo 5 - KIT-Tool - Uma ferramenta para conhecimento e melhoria de processo de

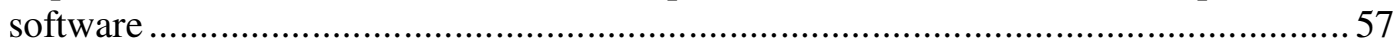

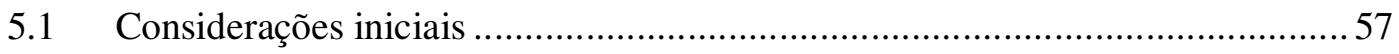

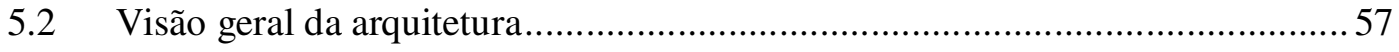

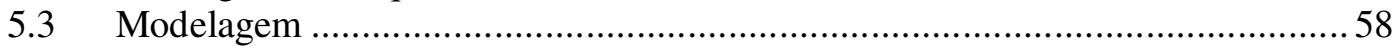

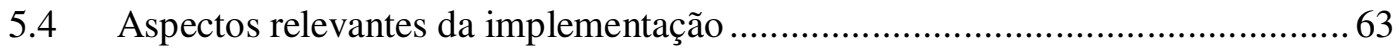

5.4.1 Diagrama Entidade-Relacionamento (DER) ...................................... 64

5.4.2 Análise do documento XML gerado pelo mapa mental KITMap............65 65

5.4.3 Algoritmos de definição de próximos passos (diretrizes de melhoria)..... 65

5.4.4 Elaboração da matriz de dependência das práticas do TMMi..................67

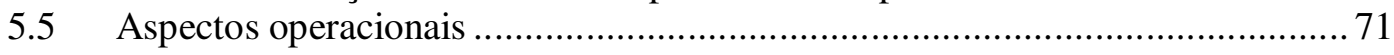

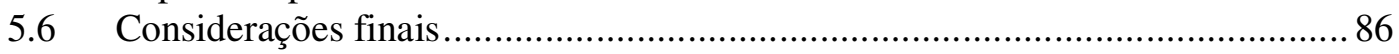

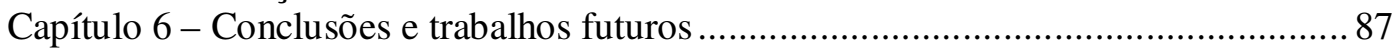

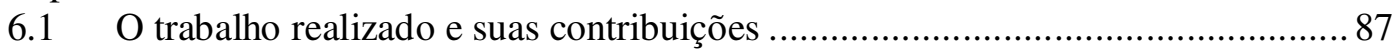

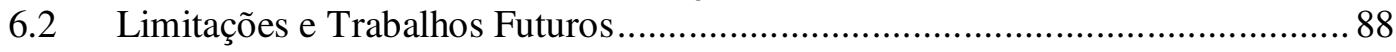

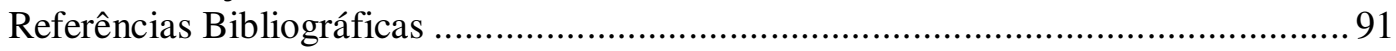




\section{Capítulo 1 - Introdução}

\subsection{Contexto}

Vivemos em uma época em que há muita informação disponível, porém muitas vezes são informações dispersas que, pelo fato de não estarem agrupadas e organizadas de maneira lógica e sistematizada, não facilitam a aquisição do conhecimento sobre o tema que elas referenciam e nem o seu uso efetivo. Esse problema está, em geral, presente em várias áreas do conhecimento, inclusive na engenharia de software. Nessa área observam-se também relatos sobre a falta de caracterização apropriada da tecnologia existente (Basili, 1985) que, se existisse, poderia auxiliar na tomada de decisão do que usar para o desenvolvimento de um determinado produto de software. Algumas iniciativas de agrupar informações sobre teste de software e de caracterizar a aplicação de algumas técnicas com base em resultados obtidos de experimentos realizados por alguns grupos de pesquisa podem ser observadas nos estudos publicados por Vegas e Basili (2005) e Juristo et al (2004). No entanto, nesses dois estudos o que se encontra é a caracterização de algumas técnicas de teste. Embora esses dois trabalhos tenham uma grande importância para a comunidade e também para este trabalho, eles não estão acessíveis em um contexto que agregue todo o conhecimento da área de teste.

$\mathrm{Na}$ engenharia de software, em particular, que é uma área bastante ampla da computação, além de haver essa deficiência na caracterização dos métodos e das tecnologias existentes propriamente dita, há também uma grande preocupação com a qualidade do processo de software que, a partir da década de 90, se tornou mais consciente e mais presente em todas as suas subáreas. Assim, visando à qualidade, além do conhecimento da tecnologia de suporte de cada subárea, há também a necessidade do conhecimento dos modelos de qualidade propostos na literatura e que têm sido usados na prática. Hoje em dia é imprescindível saber unir o conhecimento da tecnologia com o conhecimento de tais modelos, pelas próprias exigências do mercado, as quais acabam se refletindo no meio acadêmico que é o principal responsável pela boa formação dos profissionais do mercado. 
Embora esse contexto esteja presente em todas as subáreas da engenharia de software, quando se fala em qualidade, essa questão remete diretamente às atividades de qualidade de software, dentre as quais se encontra a atividade de teste. Assim, a atividade de teste tem ganhado atualmente uma forte atenção da comunidade, ao ponto de se ter um modelo de qualidade específico para ela, o modelo TMMi (Testing Maturity Model $^{l}$ ), o qual foi inspirado no modelo de qualidade de processo CMMi (Capability Maturity Model ${ }^{2}$ ).

Apesar de reconhecida a importância da atividade de teste, observa-se, tanto do ponto de vista do mercado como do ponto de vista acadêmico, certa resistência em relação a essa atividade, além da carência de formação de recursos humanos. Do ponto de vista do mercado, um fator que pesa para essa resistência é o fato de teste ser, em geral, uma atividade onerosa. No entanto, independentemente disso, tanto no mercado como na academia, observa-se uma dificuldade de acesso, principalmente a informações que caracterizem o uso da teoria sobre teste de software na prática, o que dificulta a atividade de ensino. Diga-se de passagem, que são poucos os cursos que oferecem de forma adequada e completa a disciplina de VV\&T (Verificação, Validação e Teste). Certamente, esse é um dos motivos que incentiva a ênfase dada ao teste baseado apenas na funcionalidade do software, pois para ser bem executada a atividade de teste é necessário um sólido conhecimento dos seus conceitos, de suas técnicas e critérios e de relatos de experiência que possam dar subsídios aos desenvolvedores quanto ao uso dos recursos de teste. Além disso, toda essa dificuldade de aplicação da atividade de teste é ainda acrescida a dificuldade de unir os seus conceitos com os conceitos de qualidade do modelo TMMi.

\subsection{Motivação e Objetivo}

Dado o contexto apresentado anteriormente e considerando-se que não foi encontrada na literatura uma base de conhecimento integrada em teste que reúna informações relevantes sobre essa atividade, de forma que essas informações estejam sempre atualizadas, o objetivo deste trabalho é prover à comunidade um recurso que contemplasse os seguintes requisitos:

\footnotetext{
${ }^{1}$ www.tmmifoundation.org

${ }^{2}$ www.sei.cmu.edu/cmmi/
} 
(i) ter um módulo que permitisse a centralização das informações sobre a atividade de teste, de uma maneira organizada, para facilitar a compreensão e a aquisição do conhecimento em teste;

(ii) ter um módulo que viabilizasse a interação da comunidade com o módulo de conhecimento em teste, de forma que a comunidade fosse capaz de aplicar esse conhecimento na definição de um processo de teste com qualidade, seguindo as premissas de qualidade do TMMi, que concentra as melhores práticas existentes nessa área; e

(iii) ter um mecanismo que viabilizasse a constante evolução desse conhecimento sobre teste, de forma que essa evolução fosse fundamentada na realimentação da comunidade, com base nos relatos de experiência sobre o uso das informações organizadas no módulo descrito em (i) e aplicadas na prática pelo módulo descrito em (ii).

Esses objetivos sustentam a hipótese de que a existência de um arcabouço que os contemple, possa melhorar a compreensão dessa área e motivar a aplicação de teste como um processo que pode ser definido, avaliado e melhorado.

\subsection{Metodologia}

Considerando-se o objetivo estabelecido, a metodologia de trabalho foi planejada de forma a ter-se, ao final, a definição de um arcabouço de conhecimento e melhoria de processo de teste, o qual foi denominado Arcabouço KITest - Knowledge and Improvement on Test. Como esse arcabouço deveria contemplar os três objetivos parciais mencionados anteriormente, a metodologia de trabalho se resume ao seguinte:

Para atender ao objetivo (i) foram pesquisadas iniciativas que reunissem informações e diretrizes de melhores práticas a serem utilizadas na área de teste de software. Alguns modelos de qualidade de processo de teste foram estudados e decidiuse adotar o TMMi, conforme exposto ao longo deste trabalho. Além disso, foram investigados também os processos de teste propostos na literatura e, para este item, decidiu-se adotar um processo genérico, composto das atividades essenciais associadas ao teste e ao modelo de qualidade TMMi. Ainda para esse objetivo foram investigadas alternativas relacionadas à gestão de conhecimento, que permitissem organizar o conhecimento da área de teste de maneira que acomodasse o processo genérico, os requisitos do modelo de qualidade, e que também fosse capaz de agregar material sobre o assunto para que este ficasse acessível à comunidade. Assim, escolheu-se organizar 
essa base de conhecimento em teste por meio de um mapa mental, o KITMap (Knowledge and Improvement on Test-Map), que além de atender a essas expectativas, provê uma maneira visual de acesso a toda essa informação, o que pode facilitar a aquisição de conhecimento em teste.

Para atender ao objetivo (ii), decidiu-se criar um apoio computacional que permitisse que a comunidade interessada - tanto do mercado de trabalho como da academia - conseguisse interagir com a base de conhecimento em teste, tendo acesso às informações, usando essas informações para avaliar o seu próprio processo de teste e podendo obter diretrizes de como esse processo poderia ser melhorado com base no modelo de qualidade TMMi. Assim, o módulo de interação da comunidade com a base de conhecimento em teste foi viabilizado por meio de uma ferramenta, a KITTool (Knowledge and Improvement on Test - Tool).

Para atender ao objetivo (iii), foram investigadas estratégias de melhoria de processo propostas na literatura, uma vez que fazer a gestão dos elementos - mapa de teste, ferramenta de interação e realimentação da comunidade - não deixa de ser a gestão de um processo a ser controlado constantemente. Assim, considerando as características existentes na dinâmica desse processo e os tipos de usuários possíveis, decidiu-se por adotar a estratégia Colab-SPI (Malheiros, 2010), que é uma estratégia de gestão de processos distribuídos e que provê uma arquitetura da estrutura de suporte a qual se mostrou pertinente neste contexto. Além disso, como será discutido ao longo do trabalho, essa estratégia pode também ser adotada no ambiente dos usuários do arcabouço KITest.

\subsection{Organização}

Este trabalho está organizado em 7 capítulos, como descrito a seguir:

Neste capítulo foi apresentada a introdução do trabalho, contendo o contexto em que foi desenvolvido, a motivação e os objetivos que levaram à execução do trabalho, além da metodologia adotada.

No Capítulo 2 é apresentada uma breve discussão sobre processo de teste de software. Também é abordada a visão de teste nos modelos de qualidade para melhoria de processo e as características e principais elementos que compõem o TMMi, um modelo de qualidade para processo de teste, são discutidos. Por fim, a estratégia 
colaborativa e distribuída para melhoria de processo ColabSPI (Malheiros, 2010) é sintetizada.

No Capítulo 3 são apresentados conceitos e modelos de gestão e transferência de conhecimento. Também são brevemente discutidos meios de modelagem do conhecimento, sendo abordada de forma mais específica a técnica de mapa mental.

No Capítulo 4 são apresentadas as contribuições deste trabalho referentes ao arcabouço definido para atender aos objetivos expostos neste capítulo. Também é detalhada a representação da base de conhecimento por meio do KITMap e a definição da estratégia ColabSPI adaptada para melhoria da base de conhecimento proposta.

No Capítulo 5 são detalhados a definição, implementação e os aspectos operacionais da KITTool.

O Capítulo 6 contém as conclusões, limitações encontradas durante a execução deste trabalho e possíveis trabalhos futuros. 


\section{Capítulo 2 - Teste de software e melhoria de processo}

\subsection{Considerações iniciais}

Neste capítulo apresentamos uma visão geral de processo de teste de software, identificando as principais etapas de um processo genérico. Visando a melhoria contínua dos processos, especificamente no contexto deste trabalho o processo de teste, abordamos alguns modelos de qualidade, principalmente no que referem a teste de software. Devido a essa preocupação em acompanhar, avaliar e melhorar o processo de teste, sumarizamos as principais características do TMMi, um modelo de qualidade para processo de teste.

A opção pelo modelo de maturidade TMMi neste trabalho ocorreu devido principalmente a dois fatores: disponibilidade do conteúdo do modelo (áreas de processo, práticas e subpráticas) e semelhança em estrutura ao $\mathrm{CMMi}$, tornando-o mais compreensível para a maioria das empresas que já possuem algum modelo de maturidade para processo de desenvolvimento.

Esse capítulo está organizado da seguinte forma: na Seção 2.2 é descrito o processo de teste de software. Na Seção 2.3 é apresentada a visão de teste nos modelos de qualidade para melhoria de processo; o Modelo de Maturidade para Processo de Teste (TMMi) é apresentado na Seção 2.4; na Seção 2.5 é discutida a estratégia colaborativa e distribuída para melhoria de processo de software; e na Seção 2.6 são apresentadas as considerações finais do capítulo.

\subsection{Processo de teste de software}

O teste de software faz parte das atividades de verificação e validação que visam a garantir a qualidade do produto de software. Para isso, ele deve ser conduzido ao longo de todo processo de desenvolvimento, de maneira contínua, sistemática e organizada, ou seja, um processo de teste de software deve ser definido para acompanhar e controlar o desenvolvimento do software (Lewis, 2004). 
Um processo consiste em um conjunto de ações, observações e decisões tomadas visando a alcançar algum produto de saída. Algumas dessas ações ocorrem em paralelo e outras são seqüenciais (Black,2007). No domínio de engenharia de software, processo é o conjunto de métodos, práticas, padrões, documentos, atividades, políticas e procedimentos que engenheiros de software usam para desenvolver e manter um sistema de software e seus artefatos associados (Burnstein, 2002). Em um contexto mais específico da engenharia de software, processo de teste pode ser descrito como um processo usado para revelar defeitos no software, e para estabelecer o grau de qualidade que o software obteve em relação aos atributos de qualidade definidos (Burnstein, 2002).

Teste como processo possui aspectos econômicos, técnicos e gerencias. Os aspectos econômicos estão relacionados ao tempo e aos recursos disponíveis para o teste; os aspectos técnicos estão relacionados às técnicas, métodos, medidas e ferramentas utilizados para aumentar a credibilidade do produto, tanto quanto possível, sob determinadas condições e restrições em que ele deve operar. E por ser um processo, teste deve ser bem definido e bem gerenciado, de modo que possa trazer melhores resultados, atender o cronograma e controlar os custos, e deve ser evoluído a um nível em que tenha mecanismos para fazer melhoria contínua (Burnstein, 2002; Tiann, 2005).

Um processo genérico, aplicável em todos os níveis de teste e contemplando atividades de verificação e validação, (neste trabalho consideramos ambas as atividades como partes do processo de teste), deve ser estabelecido (Hass, 2003) e depois especializado em processos instanciados de acordo com o software desenvolvido, as necessidades, recursos disponíveis e padrões da organização (Crespo et al 2010).

O processo de teste deve englobar questões fundamentais relacionadas desde os objetos que serão testados, até perspectivas e pontos de vista utilizados no teste. Diversas questões devem ser consideradas, como: definição dos artefatos que serão testados; quais técnicas serão utilizadas; que estratégia adotar; que tipos de defeitos serão enfatizados; quando parar o teste. Também não podem ser esquecidas outras atividades de gerenciamento, como alocação e ajuste de tempo e recursos, medições e monitoramento, quem deve executar e quem está envolvido com cada atividade específica; quando cada atividade será executada; quais ferramentas serão utilizadas; quais artefatos serão usados em cada atividade; que ambiente (hardware/software/ organização) será utilizado no teste (Tiann, 2005). 
Hass (2008) e Crespo et al (2010) identificam etapas semelhantes para um processo de teste genérico, que consistem em: Planejamento do teste; Projeto do teste; Execução do teste; Monitoramento e controle (ou Acompanhamento do teste); e Atividades de encerramento ou (Finalização do teste). Crespo et al (2010) descrevem as principais atividades que cada uma dessas etapas contem:

As atividades da etapa de Planejamento do teste devem determinar, pelo menos, as seguintes questões: o que deve ser testado; o que deve ficar de fora do teste; qual abordagem de teste deve ser seguida em cada tipo de projeto; quais riscos devem ser considerados; qual equipe deve participar do teste; quanto tempo deve ser dedicado e como as tarefas devem ser distribuídas nesse tempo.

O Projeto do teste deve: refinar a abordagem de teste, definida no planejamento; especificar os casos de teste; revisar os requisitos do ambiente de teste e especificar os procedimentos de teste. No planejamento devem ser consideradas questões como: quais técnicas de teste são as mais adequadas para o projeto e como as diversas funcionalidades do software em teste serão cobertas pelo teste.

$\mathrm{Na}$ etapa de Execução do teste ocorre a aplicação dos testes planejados e projetados nas etapas anteriores. A execução envolve a aplicação dos casos de teste, seguindo o procedimento de teste definido. Incidentes (manifestações de defeitos no software ou anomalia no funcionamento do ambiente) ocorridos durante a execução do teste devem ser registrados.

Durante o Acompanhamento dos testes é feita a organização e a consolidação de todas as informações relativas aos testes realizados. Esse acompanhamento deve controlar questões do tipo: número de casos de teste já executados; número de incidentes detectados e identificados; número de incidentes que continuam abertos e quantos incidentes abertos estão nas áreas de risco identificadas; quais funcionalidades já foram adequadamente cobertas pelos casos de teste aplicados; quanto do software já foi testado; e, se novos casos de teste são necessários.

As atividades para Finalização do teste tratam do encerramento do teste. Nessa etapa todas as informações sobre o teste são consolidadas em um documento (Resumo do teste) que poderá ser utilizado posteriormente como referência para outros testes e como insumo para melhoria do processo de teste. Essas informações retratam vários aspectos do teste aplicado, tais como: andamento do teste; resultados obtidos; 
desempenho da equipe; métricas definidas no processo de teste; recursos gastos; tempo gasto na execução das atividades em relação ao planejado; e lições aprendidas durante o teste do produto.

Para a definição de um processo de teste devem-se considerar alguns fatores como: o tipo de software que será testado; os requisitos desse software em relação à confiabilidade e segurança; a disponibilidade de recursos financeiros e humanos (Crespo et al, 2010). É importante ressaltar que o processo de software deve estar alinhado com o processo de desenvolvimento de software utilizado, conforme representado na Figura 2.1.

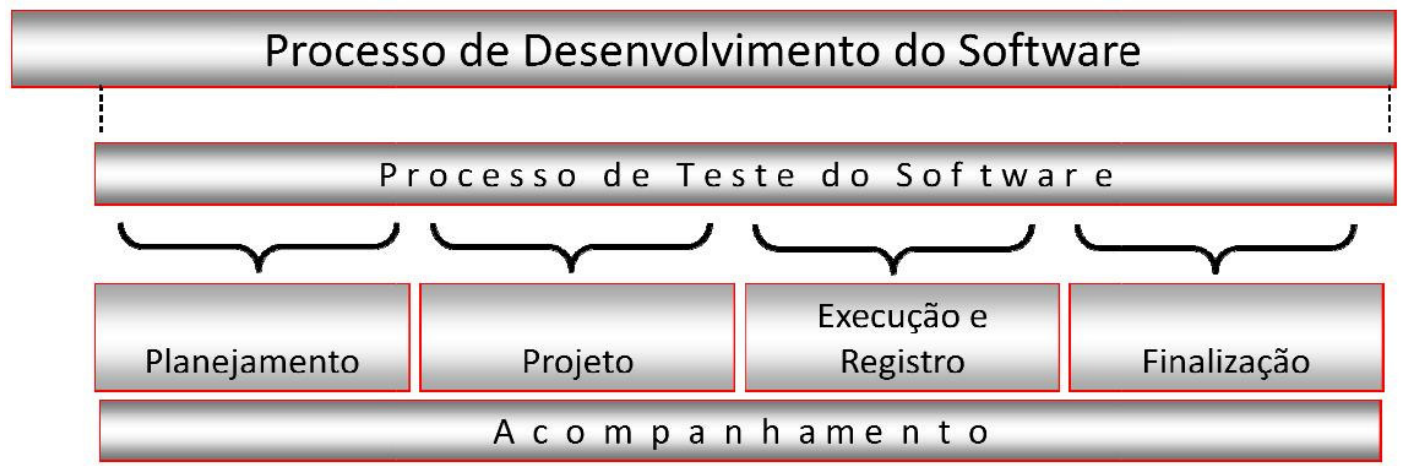

Figura 2.1: Processo de teste alinhado ao processo de desenvolvimento (Crespo et al, 2010)

Como comentado anteriormente, por ser um processo, o teste deve ser gerenciado e deve evoluir. Quando existe um processo bem definido e gerenciado, é possível: (a) repetir o processo em diversos projetos; (b) avaliar o processo usando uma variedade de métricas; (c) realizar ações para melhorar o processo visando a alcançar melhores resultados (Naik e Tripathy, 2008).

Com essa gama de informações a ser definida é importante que os profissionais de teste saibam o que está relacionado a cada etapa de um processo genérico de teste, permitindo que ele o instancie, conforme sua necessidade. E que tenha orientação do que precisa ser planejado; como ordenar, provisionar e coordenar todas as atividades, além de monitorá-las em relação ao estado real, para que ajustes sejam feitos.

Os modelos de maturidade de processo podem fornecer orientações do que deve conter em um processo bem definido, além de auxiliarem na avaliação do processo vigente e na obtenção de um entendimento do estado atual do processo. Além de servir como referência para a evolução do processo, por conter as melhores práticas da área. 
Nas próximas seções será discutido o que os modelos de maturidade de processo de desenvolvimento abordam sobre teste de software.

\subsection{A visão de teste nos modelos de qualidade para melhoria de processo}

$\mathrm{O} \mathrm{CMMI}^{3}$ (Capability Maturity Model Integration), desenvolvido pelo SEI (Software Engineering Institute), é um modelo de melhoria de processos de desenvolvimento de software que tem grande aceitação na indústria de tecnologia da informação.

A estrutura do CMMI consiste de 24 áreas de processos organizadas em 4 grupos (Gerência de processo, Gerência de projeto, Engenharia e Suporte) no modelo contínuo e ao longo de 5 níveis (Inicial, Gerenciado, Definido, Gerenciado quantitativamente e Em otimização) na versão por estágios. Cada área de processo possui objetivos, que são descrições abstratas do estado desejável que uma organização deve atingir. Além desses, existem objetivos genéricos que estão associados com a institucionalização das boas práticas. As práticas no CMMI são descrições de como alcançar os objetivos, mas cada organização pode utilizar suas próprias práticas, não tendo que seguir especificamente as recomendadas pelo CMMI (Sommerville, 2007).

As áreas de processo que são mais direcionadas para processos de teste estão concentradas no nível 3 de maturidade, ou grupo de Engenharia, no modelo contínuo, e consistem em Verificação e Validação.

O modelo MPS ${ }^{4}$ (Melhoria do Processo de Software) baseia-se nos conceitos de maturidade e capacidade de processo para a avaliação e busca ser adequado ao perfil de empresas com diferentes tamanhos e características, públicas e privadas, embora com especial atenção às micro, pequenas e médias empresas. Na sua construção, o modelo MPS herdou características do CMMI, da ISO/IEC 12207 e ISO/IEC 15504. E, de forma análoga ao CMMI, aborda as atividades de teste basicamente nas áreas de processo de Verificação e Validação. Outra área de processo que direciona para teste de software é a área de processo Integração, na qual os testes de integração e teste de regressão são abordados.

\footnotetext{
${ }^{3}$ http://www.sei.cmu.edu/cmmi/

${ }^{4}$ www.softex.br/mpsbr/_home/default.asp
} 
No contexto de software livre encontra-se o $\mathrm{OMM}^{5}$ (Open Maturity Model), desenvolvido no contexto do projeto Qualipso (Quality Platform for Open Source Software). OMM é um modelo de processo também baseado no CMMI, mas centrado em características de desenvolvimento FLOSS (Free/Libre Open Source Software) e tem como objetivo principal auxiliar na construção de processos de desenvolvimento de usam ou produzem produtos FLOSS. O OMM está organizado em três níveis e cada nível inclui elementos de confiança. Os 12 elementos de confiança em que o OMM se baseia são: (1) Documentação do produto; (2) Popularidade do produto de software; (3) Uso de padrões estabelecidos e disseminados; (4) Disponibilidade e uso de um roteiro (produto); (5) Qualidade do plano de teste; (6) Relacionamento entre interessados (usuários, desenvolvedores, etc.); (7) Licenças; (8) Ambiente técnico (ferramentas, sistemas operacionais, linguagem de programação, ambiente de desenvolvimento); (9) Número de commits e relatório de defeitos; (10) Manutenibilidade e estabilidade; (11) Contribuição para produto de software por empresas de software; (12) Resultados de avaliação do produto por empresas terceirizadas.

No OMM, os elementos que correspondem às áreas de Verificação e Validação do são Testing 1 e Testing 2, respectivamente.

Para a comunidade de teste, as áreas de processo Verificação e Validação do CMMi e os modelos que utilizam ele por base, é insuficiente, pois contém poucas áreas de processo direcionadas para processos de teste. Além disso, elas estão descritas em um nível de abstração muito alto que as torna difícil de usar na prática para especificar um processo de teste (van Veenendaal, 2011).

O OMM possui ainda um elemento chamado Qualidade do Processo de Teste que contempla algumas das atividades requeridas para a definição e melhoria de um processo de teste, se compararmos ao modelo de qualidade TMMi. Esse elemento tem os objetivos de: a) Fornecer um plano de teste de alta qualidade; b) Implementar e gerenciar o processo de teste; e (c) Melhorar o processo de teste. Apesar de contemplar processo de teste, poucos são os detalhes para todas as etapas de um processo.

Apesar de teste ser considerado um componente vital em um processo de software de qualidade, e também ser considerado uma das atividades de maior desafio e custo durante o desenvolvimento e manutenção do software, os modelos de melhoria e

${ }^{5}$ qualipso.icmc.usp.br/OMM/ 
avaliação de processo, tais como os comentados acima, não tratam adequadamente das questões relacionadas a processo de teste (Bursntein, 2002).

O TMMi (Test Maturity Model integration) surgiu na Universidade de Illinois com o intuito de suprir essa deficiência. Na próxima seção será apresentado o TMMi e sua estrutura.

\subsection{Modelo de maturidade para processo de teste TMMi (Test Maturity Model integration)}

$\mathrm{O}$ uso de padrões e modelos de processo tem mostrado ter um impacto positivo na qualidade do software entregue (Rosemberg, 2003). Padrões e modelos têm sido desenvolvidos na busca pelos benefícios pretendidos no uso de padrões de qualidade em diferentes estágios do desenvolvimento do software. Processos de teste também podem se apoiar em modelos de maturidade (TMMi, TPI) e padrões (IEEE $829^{6}$, ISO $9126^{7}$ ).

Decidir quais atividades empreender para a melhoria do processo depende do estado atual que ele se encontra. Este conceito de introduzir mudanças em pequenos incrementos, com base no estado atual do processo, é usado pelo CMMi (Jalote, 2005). Na mesma linha do CMMI, o TMMi (Test Maturity Model integration) fornece um roteiro geral para melhoria do processo de teste.

O TMMi é um framework que foi desenvolvido inicialmente pelo Illinois Institute of Technology e atualmente é mantido pela TMMi Foundation. Ele foi experimentalmente validado e está fundamentado em estabelecidas normas, padrões e outros frameworks (como IEEE 829, ISTQB ${ }^{8}, \mathrm{TPI}^{9}, \mathrm{TMap}^{10}, \mathrm{CMMi}$ ), além de ser complementar - no que se refere às atividades de verificação e validação - ao CMMi Version 1.2 (TMMi Foundation, 2009).

Endereçando questões importantes aos gerentes de teste, engenheiros de teste e profissionais de qualidade de software, as atividades de teste definidas no TMMi são aplicadas no sentido mais amplo para englobar todas as atividades relacionadas a qualidade de produto de software.

\footnotetext{
6 standards.ieee.org/findstds/standard/829-1983.html

${ }^{7}$ www.iso.org/iso/

8 istqb.org/display/ISTQB/Home

9 www.sogeti.ie/Resources--Downloads/Methodologies/TPI-Test-Process-Improvement/

${ }^{10}$ www.tmap.net
} 
Análogo à estrutura do CMMi (Figura 2.2), com cinco níveis de maturidade, o TMMi fornece características de cada nível, que podem ser usadas para avaliar o estado atual do processo de teste de uma organização. As características de cada nível sugerem também as áreas em que o processo deve ser melhorado para que ele possa passar para o nível imediatamente superior (Jalote, 2005; TMMi Foundation, 2009). Dessa forma, testes evoluem de um processo caótico e mal definido com a falta de recursos, ferramentas e testadores bem preparados, para um processo maduro e controlado, que tem a prevenção de defeitos como seu principal objetivo (TMMi Foundation, 2009).

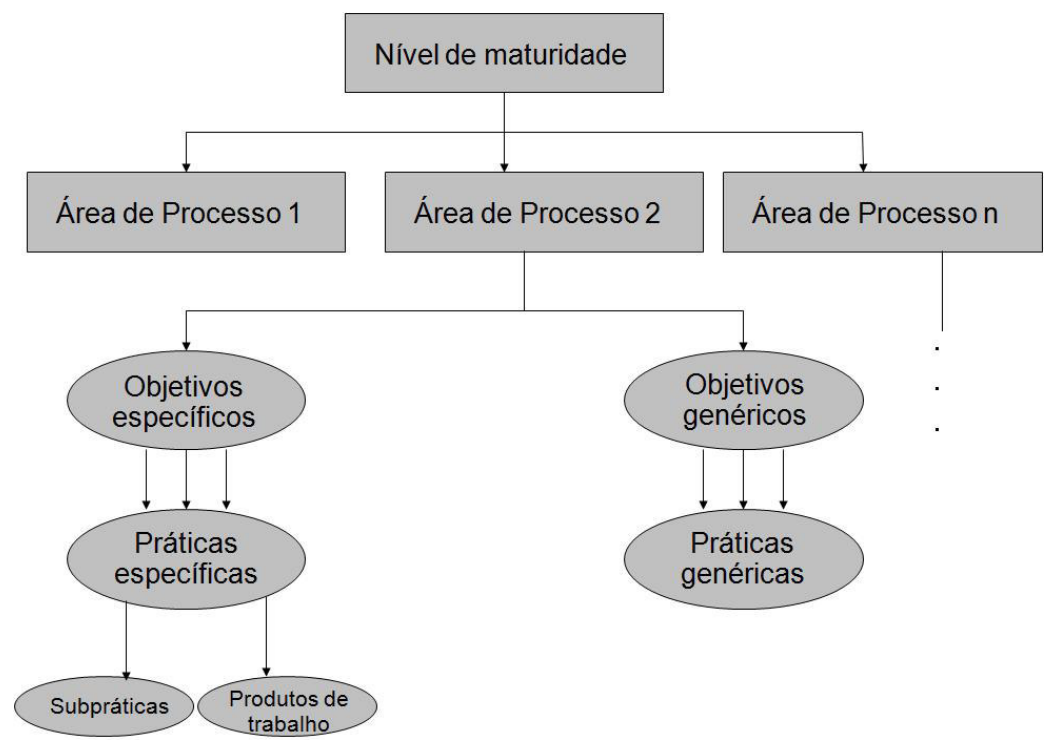

Figura 2.2 Componentes do modelo TMMi (TMMi Foundation, 2009)

\subsubsection{Níveis do TMMi}

1) Nível 1 - Inicial

- Não há objetivos de maturidade neste nível;

- Teste é um processo caótico, falta recursos, ferramentas e profissionais treinados;

- Testes são desenvolvidos de modo ad-hoc depois que a codificação é feita;

- Teste e depuração estão misturados na tentativa de retirar defeitos do software;

- O objetivo do teste é mostrar que o software executa.

2) Nível 2 - Gerenciado

- Teste está separado de depuração;

- Os níveis de teste estão claramente definidos;

- Teste é uma fase do ciclo de vida que segue codificação; 
- Teste é planejado, entretanto no final do ciclo de vida do software com um foco na execução;

- Há rastreamento completo e relatório de progresso;

- Técnicas de projeto de teste básico são utilizadas;

- Ainda não há nenhuma revisão para detectar defeitos previamente mais cedo.

3) Nível 3 - Integração

- Foco na institucionalização;

- Envolvimento do teste mais cedo;

- Ciclo de vida de teste definido integrado ao ciclo de vida de desenvolvimento;

- O teste é reconhecido como uma profissão;

- Teste também considera tipos de testes não funcionais;

- Revisões por pares são realizadas (encontrando defeitos mais cedo).

4) Nível 4 - Gestão e medição

- Revisões avançadas como parte do processo de teste, procedimentos de testabilidade, amostragem, critérios de parada, dados de defeitos coletados e utilizados.

- Programa de gestão de teste: qualidade do processo de teste, produtividade e efetividade (baseada na abordagem GQM);

- Avaliação da qualidade do software: medição da qualidade do produto.

Qualquer processo necessita evoluir para continuar cumprindo seu objetivo, sejam processos de desenvolvimento de software, processos de teste e até o próprio processo de melhoria de processos. Na seção seguinte será sintetizada uma estratégia para apoiar a melhoria colaborativa e distribuída de processos de software.

\subsection{Estratégia para melhoria de processo}

Uma estratégia colaborativa e distribuída para melhoria de processo de software, ColabPSI, foi definida por Malheiros (2010). Essa estratégia oferece um referencial para conduzir programas de melhoria de processo, visando a: (i) identificar e gerir oportunidades de melhoria para o processo; (ii) evoluir, controlar e distribuir versões do processo; (iii) facilitar a institucionalização do processo em equipes distribuídas com diferentes níveis de maturidade; (iv) aumentar a participação dos desenvolvedores no programa de melhoria de processo; e (v) facilitar a comunicação entre os envolvidos. 
Malheiros (2010) ressalta que a adoção da ColabSPI também pode promover a criação de uma base de conhecimento sobre o processo de desenvolvimento de software e suas melhorias, eventualmente fornecendo lições aprendidas para a comunidade.

A estratégia ColabSPI é composta por quatro elementos, como demonstrando na Figura 2.3: (a) princípios; (b) estrutura organizacional para melhoria de processo; (c) principais etapas da melhoria de processo; e (d) infraestrutura.

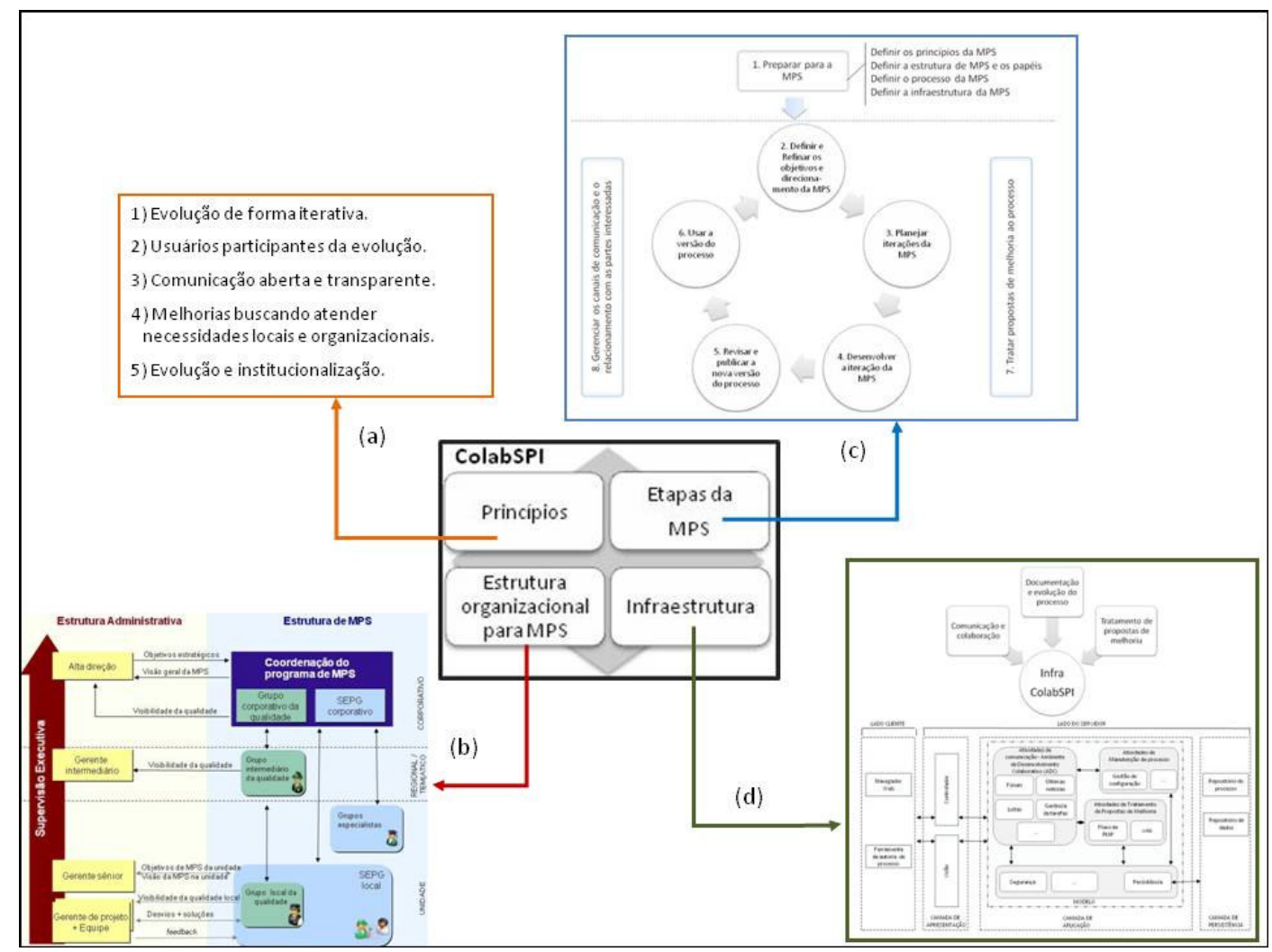

Figura 2.3: Estratégia ColabSPI (adaptado de Malheiros, 2010)

São cinco os princípios (Figura 2.3.a) que guiam a ColabSPI:

1. A evolução do processo ocorre de forma iterativa.

2. Os usuários do processo devem ser participantes na evolução.

3. No processo de melhoria deve haver uma comunicação aberta e transparente.

4. Considerando o desenvolvimento distribuído, a estratégia de melhoria de processo deve ser de forma distribuída e, conseqüentemente, as melhorias devem buscar atender as necessidades locais e organizacionais. 
5. A estratégia deve apoiar a evolução do processo de desenvolvimento e a institucionalização do processo, aumentando a aderência dos projetos ao processo.

A estrutura organizacional para melhoria de processo consiste no conjunto de papéis, responsabilidades e organização das pessoas para executar as atividades relacionadas à melhoria de processo. Em relação à ColabSPI, a estrutura organizacional deve apoiar o desenvolvimento de ações locais e, concomitantemente, as ações organizacionais que direcionem a melhoria de processo como um todo. Para garantir o alinhamento dessas ações com os objetivos de negócio da organização e o fluxo de conhecimento, a estrutura organizacional deve ser fortemente integrada à estrutura administrativa (Figura 2.3.b).

As etapas da estratégia ColabSPI compõem um ciclo de gestão para a melhoria de processo (Figura 2.3.c) e estão baseadas no modelo IDEAL. As etapas consistem em: (1) Definição - definir e refinar os objetivos e direcionamentos da melhoria de processo; (2) Planejamento - planejar iterações da melhoria de processo; (3) Desenvolvimento - desenvolver a iteração da melhoria de processo; (4) Liberação revisar e publicar a nova versão do processo; (5) Uso do processo de desenvolvimento usar a versão do processo.

Outras atividades são necessárias para apoiar esse ciclo, que são: Tratar as propostas de melhoria de processo; Controlar as mudanças no processo; Gerenciar os canais de comunicação e o relacionamento com as partes envolvidas no ciclo da melhoria de processo.

A infraestrutura necessária para a ColabSPI (Figura 2.3.d) consiste em mecanismos para comunicação e coordenação das atividades; para tratamento de proposta de melhoria e para documentação e evolução do processo. Serviços e aplicações existentes no domínio do desenvolvimento de software, como ferramentas de controle de versão, ferramentas para tratamento de erros de software e mecanismos para documentação e publicação de processos suprem essa necessidade da estratégia.

A arquitetura definida para a ColabSPI (Figura 2.4) visa a auxiliar na compreensão de como os mecanismos necessários podem se integrar, de quais das atividades da estratégia são apoiadas pela infraestrutura e de como esta pode evoluir de maneira incremental. 
Alguns características são essências para a infraestrutura da ColabSPI: ser disponibilizada na plataforma web; apresentar características de aplicações hipermídia; servir simultaneamente a diversos usuários distribuídos.

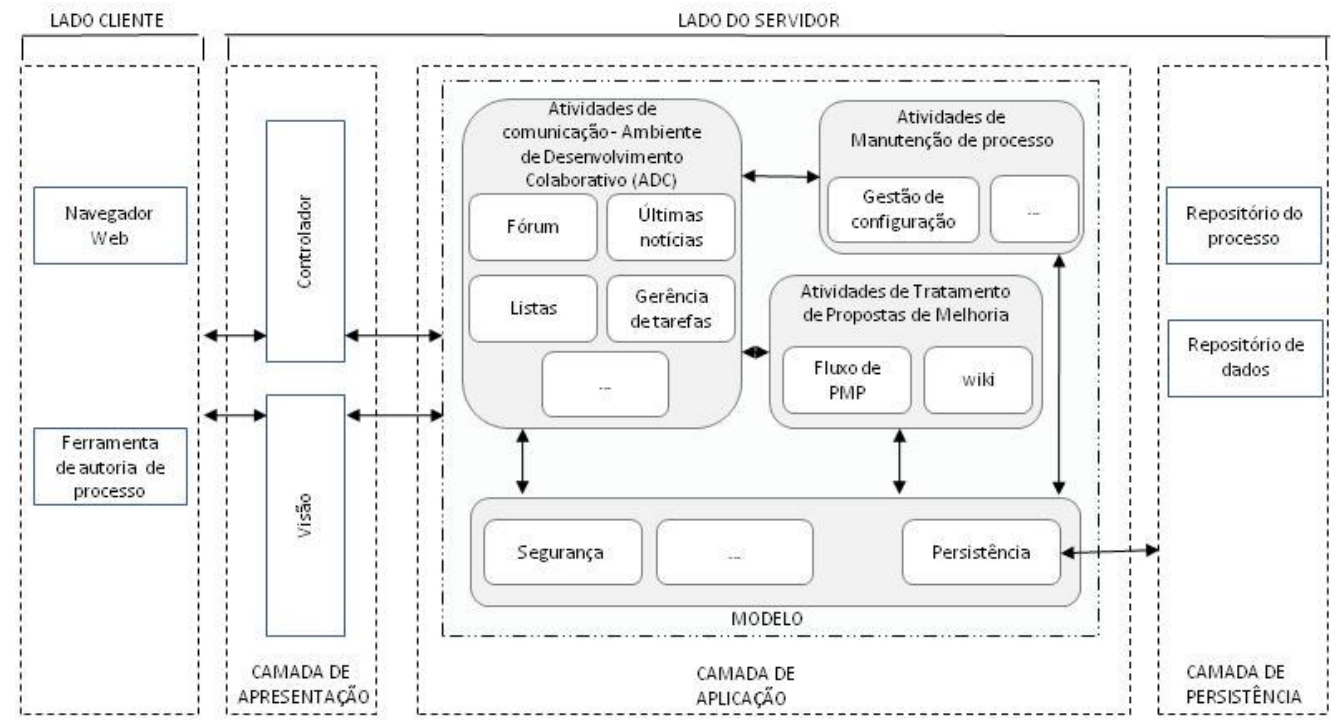

Figura 2.4: Arquitetura da infraestrutura da ColabSPI (Malheiros, 2010)

Conforme pode ser visto na Figura 2.4, o lado cliente consiste na interface gráfica para que o usuário possa interagir por meio de um navegador web e de uma ferramenta de autoria de processo. No lado servidor estão as camadas de apresentação, aplicação e persistência.

\subsection{Considerações finais}

Teste de software não é apenas uma atividade do processo de desenvolvimento de software, é também outro processo que, como tal, deve ser acompanhado, avaliado e evoluído. Os modelos de qualidade para processo de software contem áreas que contemplam atividades de teste, mas não estão voltadas para o processo de teste. Para complementar esses modelos existem outros modelos de qualidade que são para processos de teste, como o TMMi, abordado e utilizado neste trabalho.

Este capítulo também abordou a estratégia ColabSPI (Malheiros, 2010) que visa a gestão e evolução de processos de software, de forma distribuída e colaborativa. No próximo capítulo apresentaremos conceitos e modelos de gestão de conhecimento, modelagem de conhecimento e, de forma mais específica, a modelagem de mapa mental. 


\section{Capítulo 3 - Gestão de conhecimento}

\subsection{Considerações iniciais}

O objetivo deste capítulo é apresentar conceitos relacionados à gestão de conhecimento. A importância do tema no contexto do trabalho justifica-se pela própria proposta do Arcabouço KITest, uma vez que ele procura, principalmente, oferecer um conjunto de componentes para gestão do conhecimento em teste. Em particular, as informações sobre teste foram modeladas por meio de um mapa mental, recurso este comentado neste capítulo. Assim, este capítulo destaca aspectos de gestão de conhecimento relevantes para este trabalho.

O capítulo está organizado da seguinte forma: na Seção 3.2 são apresentados conceitos de gestão e transferência de conhecimento; na Seção 3.3 é abordada a importância da modelagem do conhecimento para facilitar a transferência dele; e na Seção 3.4 são apresentadas as considerações finais.

\subsection{Gestão e transferência de conhecimento}

\subsubsection{Conhecimento e gestão do conhecimento}

Dados são elementos puros e quantificáveis, eles não são dotados de relevância, propósito ou significado, mas são importantes porque são a matéria prima essencial para a criação da informação. Já informação envolve a interpretação de um conjunto de dados, ou seja, é o dado analisado e contextualizado. É um meio para extrair ou construir o conhecimento, acrescentando-lhe algo ou reestruturando-o. E conhecimento refere-se à habilidade de criar um modelo mental que descreva o objeto e indique ações e decisões a tomar. A Figura 3.1 representa o refinamento dos dados até chegar na síntese. A compreensão, a análise e a síntese, necessárias para a tomada de decisões, são realizadas a partir do nível do conhecimento (Dumont et al., 2006).

Conhecimento é a informação mais valiosa e, conseqüentemente, a mais difícil de gerenciar. É valiosa, precisamente porque alguém deu à informação um contexto, um significado, uma interpretação; alguém refletiu sobre o conhecimento, acrescentou a ele sua própria sabedoria. O conhecimento ainda implica na síntese de múltiplas fontes de 
informações e também é tácito, ou seja, é pessoal, está na mente humana e é difícil explicitar. (DAVENPORT et al., 2000.)

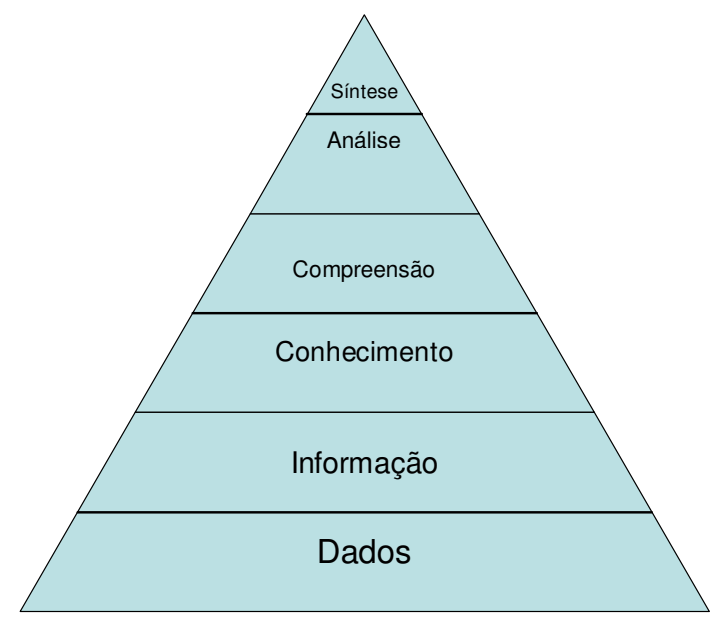

Figura 3.1: Dados, informação e conhecimento

Na Figura 3.2 estão representadas as etapas de geração de conhecimento. A interpretação e comunicação dos dados por um agente (máquina ou pessoa) é informação, que, estruturada, gera conhecimento. A inteligência somente começa quando o agente (pessoa) interage com o ambiente e gera novos conhecimentos (Dumont et al., 2006).

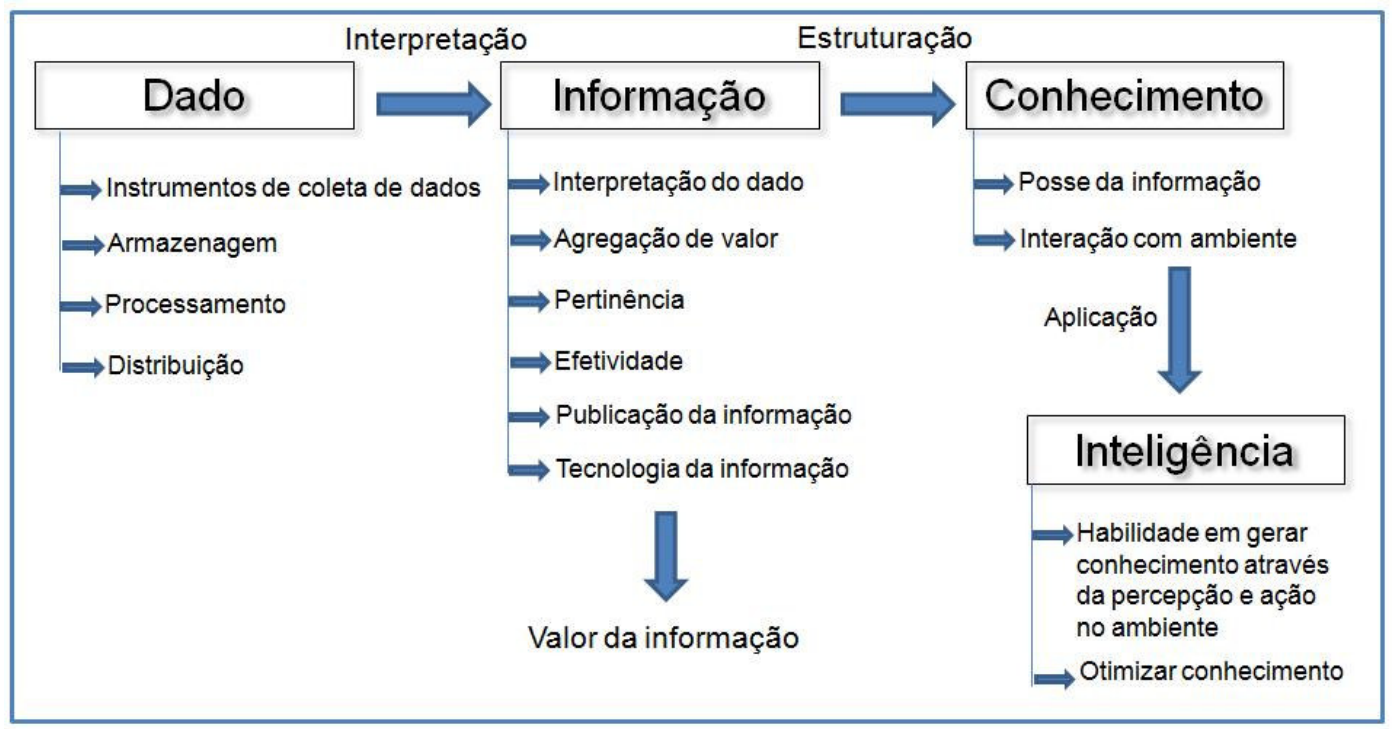

Figura 3.2: Etapas da geração de conhecimento

Nesse contexto, aprendizagem é o resultado desse processo que começa com a coleta de dados. Esses dados são organizados e transformados em informação, que, depois de analisada e contextualizada, se transforma em conhecimento - ou inteligência. 
A inteligência, por sua vez, quando aplicada a processos de decisão, gera benefícios administrativos para a organização (Dumont et al., 2006). Por isso a importância da gestão de conhecimento nas organizações.

Gestão do conhecimento é o processo sistemático de identificação, criação, renovação e aplicação dos conhecimentos que são estratégicos para uma organização. Está relacionada à prática de agregar valor à informação e de distribuí-la (Dumont et al., 2006).

Segundo Davenport e Prusak (1998), a gestão do conhecimento “...pode ser vista como uma coleção de processos que governa a criação, disseminação e utilização do conhecimento para atingir plenamente os objetivos da organização".

Para implantação desses processos faz-se necessário infra-estruturas humana e tecnológica que os apóiem (Rossato, 2003). Segundo Rossato (2003), a era do conhecimento, que sucedeu a era industrial, as inovações valorizam mais os ativos intangíveis da empresa e a transparência das informações.

Devidos a transformações no setor industrial, o eixo da riqueza e do desenvolvimento está voltado para tecnologia e conhecimento, fazendo com que a competição tenha base na capacidade de transformar informação em conhecimento e conhecimento em decisões e ações de negócios. Sendo assim, o conhecimento torna-se o principal fator de produção da nova economia (Rossato, 2003).

Rossato (2003) ainda destaca que o patrimônio intangível da organização, ou seja, o patrimônio formado pelo capital intelectual, pelo capital de relacionamento e pelo capital estrutural, é rico em conhecimentos tácito e explícito. Esses conhecimentos precisam ser compartilhados e difundidos dentro e fora da empresa, para que sejam transformados em valor de negócio e vantagem competitiva. Essas transformações exigem um ciclo contínuo e interativo de conversão de conhecimento.

Nonaka e Takeuchi (1997) apresentaram um ciclo base de transformação e compartilhamento do conhecimento. Segundo os autores, o conhecimento pode ser diferenciado em conhecimento tácito e conhecimento explícito. O conhecimento tácito é pessoal, específico ao contexto e está profundamente enraizado nas ações e experiências de um indivíduo, bem como em suas emoções, valores ou ideais, portanto é difícil de formalizar. Isso faz com que seja difícil sua transmissão e compartilhamento. Por outro lado, o conhecimento explícito pode ser formalizado e sistematizado, se tornando mais 
facilmente transmissível. Nonaka e Takeuchi (1997) defendem que o conhecimento é criado por meio da interação entre o conhecimento tácito e o conhecimento explícito. Esses dois tipos de conhecimento são unidades estruturais básicas que se complementam, e a interação entre eles é a principal dinâmica da criação do conhecimento na organização (Dumont et al., 2006). Então para a criação do conhecimento organizacional necessita-se de uma interação contínua e dinâmica entre esses conhecimentos, por meio de diferentes modos de transformação do conhecimento, ilustrada com a espiral do conhecimento na Figura 3.3. Nessa figura, adaptada por Shull et al. (2004), I representa um indivíduo, G representa um grupo e O uma organização.

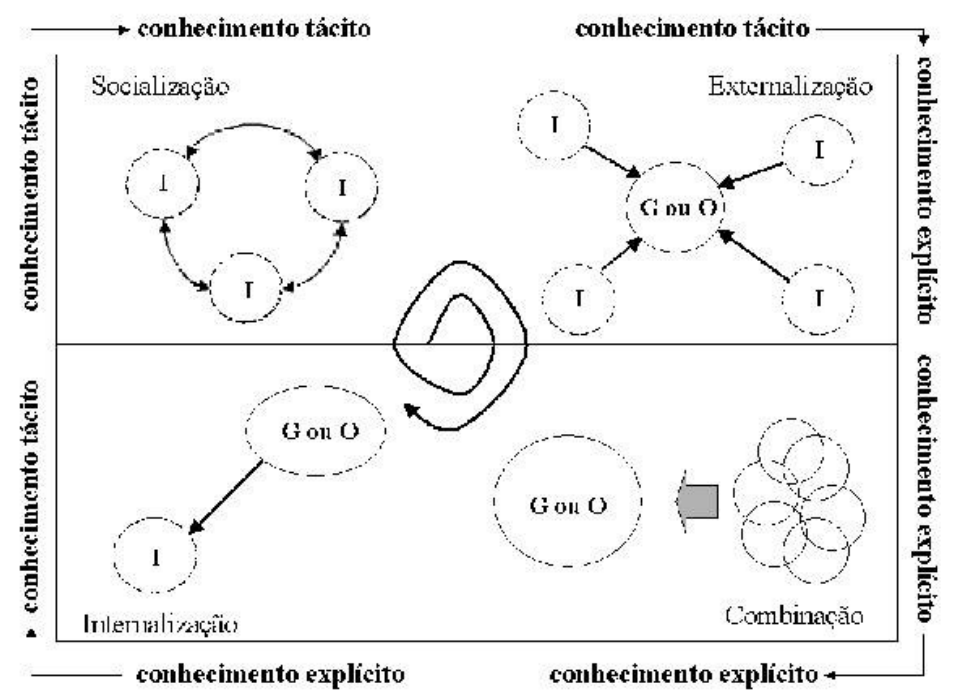

Figura 3.3: Modelo de compartilhamento do conhecimento (Shull et al., 2004)

A socialização é um processo de compartilhamento de experiência, nele o conhecimento tático é transferido entre indivíduos (Nonaka e Takeuchi, 1997; Shull et al., 2004).

A externalização é um processo de articulação do conhecimento tácito em conhecimento explícito. Ela é a chave para criação do conhecimento, pois cria conceitos novos e explícitos a partir do conhecimento tácito (Nonaka e Takeuchi, 1997). Os indivíduos explicitam seu conhecimento tácito para o grupo ou organização (Shull et al., 2004).

A combinação envolve conjuntos diferentes de conhecimentos podendo levar a novos conhecimentos (Nonaka e Takeuchi, 1997). Conhecimento explícito pode ser reorganizado em conhecimento mais sofisticado ou abstrato (Shull et al., 2004). 
E a internalização é o processo de incorporação do conhecimento explícito no conhecimento tácito. Os indivíduos absorvem conhecimento explícito combinando-o com seu próprio conhecimento e experiências para produzir novo conhecimento tácito (Shull et al., 2004).

Rossato (2003) resssalta que a conversão do conhecimento não pode ocorrer isoladamente, pois é necessário que os indivíduos interajam e que ocorram diversas ações que garantam o processo e propague o conhecimento pela empresa. Essas ações dependem dos seguintes dispositivos organizacionais, que são os mecanismos capacitadores e facilitadores: (i) estratégia organizacional; (ii) processos de negócios; (iii) ambiente organizacional; (iv) competência dos colaboradores; (v) infra-estrutura tecnológica. Um outro modelo de gestão de conhecimento é apresentado pela autora, representado na Figura 3.4:

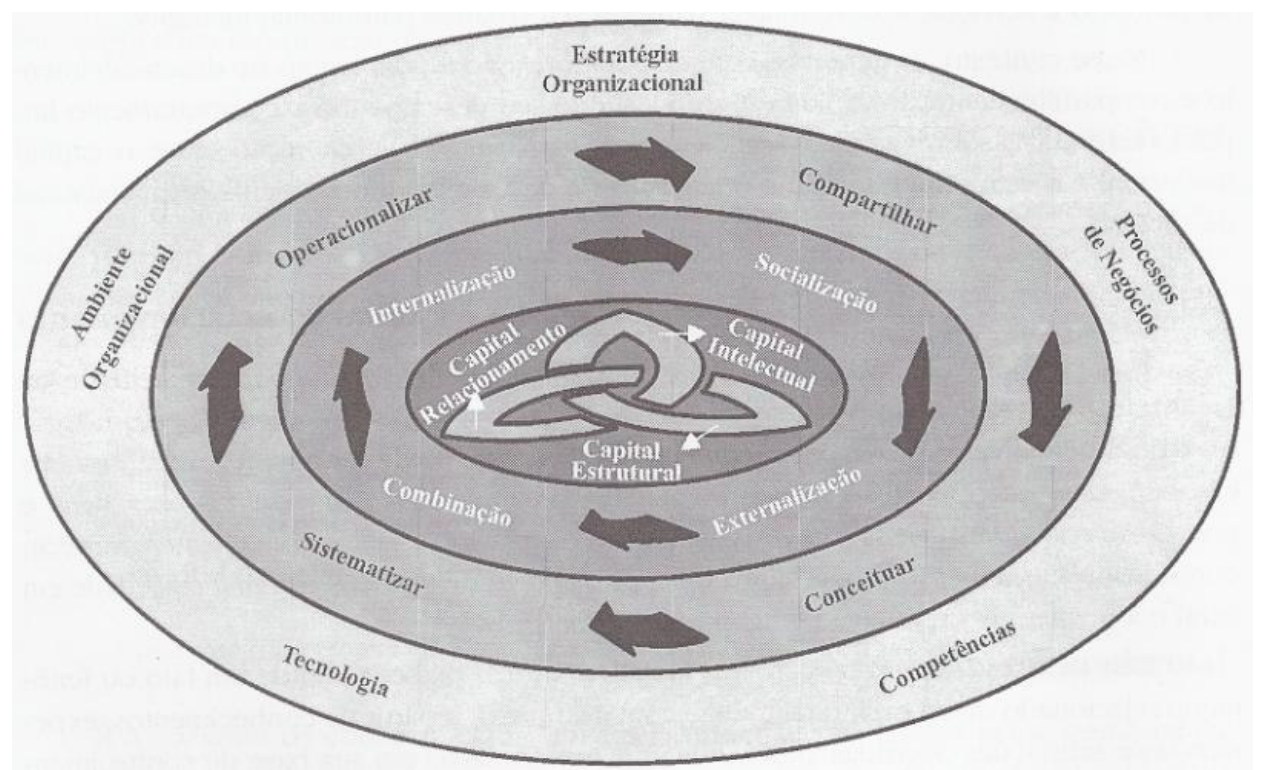

Figura 3.4: Modelo de gestão do conhecimento (Rossato, 2003)

Nesse modelo a primeira camada, indo da parte externa para a interna, representa a parte de estrutura (estratégia organizacional, processo de negócios, competências, tecnologia, ambiente organizacional), a segunda consiste nas ações (compartilhar, conceituar, sistematizar, operacionalizar), a terceira é a conversão do conhecimento (socialização, externalização, combinação, internalização) e a quarta, a mais interna, representa os ativos intangíveis (capital intelectual, capital estrutural e capital de relacionamento). 
Um dos dispositivos organizacionais apresentados, a infra-estrutura tecnológica, é importante estrategicamente quando é capaz de reduzir a dependência da empresa dos conhecimentos tácitos dos indivíduos após sua externalização, que devem ser armazenados em uma base de conhecimento e disponibilizados à toda organização. Apesar do auxílio da tecnologia, não é possível automatizar a socialização.

“[...] a criação de uma base de conhecimentos; o desenvolvimento de um sistema que a mantenha íntegra, consistente, organizada e atualizada a coleta dos conhecimentos explícitos gerados pela empresa; a validação desses conhecimentos (principalmente das teorias e conceitos) com a estratégia organizacional; a identificação do valor agregado por eles à empresa e à sociedade; a adaptação, reorganização, classificação, categorização e armazenamento desses conhecimentos na base de conhecimentos; a disponibilização da base de conhecimentos para buscas, capturas e consultas a qualquer momento; o uso de linguagem-padrão e agentes de comunicação e a construção de um protótipo de produto ou modelo de serviço". Rossatto (2002).

\subsubsection{Transferência de conhecimento}

A transferência de tecnologia consiste em um processo de aquisição, entendimento, absorção e aplicação de uma tecnologia ou de um processo tecnológico (Cysne, 1995). O problema é que o ato da transferência requer que o conhecimento esteja sistematizado e codificado e requer que o entendimento de como fazer algo (conhecimento tácito) se torne explícito para que possa ser comunicado a outros (Devinney, 1999). São necessários ciclos de compartilhamento do conhecimento para ocorrer a transferência tecnológica (Devinney, 1999; Nonaka e Takeuchi, 1997).

\subsubsection{Experimentação e pacotes de laboratório como alternativas para transferência de conhecimento}

A procura por novas tecnologias não é a principal preocupação das indústrias, mas sim a orientação de como usar a tecnologia existente. Esse é um dos maiores problemas associados à transferência tecnológica (Basili, 1985). Linkman e Rombach (1997) destacam três problemas em transferência de tecnologias de software para aplicações na indústria: (i) Novas tecnologias são consideradas não adaptáveis às necessidades comerciais; (ii) A gerência e assistentes não são suficientemente convencidos dos 
benefícios da nova tecnologia para considerar o seu uso em projetos; (iii) Experiências de projetos passados não são reutilizadas em novos projetos, geralmente porque não houve esforço suficiente para registrar e demonstrar seus benefícios.

Para esses autores, uma maneira de amenizar esse problema é utilizar a experimentação para apoiar a transferência tecnológica. Sua aplicação pode ser um mecanismo efetivo e necessário para conduzir a apresentação de novas tecnologias em ambiente industrial, mostrando-se ser um componente tanto de pesquisa quanto educacional na engenharia de software. A experimentação torna o processo de aprendizado em engenharia de software fundamentado no método científico, o qual pode ser resumido nas seguintes etapas: (i) Construção de modelos; (ii) Análise da corretitude dos modelos por meio de teste e experimentação; (iii) Análise dos resultados de experimentos visando ao aprendizado, ao empacotamento do conhecimento e ao refinamento do modelo existente; (iv) Evolução do conhecimento baseada na experiência ao longo do tempo.

O trabalho experimental entre indústria e academia resulta em relevantes ganhos para ambos os lados. A indústria encontra nessa cooperação um universo de replicações, dados de pacotes de laboratório e artefatos de domínios genéricos que possibilitam comparar sua efetividade com a efetividade média obtida em outras experiências, motivando-a, conseqüentemente, para a utilização da tecnologia e levando-a também a compartilhar os resultados obtidos internamente (Höhn, 2003).

Para a academia essa integração possibilita a validação externa dos resultados experimentais obtidos por uma nova tecnologia, o que permite a generalização destes, viabiliza a evolução dos pacotes de laboratório, inclusive introduzindo artefatos de domínios de aplicações reais e motiva a pesquisa de novas tecnologias.

As principais etapas identificadas para transferir uma tecnologia para uma indústria utilizando experimentação são:

1. Instanciação do pacote de laboratório no domínio alvo da organização;

2. Formação de replicadores;

3. Disseminação na organização;

4. Disseminação e troca de experiência com a comunidade 


\subsection{Modelagem do conhecimento}

Uma das definições para conhecimento refere-se a ele como informação que tem sido organizada e analisada, tornando-a compreensível e aplicável a solução de problemas ou tomada de decisão (Biffl e Halling, 2003). Com os dados organizados, estruturados e acrescidos de lógica, a gestão de conhecimento utiliza esse conhecimento gerado para alcançar os seus objetivos (Figura 3.5) (Dumont et al, 2006). Quando a estruturação dos dados é feita de forma visual, facilita a internalização, a transformação da informação em conhecimento, por parte do indivíduo. Dessa forma, apóia também a transferência de conhecimento.

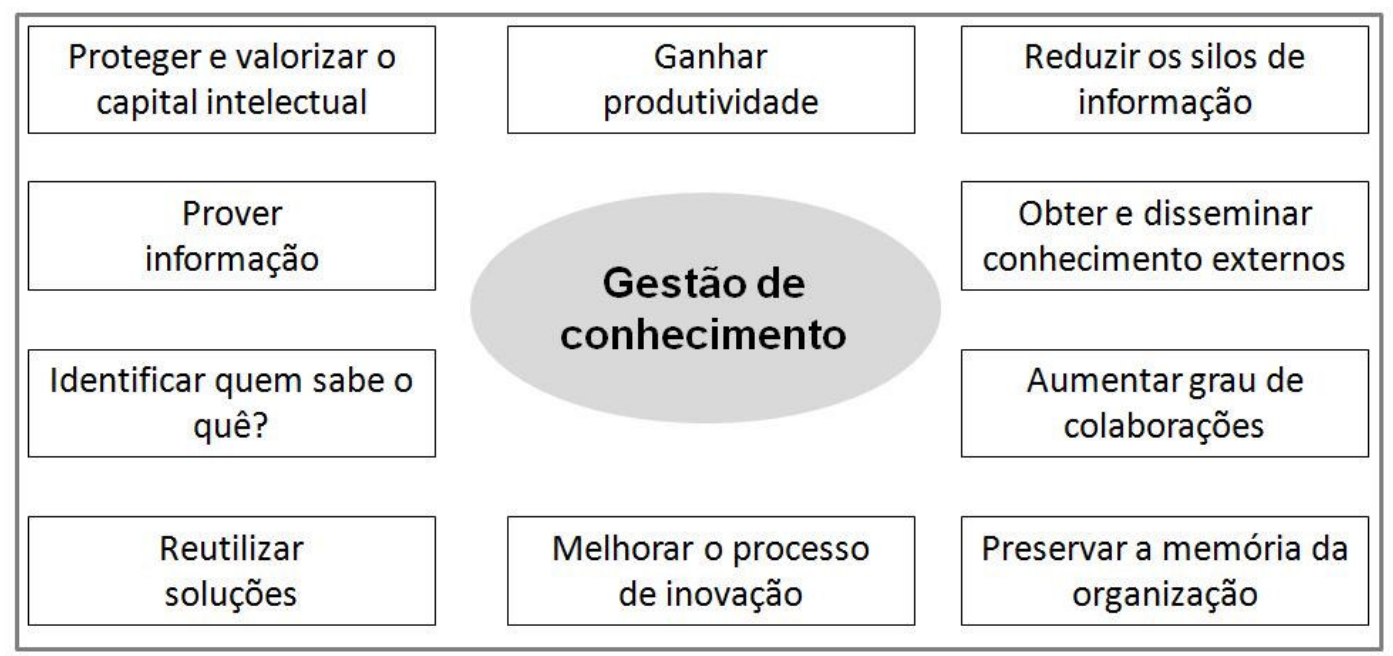

Figura 3.5: Objetivos da gestão de conhecimento (Dumont et al, 2006).

De acordo com Willis e Miertschin (2006), o uso de imagens pode auxiliar na compreensão da informação, já que imagens fazem parte da cognição humana. $\mathrm{O}$ pensamento visual (não-lingüístico) é uma parte fundamental e única da cognição humana, e deve ser associado às formas lingüísticas de expressar idéias e pensamentos.

Técnicas de aprendizagem visual podem ajudar a: (a) tornar as idéias abstratas em visíveis e concretas; (b) conectar conhecimento prévio a novos conceitos; (c) fornecer estrutura para o pensamento, escrita, discussão, planejamento e comunicação; e (d) concentrar pensamentos e idéias que levam a entendimento e interpretação.

Uma dessas técnicas de aprendizagem visual é o mapa mental, que vem sendo utilizado em diversas áreas, tanto no estudo individual, quanto como recurso para transferência de conhecimento, estruturando-o e facilitando a compreensão e internalização para outros indivíduos. 


\subsubsection{Mapas mentais}

Ferramentas cognitivas que utilizam técnicas visuais podem ser aplicadas a uma variedade de domínios. Elas têm como atributos poder representar o conhecimento daquele domínio; envolver na reflexão crítica sobre o assunto; ajudar a adquirir competências que são generalizáveis e transferíveis para outros contextos. Além disso, são ferramentas simples, mas poderosas no sentido de incentivar o pensamento e o processamento mais profundo da informação (Willis e Miertschin, 2006).

Segundo Willis e Miertschin (2006), uma das melhores ferramentas de organização semântica conhecidas é o mapa mental. Um mapa mental é uma representação gráfica das conexões entre conceitos e idéias que estão relacionadas a um tema central. Segundo o criador de mapas mentais, Buzan T., o mapa mental é uma expressão do pensamento e, portanto, uma função natural da mente humana. Os mapas mentais são representados como uma rede de conceitos interconectados, permitindo expressar o entendimento abstrato sobre um objeto (Buzan e Buzan, 1997). Eles apóiam o processo do pensamento natural, que acontece de forma natural e não linear (Brinkmann, 2003).

A estrutura hierárquica de um mapa mental está em conformidade com o princípio de que a representação cognitiva do conhecimento é estruturada hierarquicamente (Brinkmann, 2003). Com um mapa mental o usuário pode "ver" a estrutura da informação.

A apresentação gráfica ajuda o usuário a organizar o seu conhecimento, podendo conectar novas informações em um conhecimento já existente (Brinkmann, 2003). Uma teoria sugere que quanto maior o nível de processamento utilizado no aprendizado de um assunto, melhor será o nível de recordação (recall) em relação a processamentos superficiais, como leitura de textos simples (Farrand et al., 2002).

No processo de criação do mapa, informações que inicialmente estavam contidas em textos tornam-se hierarquicamente organizada, com a informação mais geral no centro do mapa mental e material de maior detalhe sendo apresentado nos extremos (Farrand et al., 2002). Ou seja, os mapas sempre têm o mesmo formato básico de uma árvore, com um único ponto de partida na raiz (tema central) que se ramifica em diversos níveis. A partir da raiz, ramos principais são acrescentados para cada uma das principais idéias relacionadas ao tema. A partir desses ramos, sub-ramos são desenhados 
para as idéias secundárias e assim por diante. Sempre seguindo do abstrato para o concreto, do geral para o específico (Brinkmann, 2003).

Para a criação de um mapa mental, Diba et al. (2004) sugerem que alguns passos sejam seguidos: (a) Passo 1: O assunto principal deve ser o centro do mapa e deve ser feita uma descrição dele com poucas palavras. Cores e sombreamento podem ser utilizados; (b) Passo 2: Os sub-temas devem ser colocados em ramos saindo do tema principal, a raiz. Utilize palavras-chave para descrever os sub-temas. Sempre que possível, utilize figuras e cores, pois elas facilitam a memorização. A Figura 3.6 apresenta um exemplo de mapa mental.

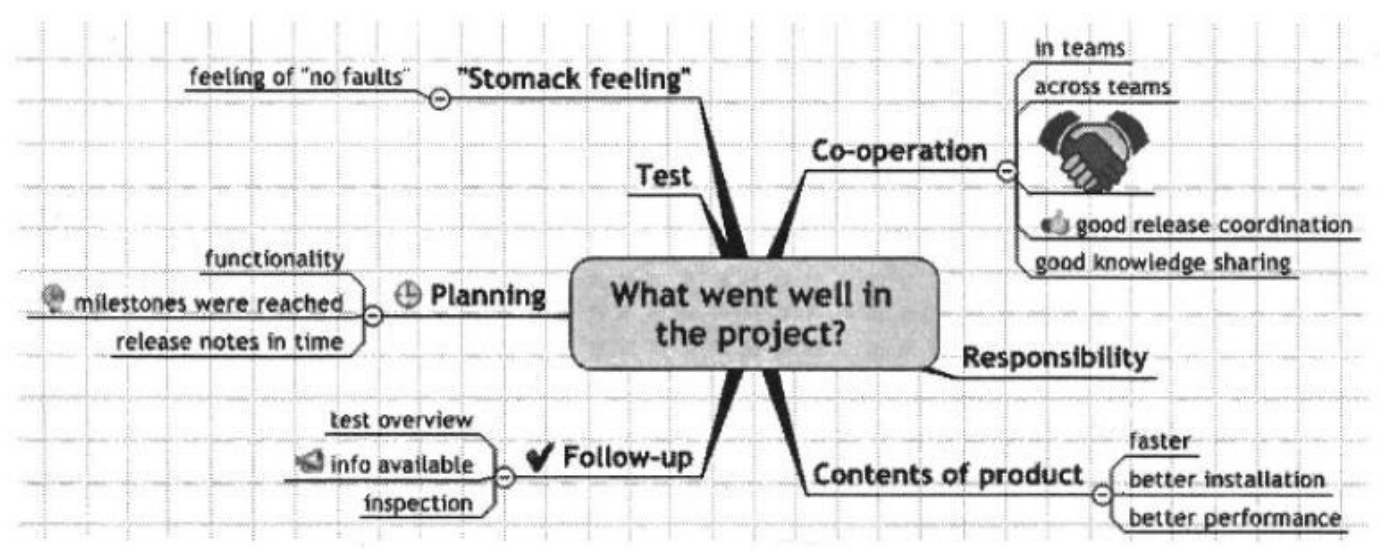

Figura 3.6: Exemplo de mapa mental (Diba et al, 2004)

\subsection{Considerações finais}

Neste capítulo foram apresentados conceitos de gestão de conhecimento e abordado mecanismo de transferência de conhecimento. A forma como o conhecimento é estruturado e representado pode ajudar na tarefa de transferência dele. Devido a isso algumas técnicas de modelagem do conhecimento vêm sendo adotadas. Uma dessas técnicas consiste no mapa mental, o qual por meio de recursos visuais auxilia no aprendizado de novos conceitos e no encadeamento deles com o conhecimento já existente.

No próximo capítulo apresenta-se o arcabouço KITest no qual mapas mentais são utilizados tanto como ferramenta de síntese do conhecimento, representando uma base de conhecimento, quanto como ferramenta de transferência do conhecimento. 


\section{Capítulo 4 - Um arcabouço de conhecimento e melhoria de processo de teste KITest}

\subsection{Considerações iniciais}

Como comentado no Capítulo 1, observa-se na comunidade e na literatura uma preocupação em se produzirem evidências sobre as vantagens e desvantagens no uso das tecnologias, ou mesmo caracterizá-las de forma que os desenvolvedores encontrem suporte para tomada de decisão sobre a viabilidade de usá-las. Porém, além da caracterização das tecnologias é importante que se tenha acesso também à teoria relacionada, para que tanto a caracterização como a própria tecnologia sejam usadas de forma adequada. Nesse contexto, existe a iniciativa encontrada no portal do software público brasileiro $5 \mathrm{CQualiBr}^{11}$, que fornece algum material sobre a atividade de teste, embora parcial e, aparentemente, sem atualização constante.

No entanto, a área de teste de software está sempre em evolução, acompanhando a engenharia de software com novas técnicas, critérios, ferramentas, adaptações a novos modelos e métodos de desenvolvimento e experiências de uso dessa tecnologia. Em geral, como foi mencionado acima, as informações relacionadas a essa área são encontradas de forma dispersa e, geralmente, sem associação ao seu uso em um processo de teste definido.

Assim, dada a importância da atividade de teste para o processo de desenvolvimento como um todo, definiu-se neste trabalho um arcabouço de conhecimento e melhoria de teste (KITest - Knowledge and Improvement on Test) composto por uma base de conhecimento em teste de software, por um mecanismo de utilização desse conhecimento pela comunidade, ajudando na definição de um processo de teste e de sua melhoria e por uma estratégia para fazer a gestão da evolução da base de conhecimento.

\footnotetext{
${ }^{11} \mathrm{http}: / /$ www.softwarepublico.gov.br/5cqualibr/xowiki/Teste
} 
Neste capítulo é descrito o arcabouço KITest, apresentando, na Seção 4.2, uma visão geral dele; na Seção 4.3 uma descrição da base de conhecimento em teste, sua representação por meio de um mapa mental (KITMap - Knowledge and Improvement on Test Map) e uma estratégia para evoluir esse mapa; e na Seção 4.4 as considerações finais. $\mathrm{O}$ mecanismo proposto para utilizar essas informações e sua implementação na ferramenta KITTool (Knowledge and Improvement of Test process Tool) serão detalhados no Capítulo 5.

\subsection{KITest - Knowledge and Improvement on Test}

$\mathrm{O}$ arcabouço KITest foi definido com o objetivo de centralizar as informações sobre teste de software e auxiliar no uso dessas informações para compor um processo de teste e fazer a sua evolução.

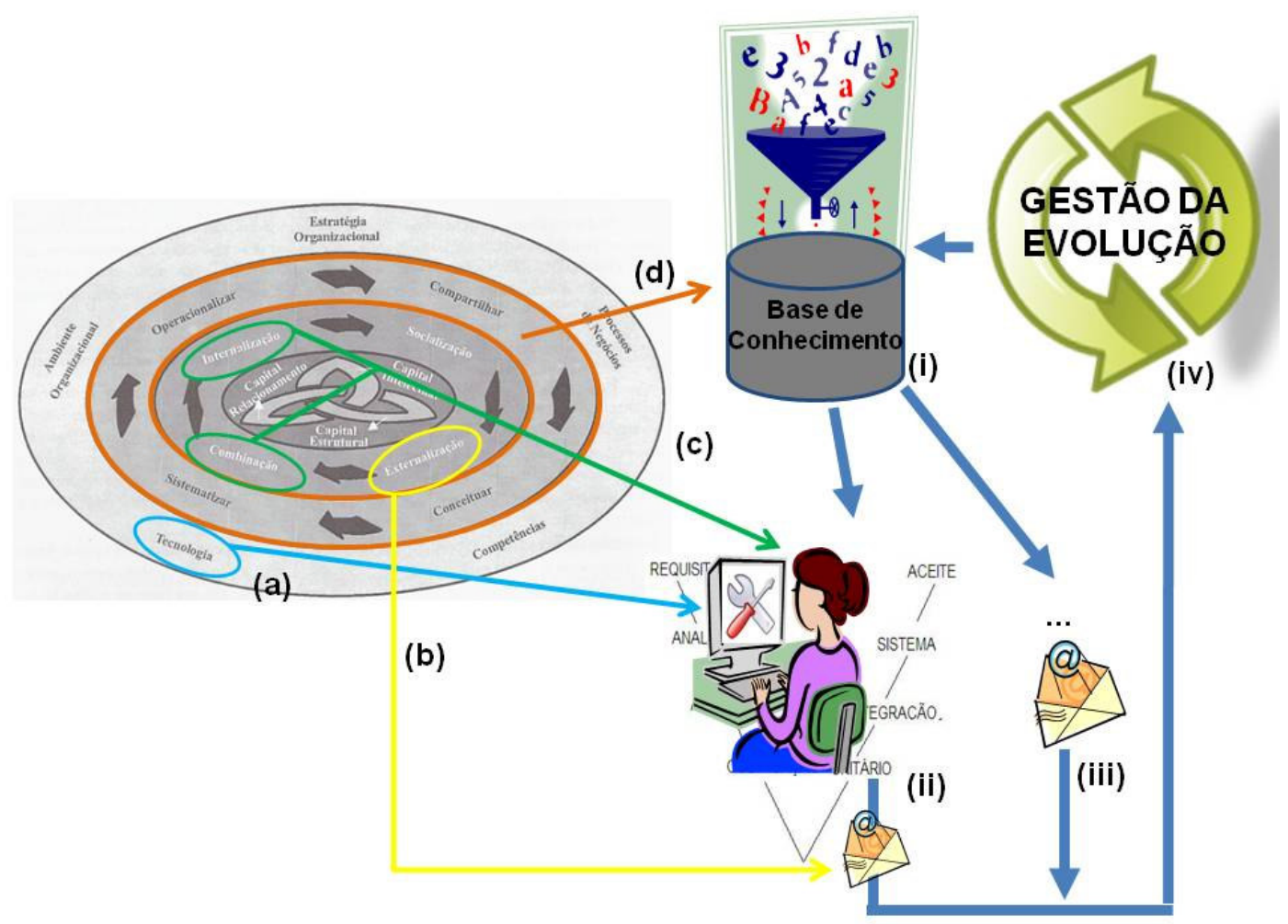

Figura 4.1: Arcabouço KITest e gestão de conhecimento.

Na Figura 4.1 são retratados o arcabouço KITest e as partes do modelo de gestão de conhecimento proposto por Rossato (2003) em que ele atua. O arcabouço pode ser sintetizado da seguinte forma: (i) a base de conhecimento é o componente que fica disponível para a comunidade e que contém um processo genérico de teste e suas atividades, às quais estão vinculadas informações da área de teste - técnicas, critérios, 
estratégias de teste, experiência de uso das tecnologias, lições aprendidas, documentação, entre outras; (ii) mecanismo de acesso ao conhecimento inserido na base, que viabilize e facilite o uso dele, permitindo que a comunidade possa diagnosticar a sua atividade de teste e definir o seu processo de teste de acordo com melhores práticas na área, além de obter diretrizes de como evoluí-lo; (iii) uma vez que a comunidade utilize o arcabouço para definir e evoluir seus próprios processos de teste, ela pode fornecer retroalimentação para a evolução da base de conhecimento; (iv) gestão da evolução da base de conhecimento.

Quanto ao modelo de gestão de conhecimento, o mecanismo de acesso ao conhecimento, disponibilizado no arcabouço KITest, representa um dispositivo organizacional de infra-estrutura tecnológica, ou seja, um mecanismo facilitador que faz parte da camada de estrutura do modelo de gestão proposto por Rossato (2003) (item (a) da Figura 4.1).

Da camada de conversão de conhecimento, identificam-se as etapas de externalização, internalização e combinação no arcabouço KITest. A externalização acontece quando o conhecimento tácito é explicitado e formalizado. No KITest, essa etapa ocorre quando o usuário aprende lições durante a definição e evolução de seu processo e então compartilha essas lições aprendidas por meio de sugestões para atualização da base de conhecimento (item (b) da Figura 4.1). O uso da base de conhecimento juntamente com o mecanismo de acesso às informações dela propicia a internalização do conhecimento e a combinação dele com conhecimentos que o usuário já possui (item (c) da Figura 4.1).

A camada que consiste nas ações, ou seja, compartilhar, conceituar, sistematizar e operacionalizar (item (d) da Figura 4.1) está relacionada à estruturação e organização do conhecimento em uma base de dados no arcabouço KITest. Por meio da infra-estrutura tecnológica adotada no arcabouço esse conhecimento pode ser acessado, operacionalizado e compartilhado.

Uma instanciação desse arcabouço é apresentada na Figura 4.2. A base de conhecimento foi representada em um mapa mental (KITMap - Knowledge and Improvement on Test Map), em que se buscou organizar o conteúdo sobre o assunto teste de software, em um processo genérico de teste, utilizando-se o modelo de maturidade para teste TMMi como referência. As áreas de processo (AP) do TMMi, bem como artefatos que exemplifiquem e esclareçam os assuntos de teste, foram 
vinculadas às etapas do processo genérico. O KITMap está disponibilizado para a comunidade, a qual pode utilizá-lo e realimentá-lo por meio de sugestões de melhoria enviadas ao gestor.

O mecanismo de acesso ao conhecimento, o qual permite que a comunidade possa diagnosticar a sua atividade de teste e definir o seu processo de teste com base no KITMap, além de obter diretrizes de como evoluí-lo, de acordo com o modelo TMMi, foi implementado na ferramenta (KITTool - Knowledge and Improvement of the Test process Tool). Por fim, a evolução do KITMap é gerenciada com apoio da estratégia de melhoria colaborativa e distribuída de processo ColabSPI [Malheiros, 2010].

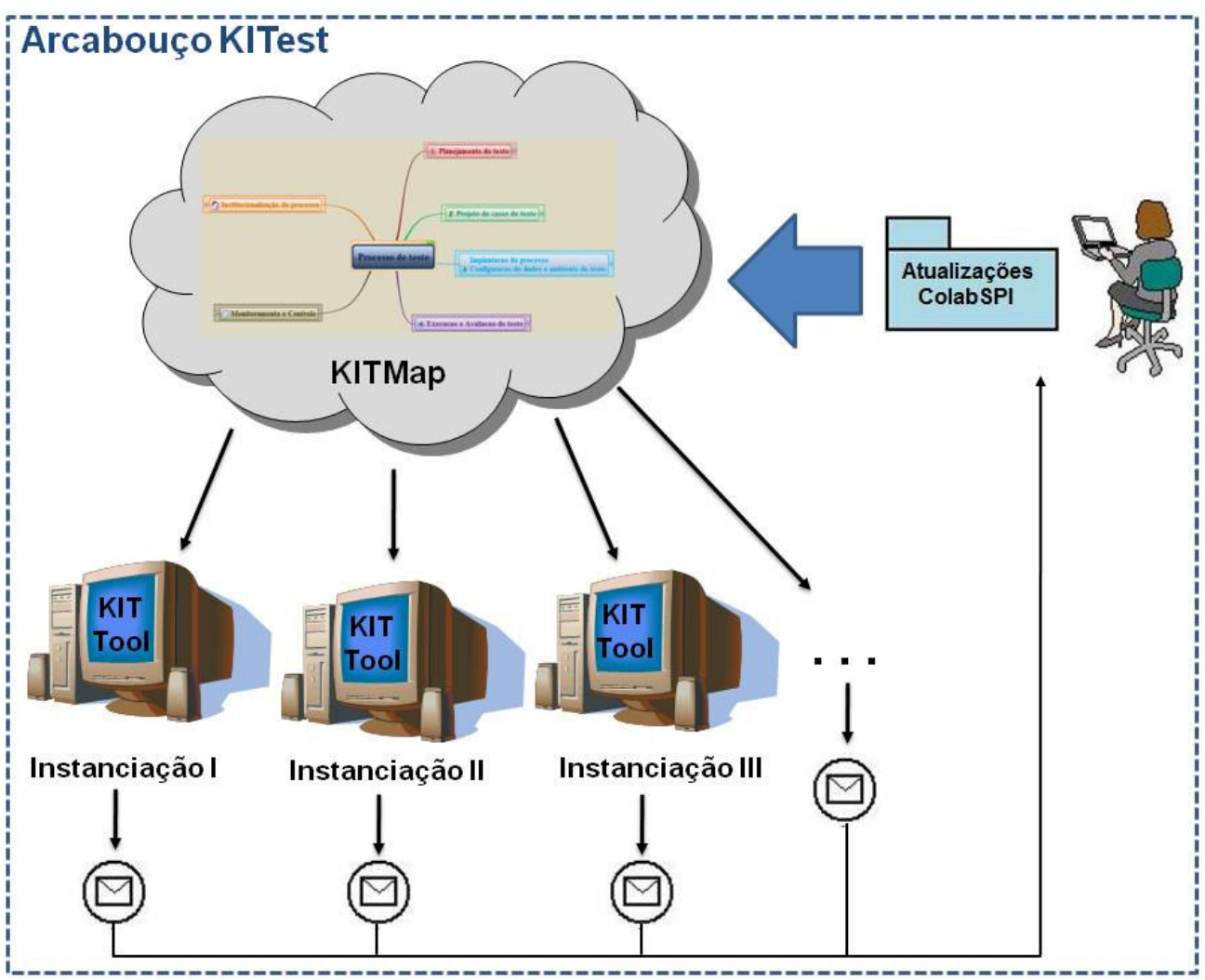

Figura 4.2: Arcabouço KITest: KITMap, KITTool e estratégia de gestão de melhorias ColabSPI.

Assim, cada usuário da comunidade que desejar utilizar essa base de conhecimento em teste para ajudá-lo a definir e evoluir seu processo, deve instalar a KITTool em seu ambiente, importar as informações do KITMap e utilizá-las para definição e melhoria de seu processo de teste. Os resultados observados nessas experiências podem contribuir na atualização do KITMap, tornando esse processo contínuo e evolutivo. 


\subsection{Base de conhecimento em teste - KITMap}

Conforme apresentado na seção anterior, a base de conhecimento é um dos componentes do arcabouço KITest. É necessário que as informações dessa base estejam organizadas, e possam ser recuperadas, de forma a facilitar a internalização do conhecimento pelo usuário, aumentando sua compreensão sobre a área de teste e sobre o relacionamento dos tópicos dessa área entre si. Outro ponto importante é que ela contenha informações que sirvam de referência para que o usuário possa definir e melhorar seu próprio processo de teste.

Nesta seção é apresentada uma representação da base de conhecimento do arcabouço KITest por meio de um mapa mental - KITMap, utilizando o TMMi como referência de melhores práticas em teste. As áreas de processo do TMMi, bem como artefatos que exemplifiquem e esclareçam os assuntos de teste relacionados a essas áreas, foram vinculadas às etapas de um processo genérico de teste. Outro componente do arcabouço, a estratégia para evolução da base de conhecimento, também é apresentada. Devido à característica de usuários distribuídos geograficamente, resolveuse aplicar a estratégia de gestão de melhoria para processo de software distribuídos ColabSPI (Malheiros, 2010). A adaptação dessa estratégia para o arcabouço KITest será detalhada na Seção 4.3.2.

A decisão por representar um processo genérico de teste juntamente com as práticas de um modelo de referência para processo de teste, no caso o TMMi, em um mapa mental foi baseada nas características de mapa mental, comentadas na Seção 3.3.1, do Capítulo 3. Características como a de ser uma ferramenta simples, mas que facilita ao usuário a organizar o conhecimento e ajuda na aprendizagem do assunto (Willis e Miertschin (2006); Brinkmann, 2003). Por ser uma ferramenta de organização semântica, representando conexões entre conceitos e idéias de forma gráfica, relacionando-as a um tema central (Willis e Miertschin 2006), o mapa mental se torna uma ferramenta poderosa para disseminar e compartilhar informações sobre processo de teste com a comunidade.

Como o processo do pensamento natural não é linear, torna-se difícil compreender e assimilar informações de forma textual, como as apresentadas nos documentos de modelos de melhoria, livros e artigos. Essas atividades se tornam complexas, dificultando inclusive a conexão das informações, e o entendimento de como elas se relacionam. 
Assim, o uso de mapas mentais visa a auxiliar no aprendizado das informações, apoiando-se no princípio de que a representação cognitiva do conhecimento é estruturada hierarquicamente (Brinkmann, 2003). Dessa forma, o fato do processo de teste estar representado por meio de um mapa mental disponibilizado na web permite: (i) que a informação esteja mais bem estruturada e seja, conseqüentemente, melhor compreendida; (ii) que a informação tenha um alcance maior na comunidade, que poderá visualizá-lo, facilitando o compartilhamento do conhecimento, incluindo a internalização e a transferência dele.

Para a modelagem do mapa foi utilizada a ferramenta de mapa mental Mindomo $^{12}$, podendo ser utilizadas outras ferramentas, por exemplo, XMind $^{13}$ ou FreeMind ${ }^{14}$, bastando algumas alterações no tradutor, como será comentado na Seção 5.5. A escolha dessa ferramenta foi motivada pelos seguintes atributos: é uma ferramenta web que pode ser acessada facilmente, o que ajuda na disponibilização do mapa; tem uma boa estética e bons recursos visuais; exporta os mapas para outros formatos, como XML e para extensões de outros mapas mentais; os mapas podem ser compartilhados, viabilizando trabalhos cooperativos, contando inclusive com ferramenta de conversa on-line (chat).

\subsubsection{Construção do KITMap}

O nó raiz do mapa deve receber o nome do tema principal, que no caso deste trabalho é "processo de teste". Os nós criados em um nível logo abaixo da raiz representam as etapas principais de um processo de teste genérico: Planejamento do teste; Projeto de casos de teste; Configuração de dados e do ambiente de teste; Execução e avaliação do teste; Monitoramento e controle; Institucionalização do processo. $\mathrm{Na}$ Figura 4.3 são apresentados o nó raiz e os nós do primeiro nível do mapa mental do Processo de teste.

Os níveis seguintes na hierarquia do mapa passam a fazer correspondência com a estrutura do TMMi, da seguinte forma: o nível dois corresponde às Áreas de Processo; o nível três aos Objetivos; o nível quatro às Práticas Específicas; e o nível cinco às Subpráticas, as quais correspondem às folhas do KITMap. As folhas devem conter material

12 WWW.mindomo.com

13 www.xmind.net.

${ }^{14}$ freemind.sourceforge.net/ 
de referência que dê suporte à realização do que é especificado nas Práticas e Subpráticas.

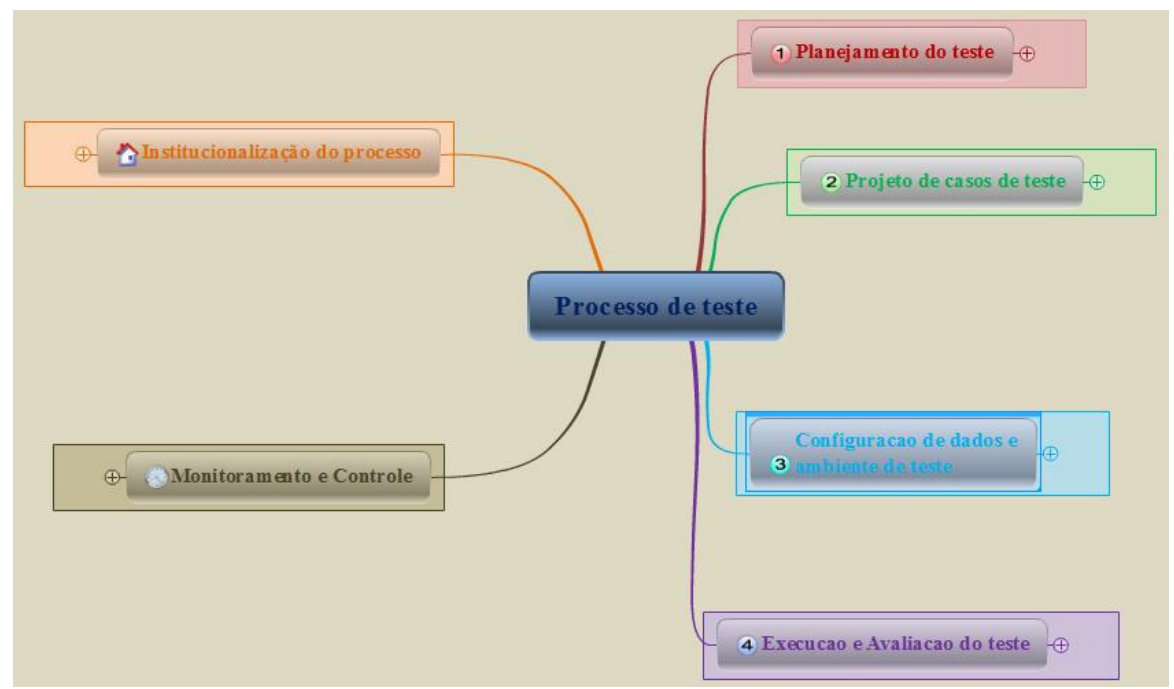

Figura 4.3: Primeiro nível do mapa mental de processo de teste.

A distribuição dos componentes do TMMi entre os elementos do KITMap foi determinada pelos objetivos das Áreas de Processo, ou seja, quem determinou os componentes do nível dois foram os elementos do nível três. Assim, como pode ser observado na Figura 4.4, a mesma AP pode estar associada a mais que uma fase do processo genérico de teste (a mais que um elemento do nível um do KITMap). Isso acontece porque cada AP possui vários objetivos e cada um deles está relacionado a uma fase do processo de teste.

Assim, os objetivos relacionados ao planejamento do teste, independentemente a qual AP ele pertencesse, foram associados ao nó "Planejamento de teste"; os relativos à criação dos casos de teste foram vinculados ao nó "Projeto de casos de teste"; os que tratam dos dados e ambiente necessários para $\mathrm{o}$ teste foram agregados em "Configuração de dados e do ambiente de teste"; no nó "Execução e Avaliação do teste" foram associados objetivos de execução do teste propriamente dito e avaliação do resultado dessa execução; o nó "Monitoramento e controle" agregou objetivos que dizem respeito ao monitoramento de todas as atividades do teste e de seu ambiente de execução; e por fim, o nó "Institucionalização do processo" agrupou os objetivos relacionados à política organizacional de teste e à estratégia de teste na organização. 


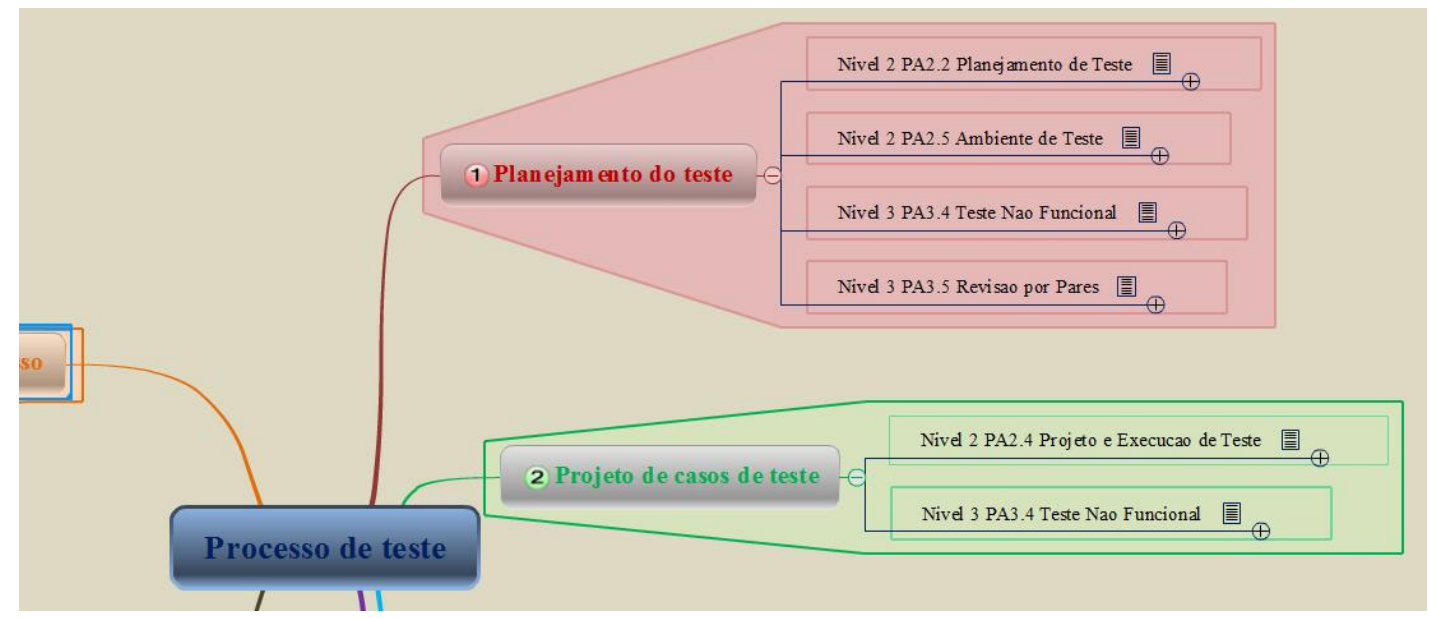

Figura 4.4: Componentes do TMMi distribuídos nas fases do processo de teste

Um exemplo do que foi explicado anteriormente pode ser observado na Figura 4.5 em que o nível três do KITMap contém os objetivos genéricos da área de processo Teste Não Funcional. Ressalta-se que essa área de processo, mostrada na Figura 4.5, aparece em duas fases, ou seja, tanto em Planejamento do teste quanto em Projeto de casos de teste.

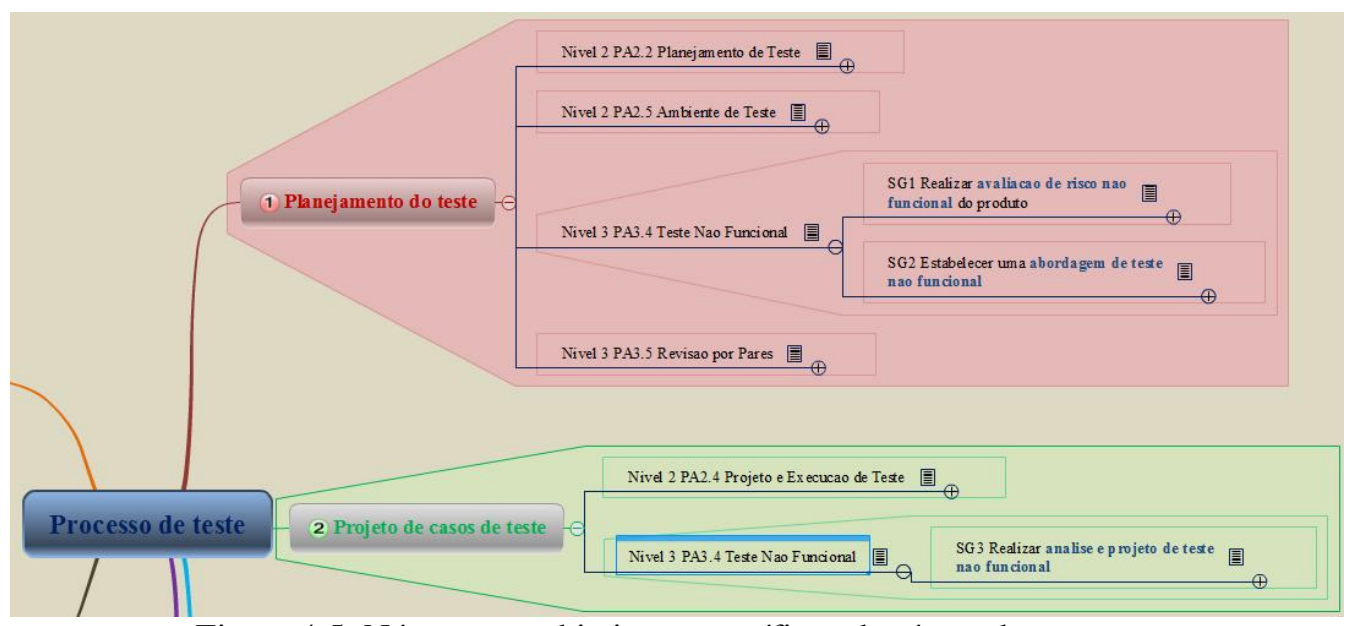

Figura 4.5: Nós com os objetivos específicos das áreas de processo

Como já mencionado anteriormente, após o nível dos objetivos está o nível quatro, das práticas, conforme exemplificado na Figura 4.6. 


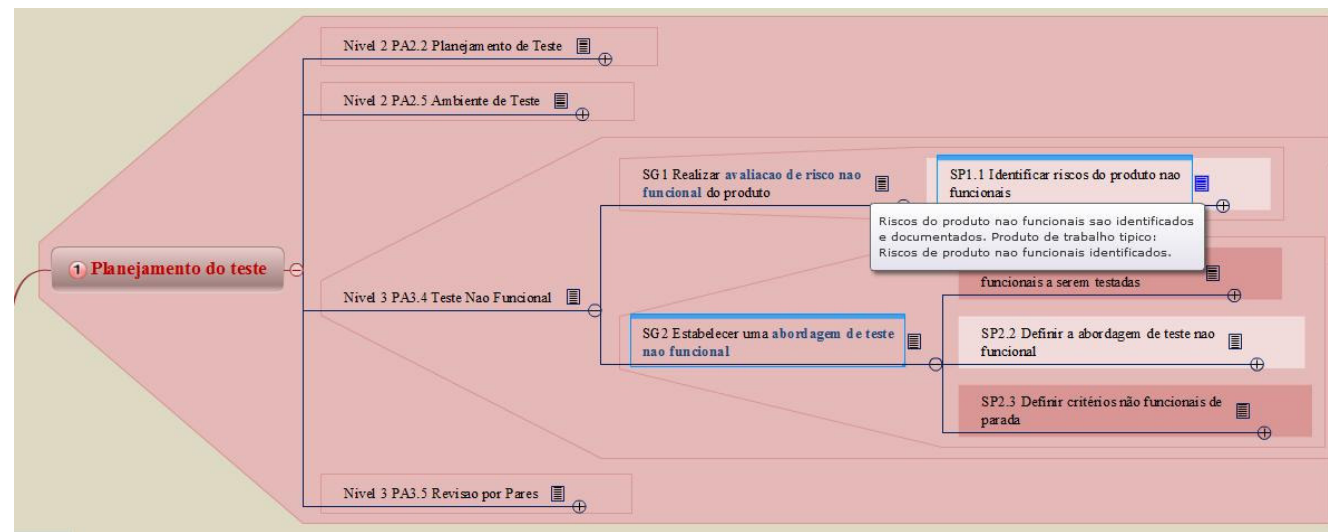

Figura 4.6: Nós com as práticas específicas

As folhas da árvore, correspondentes ao nível cinco, contêm as subpráticas, as quais servem como orientação do que é necessário ser feito para cumprir as práticas, como exemplificado na Figura 4.7. Às folhas devem ser vinculadas informações que visam a auxiliar na compreensão do assunto abordado por elas, por exemplo, hiperlinks a páginas que tratem do assunto, referências a livros especializados ou aos especialistas, exemplos de aplicação ou dados de experimentos conduzidos, etc.

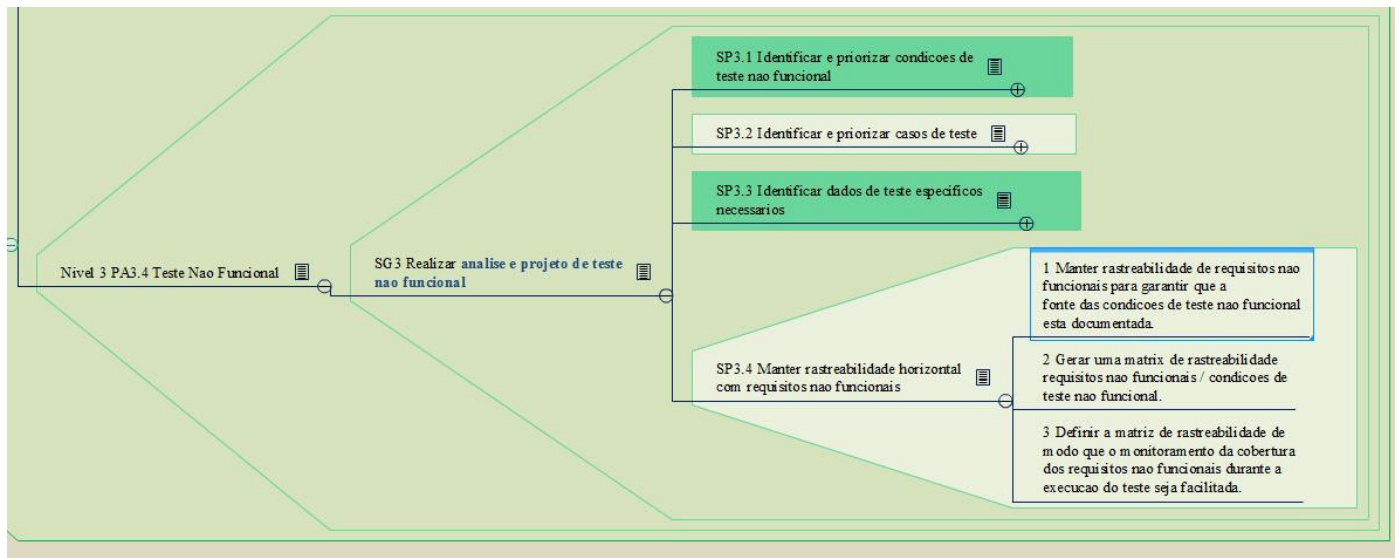

Figura 4.7: Nós com as subpráticas

\subsubsection{Gestão e evolução da base de conhecimento}

Conforme definido na Seção 4.2, outro componente do arcabouço KITest é a estratégia para gestão e evolução da base de conhecimento. A estratégia que for escolhida para gerenciar as atualizações deve considerar a característica de usuários distribuídos com diferentes perfis, além de outras fontes de informações, como pesquisas na literatura. Considera-se que a atualização constante do mapa deve ocorrer com a ajuda da comunidade, por meio de sugestões de material de referência e lições aprendidas. Necessitando então de uma política de tratamento das informações para 
atualização, a qual será apresentada posteriormente quando da definição do ciclo de melhoria do KITMap.

Para a instanciação do arcabouço KITest que estamos apresentando, na qual a base de conhecimento é implementada pelo KITMap, e considerando que o KITMap está disponível na internet como fonte de referência em teste, seu uso pode ser representado pela Figura 4.8. Apesar de o mapa poder ser consultado livremente pela comunidade, para poder aplicá-lo efetivamente na definição e gestão de um processo de teste em particular, é necessária a utilização da ferramenta de apoio KITTool, desenvolvida ao longo deste trabalho e disponibilizada na internet para download.

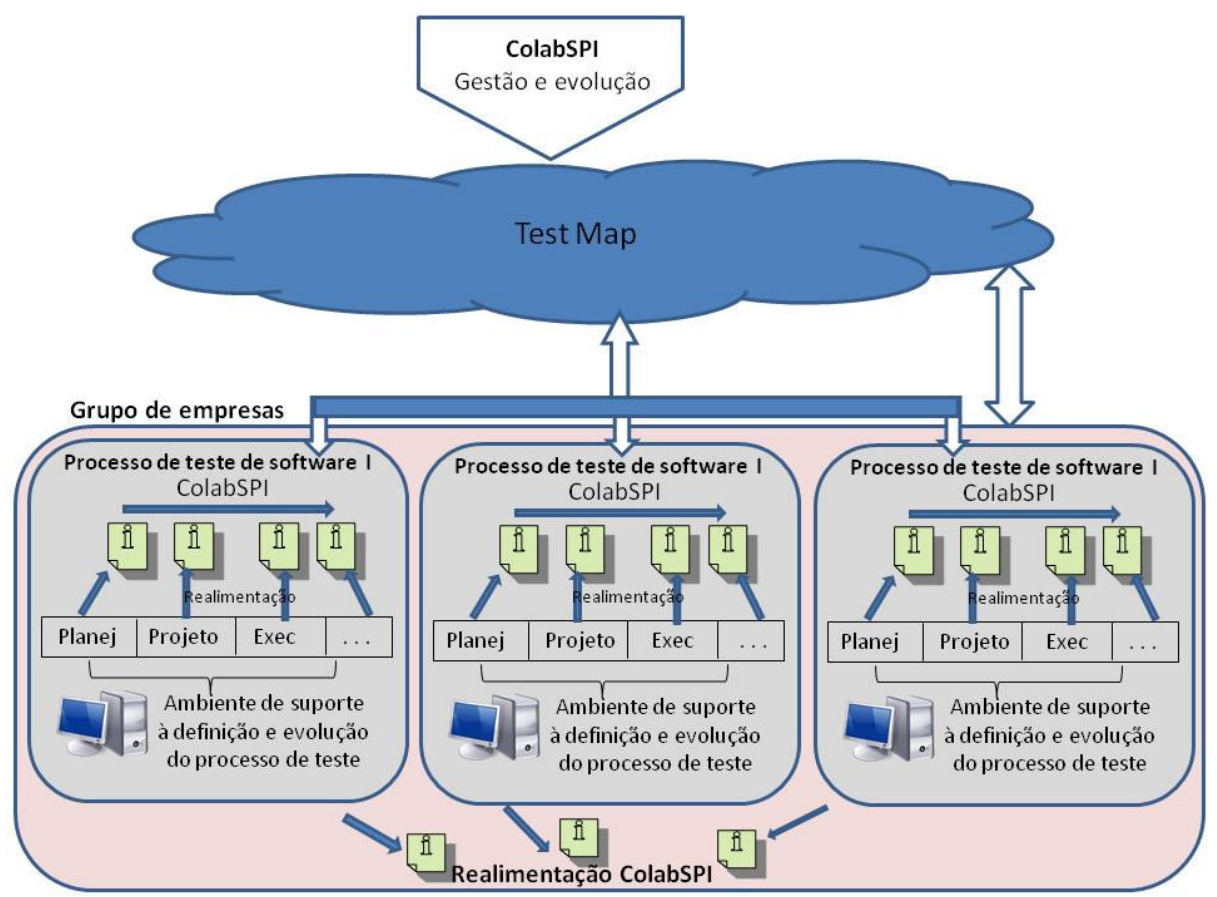

Figura 4.8: Representação da Relação do KITMap com seus usuários

Os usuários do KITMap e da KITTool podem ser empresas e grupos de empresas que visam à definição e melhoria de seus processos de teste, além da academia como ferramentas de transferência de conhecimento. A Figura 4.8 exemplifica o caso de três usuários do arcabouço KITest. Assim, cada usuário pode visualizar o KITMap na internet e pode tê-lo localmente, por meio da KITTool, com a qual também obtém recursos para diagnosticar o seu processo atual de teste, definir um novo processo com base nas informações disponibilizadas no KITMap e mesmo gerenciar a sua evolução. A situação retratada na Figura 4.8 poderia também ser interpretada como sendo uma cooperativa de empresas, que estariam usando o arcabouço de forma conjunta. 
Assim, os usuários podem fornecer feedback com sua experiência, colaborando principalmente com a evolução do KITMap e, eventualmente, do próprio arcabouço KITest. Conseqüentemente, torna-se necessária a gestão da evolução da base de conhecimento, a qual se propõe fazer com o apoio da estratégia de melhoria colaborativa e distribuída de processo ColabSPI [Malheiros, 2010], apresentada na Seção 2.5. Essa mesma estratégia pode ser utilizada para gestão e evolução dos processos de teste dos usuários, internamente em suas organizações.

Considerando a ColabSPI, seu ciclo de gestão para a melhoria de processo pode ser aplicado com pequena adaptação para a gestão da evolução do KITMap. A Figura 4.9 apresenta as atividades e etapas adaptadas, que são: (1) Preparar para a evolução do mapa; (2) Refinar objetivos e definir os direcionamentos do mapa; (3) Planejar atualização do mapa; (4) Desenvolver alteração do mapa; (5) Revisar mudanças no mapa; (6) Publicar a nova versão do mapa; (7) Tratar propostas de melhorias do mapa; (8) Gerenciar os canais de comunicação.

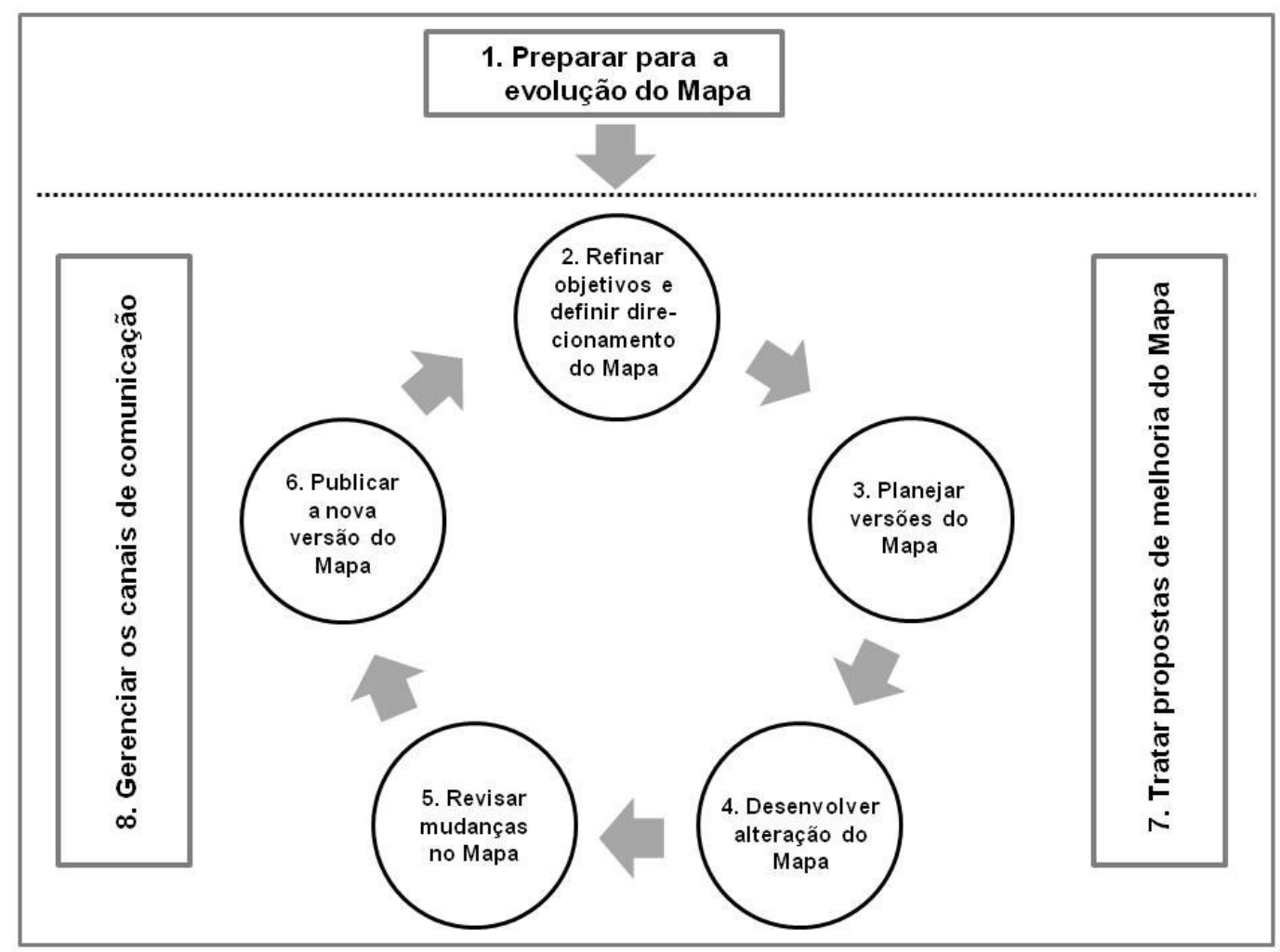

Figura 4.9: Etapas do ciclo de melhoria do KITMap 
Para execução da etapa (1) Preparar para a evolução do mapa, deve-se fazer um levantamento na comunidade de teste e na literatura sobre novas informações relacionadas a processo de teste e atividade de teste em geral (técnicas, critérios, ferramentas etc.). Essa etapa deve ser contínua, armazenando as informações levantadas para o momento em que uma atualização venha a ocorrer.

$\mathrm{Na}$ etapa (2) Refinamento e definição, usam-se como base as informações levantadas na etapa (1) e as sugestões ou propostas de melhoria (tratadas de forma contínua na etapa (7). Assim, planejam-se as alterações que serão feitas no KitMap, onde devem ser inseridas as novas informações e de que forma serão inseridas - se corresponderão a novos nós na árvore, se serão links ou arquivos nas folhas, etc.

Na etapa (3) Planejar versões do mapa, as conclusões obtidas na etapa (2), devem nortear o planejamento de possíveis versões. Algumas alterações maiores, principalmente quando ocorrem na estrutura já existente do mapa, podem ocasionar incompatibilidade na versão da KITTool que está sendo usada por alguns usuários. Nesse caso, cabe ao gestor decidir sobre a criação de novas versões do mapa, mantendo atualizações de folhas ou material informativo para a versão corrente - o que pode ser divulgado com uma freqüência maior - e criando versões com alterações estruturais, que devem ter uma divulgação e esclarecimentos maiores, devido aos usuários do arcabouço KiTest.

A etapa (4) Desenvolver alterações no mapa consiste em implantar as alterações decididas na etapa (3). Na etapa (5) Revisar mudanças no Mapa, todas as alterações executadas devem ser revisadas, considerando padronização, grafia, teste de links, abertura de arquivos vinculados, visualização no navegador e exportação de arquivo XML. Se algum problema for detectado, deve ser solucionado e novamente revisado.

A etapa (6) Publicar a nova versão do KITMap, consiste na disponibilização e divulgação da nova versão. Caso a nova versão contenha alterações estruturais e/ou existam duas ou mais versões disponíveis, isso deve ser ressaltado na divulgação. A etapa (7) Tratar as propostas de melhoria de processo e a etapa (8) Gerenciar os canais de comunicação apóiam o ciclo todo, de forma contínua.

Para a etapa (7), as propostas de melhoria devem ser registradas e acompanhadas até o final do fluxo de tratamento delas, pois devido ao uso distribuído do mapa por usuários de perfis diferentes, podem ocorrer propostas semelhantes e até conflitantes. $\mathrm{O}$ 
registro da situação de cada proposta, até chegar à sua implantação ou rejeição, e contendo também as decisões tomadas ao longo do fluxo, assim como a justificativa de rejeição, auxiliam no tratamento de novas propostas, além de manter um histórico das alterações na base de conhecimento.

O fluxo de tratamento para as propostas de melhoria está representado pela Figura 4.10 por meio da notação BPMN (Business Process Modeling Notation ${ }^{15}$ ). Os três papéis envolvidos são: a comunidade, como usuário, o gestor do KITMap e o especialista em teste.

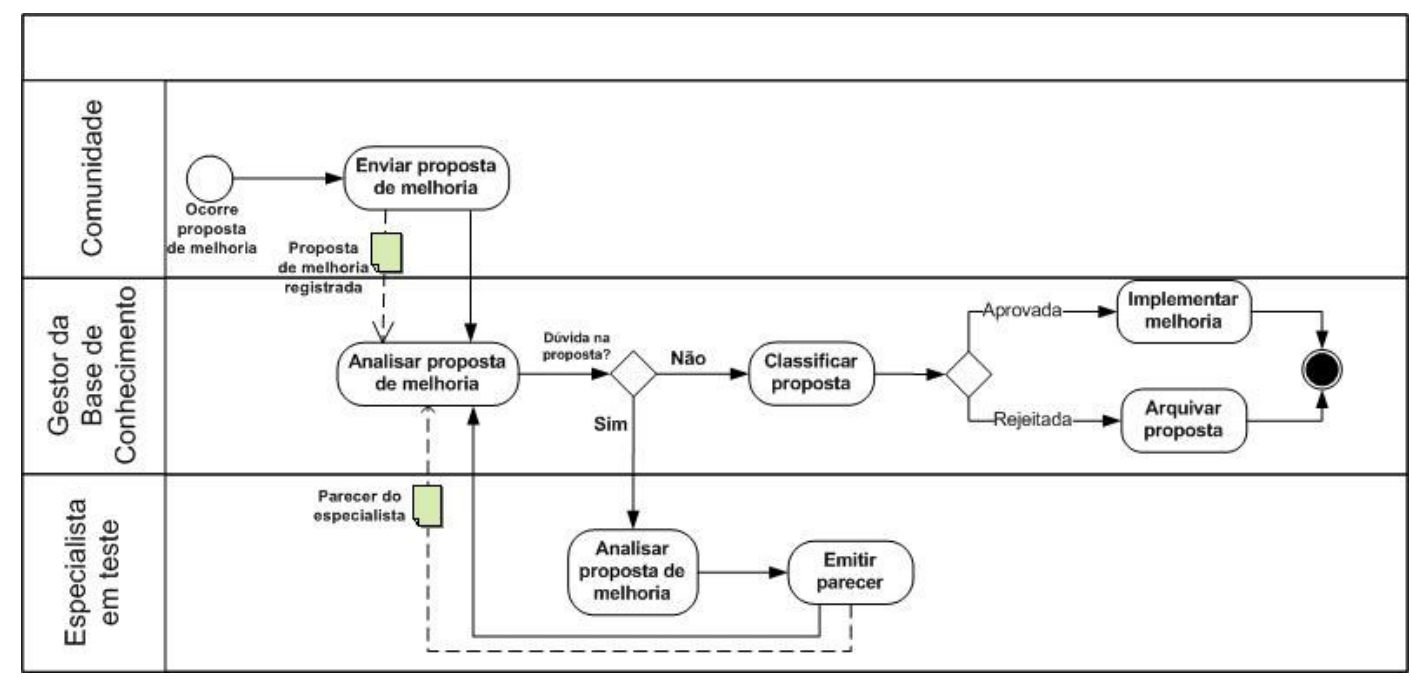

Figura 4.10: Fluxo de tratamento para as propostas de melhoria

O fluxo inicia-se com o envio de uma proposta de melhoria pela comunidade, então essa proposta é analisada pelo gestor do KITMap, para decidir sobre sua aceitação ou não. Se o gestor possuir dúvidas a respeito da proposta, ele deve encaminhar a um especialista em teste, o qual deve analisá-la, emitir um parecer e enviar de volta ao gestor para nova análise. O gestor analisa o parecer do especialista e aprova ou rejeita a proposta. Caso o gestor aprove a proposta, ela deverá ser implementada e o fluxo é finalizado. Caso o gestor rejeite a proposta, ele deve arquivá-la junto com a justificativa da rejeição e, então, o fluxo é finalizado.

${ }^{15}$ www.bpmn.org/ 


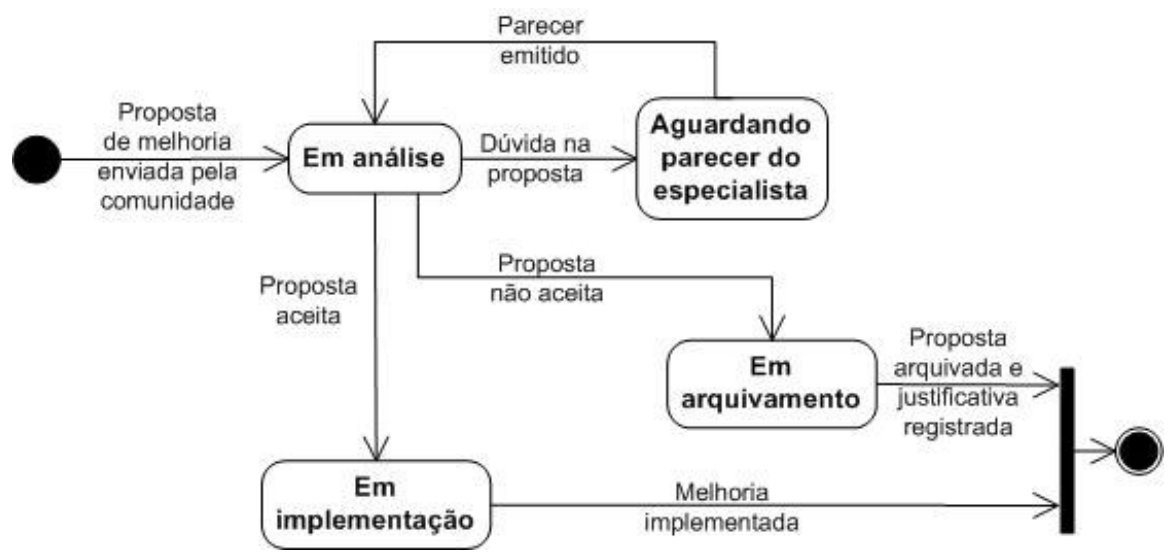

Figura 4.11: Diagrama de estados das propostas de melhoria

Na Figura 4.11 é apresentado um diagrama dos estados em que cada proposta passa durante o fluxo de tratamento. Assim que a proposta de melhoria é enviada pela comunidade, ela vai para análise do gestor, no estado Em análise. Caso o gestor possua dúvidas, ele encaminha a proposta para um especialista, passando-a para o estado Aguardando parecer do especialista. Uma vez que o especialista emita o seu parecer, a proposta volta para o gestor e para o estado Em análise. O gestor analisa o parecer e decide sobre a aceitação ou a rejeição da proposta. Se ele aceitar a proposta, ela vai para o estado Em Implementação. Quando a implementação da melhoria for concluída, o fluxo será encerrado. Se o gestor rejeitar a proposta, ela vai para o estado Em arquivamento e, assim que a proposta for arquivada e a justificativa de rejeição registrada, o fluxo será encerrado.

A execução da etapa (8) é feita por meio dos canais de comunicação, pelos quais devem ser enviadas sugestões, críticas, dúvidas e materiais. Além disso, é possível gerenciar atividades de alterações no mapa, trocando informações entre dois ou mais gestores do mapa, permitindo assim um trabalho distribuído e coordenado.

De forma análoga à ColabSPI, apresentada na Seção 2.5, a infraestrutura necessária para apoiar o uso do arcabouço KITest consiste em mecanismos para comunicação e coordenação das atividades (por exemplo, email, chat, listas, fóruns e redes sociais); para tratamento de proposta de melhoria (por exemplo, ferramentas para tratamento de erros) e para controle da documentação do material de referência anexado às folhas do KITMap (por exemplo, ferramentas de controle de versão). A Figura 4.12 mostra a arquitetura da infra-estrutura, a qual foi adaptada da ColabSPI e que, assim como aquela, adota o padrão MVC (Model-View-Controller). O lado do cliente possui dois itens obrigatórios para poder utilizar o arcabouço KITest e um item opcional. Os 
itens obrigatórios são: um navegador web para acessar o KITMap, a KITTool para fazer o diagnóstico do processo de teste e para obter diretrizes de evolução. $\mathrm{O}$ item opcional consiste de uma ferramenta de autoria de processo, como o EPF Composer ${ }^{16}$, caso o usuário deseje registrar, publicar e acompanhar o seu processo de teste.

O lado do servidor possui as camadas de apresentação, aplicação e persistência. A camada de apresentação é responsável pela interface com o usuário, e no caso do arcabouço KITest o gerenciamento dessa interface é realizado pelas próprias ferramentas utilizadas no arcabouço - Mindomo, ferramentas de comunicação e máquinas de busca. A camada de aplicação contém a lógica do negócio, ou seja, contém as principais funcionalidades que integram o arcabouço, as quais estão organizadas em três grupos funcionais: (a) Atividades de criação e publicação do mapa mental, (b) Atividades de manutenção e evolução da base de conhecimento em teste e (c) Atividades de comunicação.

As Atividades de criação e publicação do mapa são realizadas em uma ferramenta de criação de mapas mentais e publicadas na web. Atualmente, no KITest essas duas atividades são realizadas em uma só ferramenta, Mindomo, que possui tanto edição quanto publicação de mapas. Outras ferramentas podem ser utilizadas, se as devidas adaptações no tradutor de XML da KITTool forem realizadas, como será explicado na Seção 5.5. As Atividades de manutenção e evolução da base de conhecimento em teste compreendem (a) atividades para tratamento das propostas de melhoria e (b) atividades de pesquisa na literatura e consulta a especialistas. Para fazer o tratamento das propostas de melhoria, o arcabouço KITest contém uma política de tratamento, representada pelo fluxo contido nas Figuras 4.9 e 4.10, sendo que o controle das propostas durante esse fluxo pode ser registrado e acompanhado por uma ferramenta de tratamento de defeitos (do inglês, bug tracking ou issue tracking). Na condução de pesquisas na literatura, o arcabouço adota o uso de máquinas de busca (na web e localmente, em bibliotecas), no intuito de obter informações atualizadas na área de teste.

As Atividades de comunicação do arcabouço KITest são apoiadas por ferramentas de comunicação, como email, fórum e redes sociais. A camada de persistência, responsável pela segurança e persistência dos dados, é implementada pelos próprios recursos adotados no arcabouço. Ou seja, os dados do mapa mental são persistidos pela

${ }^{16}$ www.eclipse.org/epf/ 
ferramenta Mindomo; as informações das decisões tomadas durante o tratamento das propostas de melhoria são persistidas pela ferramenta de tratamento de erros escolhida; o acesso e os dados trocados durante a comunicação são gerenciados pelas ferramentas utilizadas para email, fórum e redes sociais.

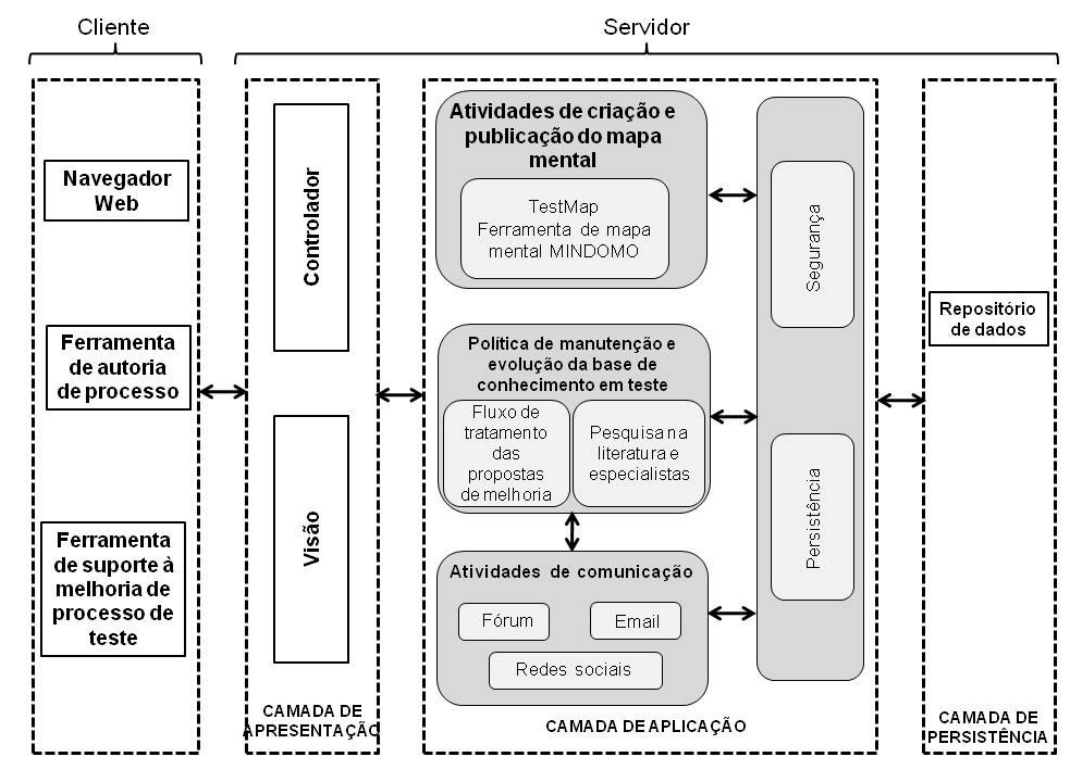

Figura 4.12: Adaptação da arquitetura da infraestrutura da ColabSPI para gestão e evolução do mapa mental de teste.

\subsection{Considerações finais}

Conforme comentado anteriormente, as informações relacionadas à área de teste de software encontram-se de forma dispersa e desconexa, ou seja, sem associação dos elementos de informação entre si, de maneira que se tenha uma compreensão mais abrangente. Um exemplo disso é a disponibilidade de informações específicas sobre técnicas, critérios e ferramentas de teste, sem associá-las às etapas de um processo de teste em que podem ser aplicadas, nem destacando quais itens de qualidade elas atendem, nem quais evidências de qualidade elas produzem.

Assim, apresentou-se neste capítulo o arcabouço KITest cujo objetivo é justamente fornecer à comunidade esse repositório centralizado sobre teste de software, de forma que a comunidade encontre nele um referencial que dê subsídios à definição de processos de teste.

Como mencionado na literatura, um produto com qualidade é decorrente de um processo com qualidade, ou seja, dificilmente consegue-se inserir qualidade em um produto depois que ele está finalizado. Tendo como principal objetivo dar subsídios à 
definição de processos de teste, houve então uma preocupação constante, durante a definição do KITest, com aspectos de qualidade associados a esse tipo de processo. Dessa forma, estabeleceu-se como base para todo o trabalho, o modelo de maturidade em teste TMMi $[\mathrm{xx}]$.

O arcabouço KITest é composto de três elementos: (i) uma base de conhecimento contendo informações da área de teste de software distribuídas nas etapas de um processo genérico de teste, com referências de melhores práticas; (ii) um mecanismo de acesso ao conhecimento da base, que viabilize e facilite o uso dele, permitindo que a comunidade possa diagnosticar a sua atividade de teste e definir o seu processo de teste de acordo com melhores práticas na área, além de obter diretrizes de como evoluí-lo; (iii) uma estratégia para gestão da evolução da base de conhecimento.

Uma instanciação desse arcabouço foi apresentada, na qual a base de conhecimento foi representada em um mapa mental - KITMap. Esse mapa concentra informações sobre a área de teste e está organizado de acordo com as etapas de um processo genérico de teste, o qual foi preenchido com as atividades recomendadas no TMMi e com material de referência, para essas atividades, fornecidos pela comunidade ou mencionados na literatura. O mecanismo de acesso às informações do KITMap foi implementado em uma ferramenta - KITTool - que viabiliza o uso das informações pela comunidade para que esta possa realizar o diagnóstico de seu processo de teste, a definição de um processo de acordo com as premissas do TMMi, e sua evolução. Por fim, para a estratégia de evolução do KITMap, foi feita uma adaptação da estratégia ColabSPI (Malheiros, 2010). Essa estratégia também pode ser aplicada pelos próprios usuários do arcabouço em seus respectivos processos. 


\section{Capítulo 5 - KIT-Tool - Uma ferramenta para conhecimento e melhoria de processo de software}

\subsection{Considerações iniciais}

Como mencionado no capítulo anterior, um dos componentes do arcabouço KITest é a ferramenta KITTool, a qual viabiliza a utilização do mapa de teste - KITMap - para fazer o diagnóstico do processo de teste de um usuário e para a definição de um novo processo, de acordo com as recomendações de melhoria.

Este capítulo apresenta os detalhes da ferramenta, sendo que na Seção 5.2 é apresentada a arquitetura da ferramenta; a Seção 5.3 contém a modelagem, para a qual foi utilizada a $\mathrm{UML}^{17}$ (Unified Modeling Language); na Seção 5.4 são apresentados os aspectos relevante da implementação da KITTool; os aspectos operacionais da ferramenta são apresentados na Seção 5.5; e na Seção 5.6 estão as considerações finais.

\subsection{Visão geral da arquitetura}

A arquitetura da ferramenta KITTool, apresentada na Figura 5.1, consiste em uma arquitetura multicamadas que foi projetada utilizando o padrão de projeto MVC Model View Controller [Reenskaug, 1979]. O MVC separa a lógica de negócios da interface com o usuário. Na camada de apresentação encontra-se a interface da ferramenta, por meio da qual é realizada a interação entre o usuário e o sistema. Abaixo dessa camada está a camada de negócios, que representa as principais funcionalidades da ferramenta. Essa camada é responsável: (i) pela visualização, em árvore do tipo diretório, do mapa mental KITMap; (ii) pela avaliação do processo vigente, com visualização tabular do resultado e visualização gráfica por meio de dois tipos de gráficos (um no tipo radar e outro do tipo pilha); e (iii) pela análise e sugestão das próximas atividades que devem ser implementadas.

${ }^{17}$ www.uml.org/ 


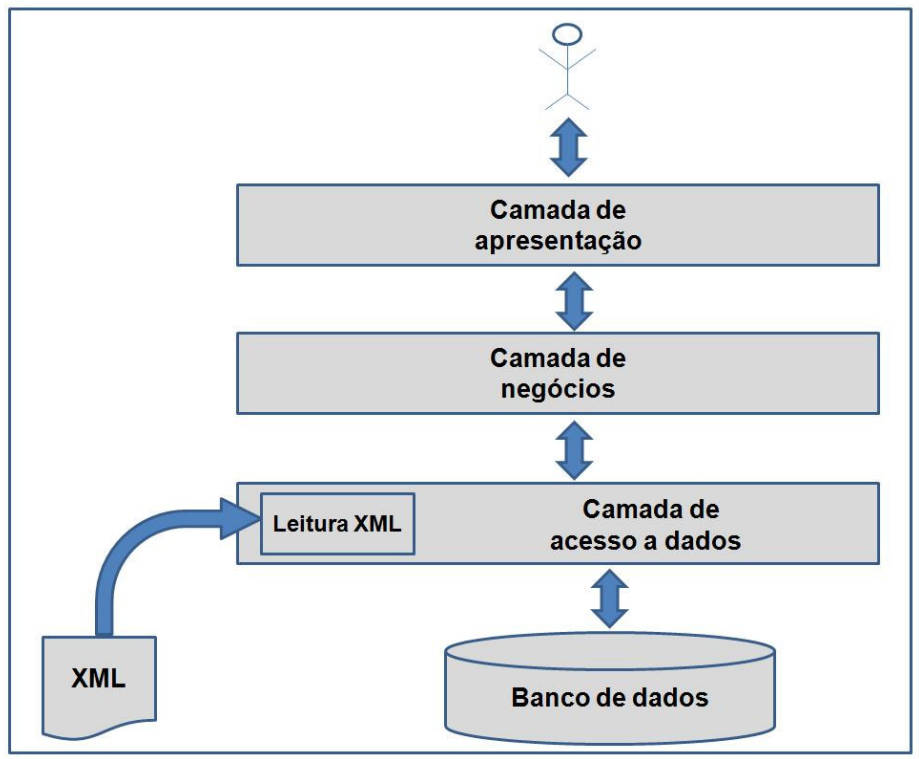

Figura 5.1: Arquitetura da ferramenta KITTool

Imediatamente abaixo da camada de negócios encontra-se a camada de acesso aos dados. Uma das responsabilidades dessa camada, conforme ilustrado na Figura 5.1, consiste na leitura e interpretação do documento XML que foi exportado pelo Mindomo e que representa o mapa de teste criado neste trabalho (Seção 4.3.1). Além disso, é dessa camada a responsabilidade de comunicação com o banco de dados, armazenando e recuperando os dados relativos ao mapa mental importado, os resultados das avaliações do processo de teste vigente e as próximas atividades a serem implantadas no processo.

\subsection{Modelagem}

A modelagem da KITTool foi elaborada com base na UML. A ferramenta funciona de modo independente (do inglês standalone), requerendo apenas as informações de um mapa mental. Como mencionado na Seção 4.3.1, a ferramenta de construção do mapa mental correntemente utilizada é o Mindomo ${ }^{18}$, que possui versões operacionais standalone e web. O tradutor de arquivos XML vigente na KITTool traduz o documento XML produzido pelo Mindomo e armazena os dados no banco de dados. Ressalta-se que qualquer outra ferramenta de construção de mapas mentais pode ser utilizada, bastando para isso que a ferramenta exporte o mapa para o formato XML e que sejam feitos os ajustes no tradutor de XML da KITTool para adequá-lo à estrutura do documento XML gerado pela ferramenta escolhida.

${ }^{18}$ www.mindomo.com 
O diagrama de caso de uso geral do sistema é apresentado na Figura 5.2. Na seqüência detalham-se os casos de uso definidos.

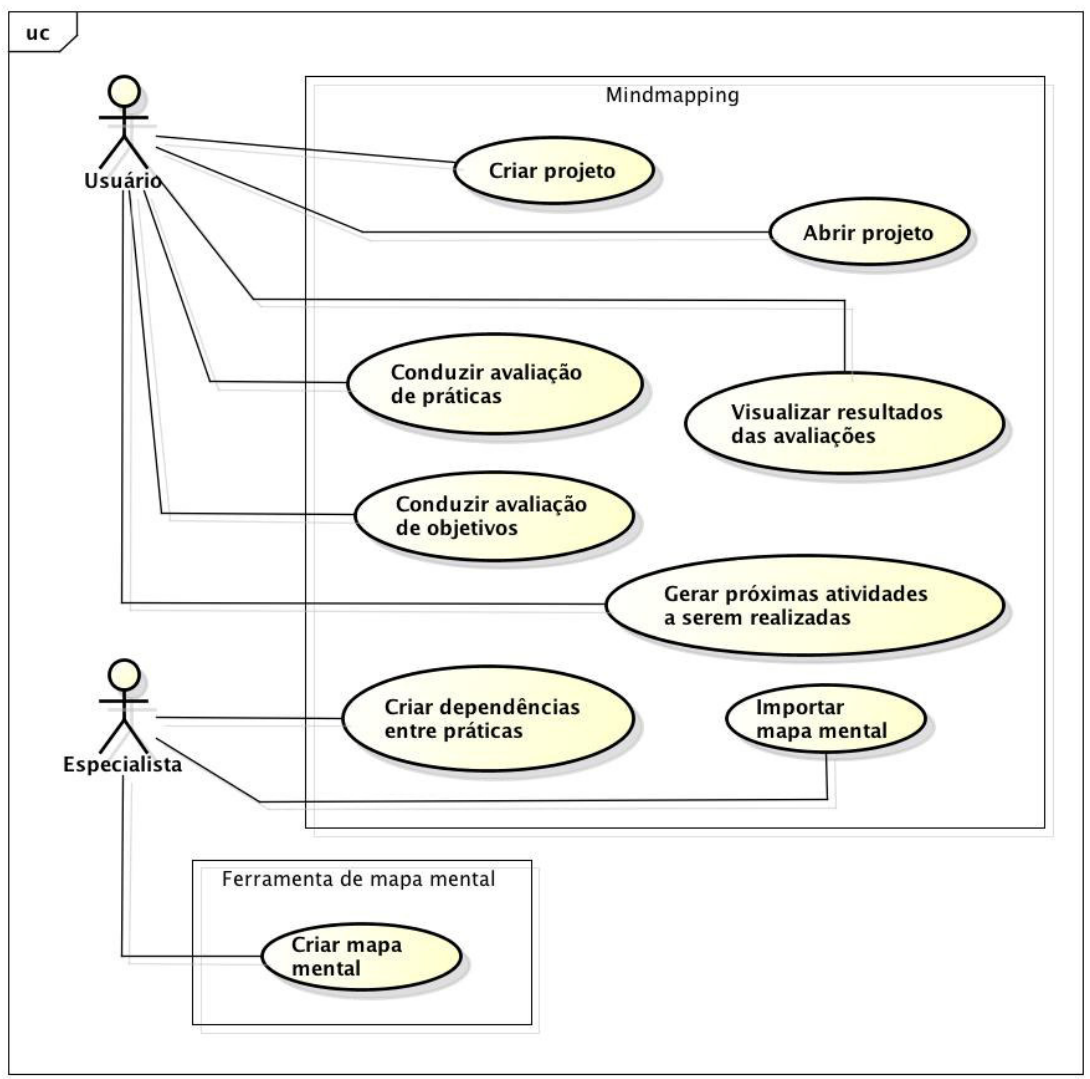

Figura 5.2: Diagrama de casos de uso: Principais funcionalidades da KITTool

\section{- Casos de uso do ator Especialista:}

- Criar mapa mental: O usuário especialista deve criar um mapa mental em uma ferramenta específica de criação de mapas mentais. Neste trabalho, foi utilizada a ferramenta Mindomo para criar o mapa e exportá-lo em formato XML próprio do Mindomo.

- Importar mapa mental: O usuário especialista pode importar mapas mentais em formato XML. Atualmente a ferramenta KITTool implementa o tradutor (do inglês parser) para interpretação do documento XML criado pelo Mindomo. Outras ferramentas podem ser utilizadas, desde que sejam feitos ajustes no tradutor.

- Criar dependências entre práticas: As práticas possuem algumas dependências entre si, o que torna necessário uma ordem para a implantação de práticas, de forma a resolver tais dependências. Após analisar as práticas, 
o usuário especialista pode criar essas dependências, as quais serão utilizadas pela ferramenta como base para gerar diretrizes de melhoria do processo de teste diagnosticado anteriormente. Maiores detalhes dessa funcionalidade serão apresentados na Seção 5.5.

\section{- Casos de uso do ator Usuário:}

- Criar projeto: O usuário pode criar um projeto utilizando um mapa mental (KITMap) previamente importado na ferramenta. O projeto é um par (diagnóstico, recomendações de melhoria), ou seja, serve para armazenar os resultados de um diagnóstico de processo de teste do usuário e, com base nesses resultados, gerar diretrizes de melhoria desse processo. Caso o usuário não tenha processo algum de teste, a ferramenta fornece recomendações de atividades iniciais de planejamento da atividade de teste a serem executadas.

- Abrir projeto: O usuário pode abrir um dos seus projetos já criados.

- Conduzir avaliação por objetivos: O usuário pode conduzir avaliações do seu processo vigente, fornecendo notas para os objetivos das áreas de processo. Podem ser feitas atualizações dessas notas quando houver evolução do processo.

- Conduzir avaliação por práticas: Outra avaliação que pode ser conduzida é a avaliação por prática. Essa avaliação é mais detalhada do que a avaliação por objetivos, requerendo que o usuário forneça notas para cada prática, de cada objetivo das áreas de processo.

- Visualizar resultado da avaliação: O usuário pode visualizar o resultado da avaliação que conduziu, de forma gráfica ou tabular, para todos os tipos de avaliações solicitadas, ou seja, tanto por objetivos quanto por práticas.

- Gerar diretrizes de melhoria do processo de teste: uma vez que haja um diagnóstico, o usuário pode solicitar que as diretrizes de melhoria do processo avaliado sejam produzidas.

O modelo conceitual da KITTool é mostrado na Figura 5.3. Esse modelo captura as informações essenciais para a visualização, a avaliação e a definição das melhorias de um processo de teste de software. 


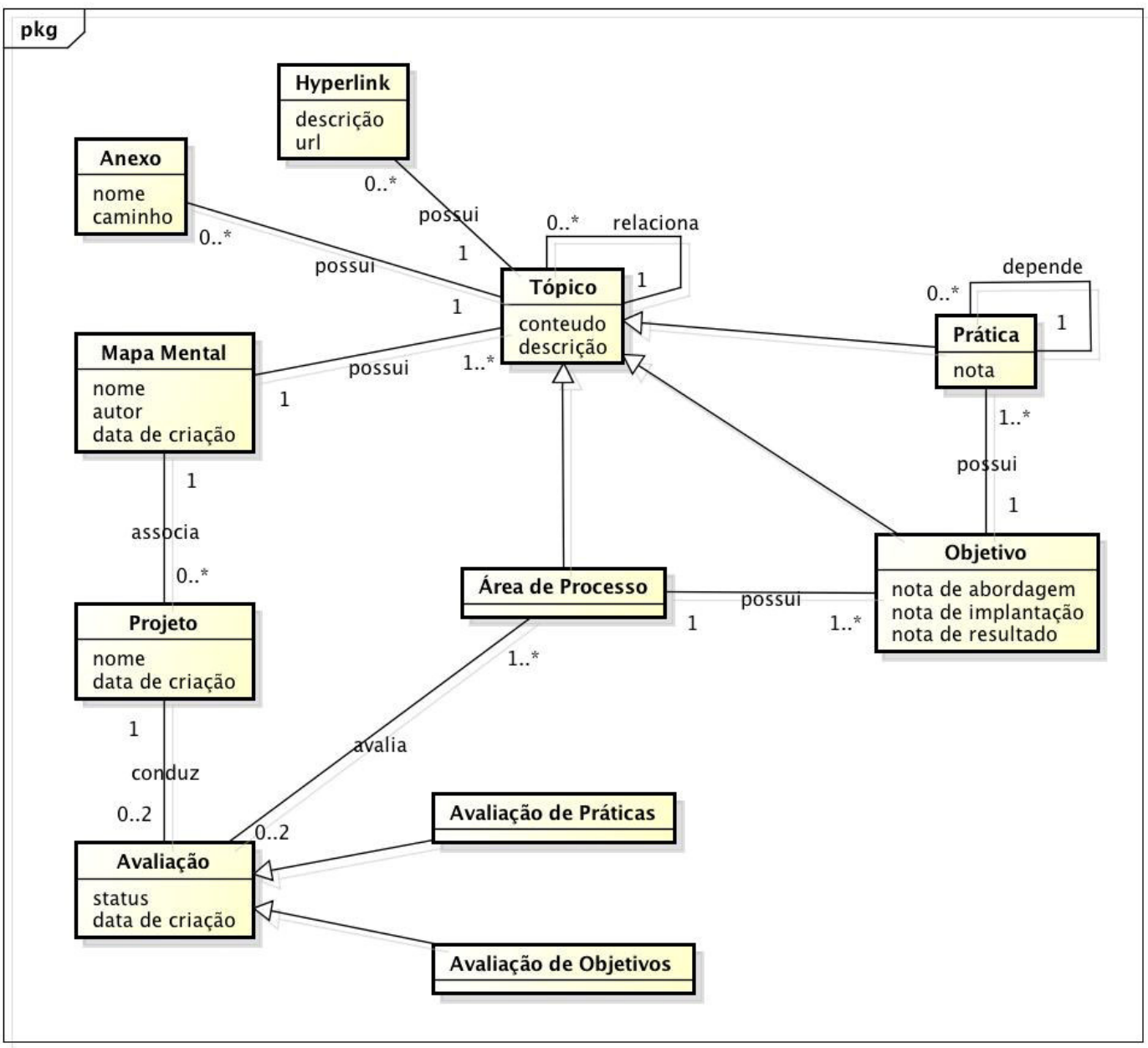

Figura 5.3: Diagrama conceitual da ferramenta KITTool

De acordo com a Figura 5.3, um Projeto é criado com base em um Mapa Mental. O Mapa Mental é composto de Tópicos, os quais podem possuir Anexos e/ou Hiperlinks. O Tópico pode ser uma Área de Processo, um Objetivo ou uma Prática do TMMi. Podem existir também relacionamentos de um Tópico com outro independentemente da relação de hierarquia que existe entre eles, decorrente do TMMi, no qual uma Área de Processo possui um ou mais Objetivos, e estes possuem uma ou mais Práticas. As Práticas podem ser dependentes entre si, ou seja, para que uma determinada Prática seja implantada, pode ser necessário que outra Prática seja implantada antes.

Cada Projeto possibilita acompanhar um processo do usuário, o que é feito por meio dos diagnósticos conduzidos, os quais fornecem Avaliações das Áreas de Processo atendidas por esse processo. As Avaliações podem ser feitas de forma mais detalhada, conduzindo-se uma Avaliação por Práticas, ou de forma mais genérica, a Avaliação por 
Objetivo. A avaliação corresponde ao diagnóstico do processo vigente, a qual determina quão aderente é esse processo em relação ao TMMi.

As Figuras 5.4 e 5.5 apresentam as atividades que devem ser realizadas para conduzir as avaliações por objetivos e por práticas, respectivamente.

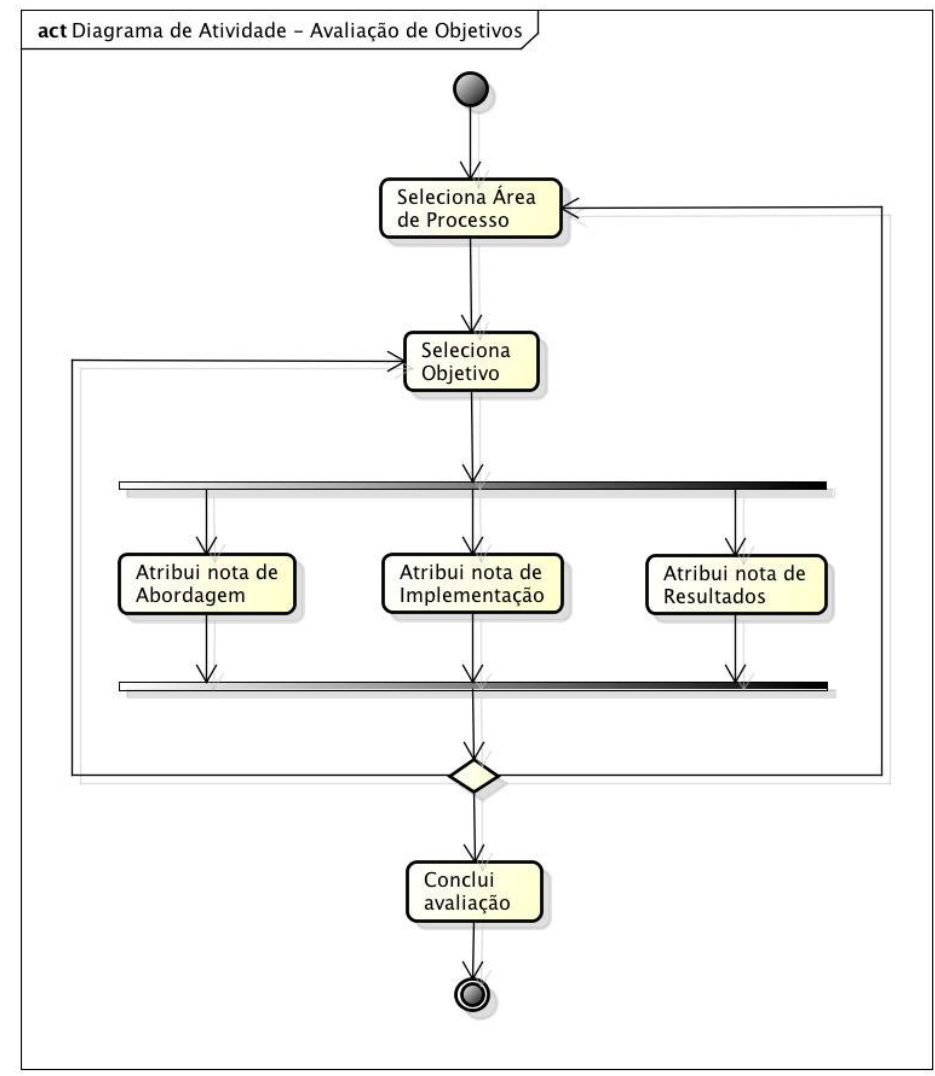

Figura 5.4: Diagrama de atividades: Avaliação por objetivos

A avaliação por objetivos é detalhada na Figura 5.4. Quando o usuário escolhe conduzir essa avaliação, ele deve selecionar a área de processo para a qual vai avaliar os objetivos. Para cada objetivo selecionado, o usuário deve atribuir notas relacionadas (i) à abordagem daquele objetivo, ou seja, o quanto foi planejado para aquele objetivo; (ii) à implementação do objetivo; e (iii) aos resultados obtidos com a implementação daquele objetivo. As notas que serão atribuídas pelo usuário devem seguir a tabela de referência fornecida, como poderá ser visualizado na Seção 5.5 - Aspectos operacionais. A nota final de cada objetivo será a média das notas recebidas para a abordagem, implementação e resultados daquele objetivo. Dessa forma é possível pontuar de uma forma mais real, pois com um só valor é difícil representar bem a realidade de cada objetivo. E a nota da área de processo será a medida das notas dos seus objetivos. 
Para a avaliação por práticas, detalhada na Figura 5.5, o usuário deve inicialmente selecionar uma área de processo e um objetivo daquela área de processo. Em seguida, para cada prática do objetivo selecionado, o usuário deve atribuir uma nota percentual seguindo uma tabela de referência, baseada no modelo SCAMPI ${ }^{19}$. Esse percentual diz respeito ao enfoque e aplicação da prática no processo. A nota do objetivo será a média das notas das práticas que pertencem a esse objetivo. Já a nota da área de processo será a média das notas dos seus objetivos.

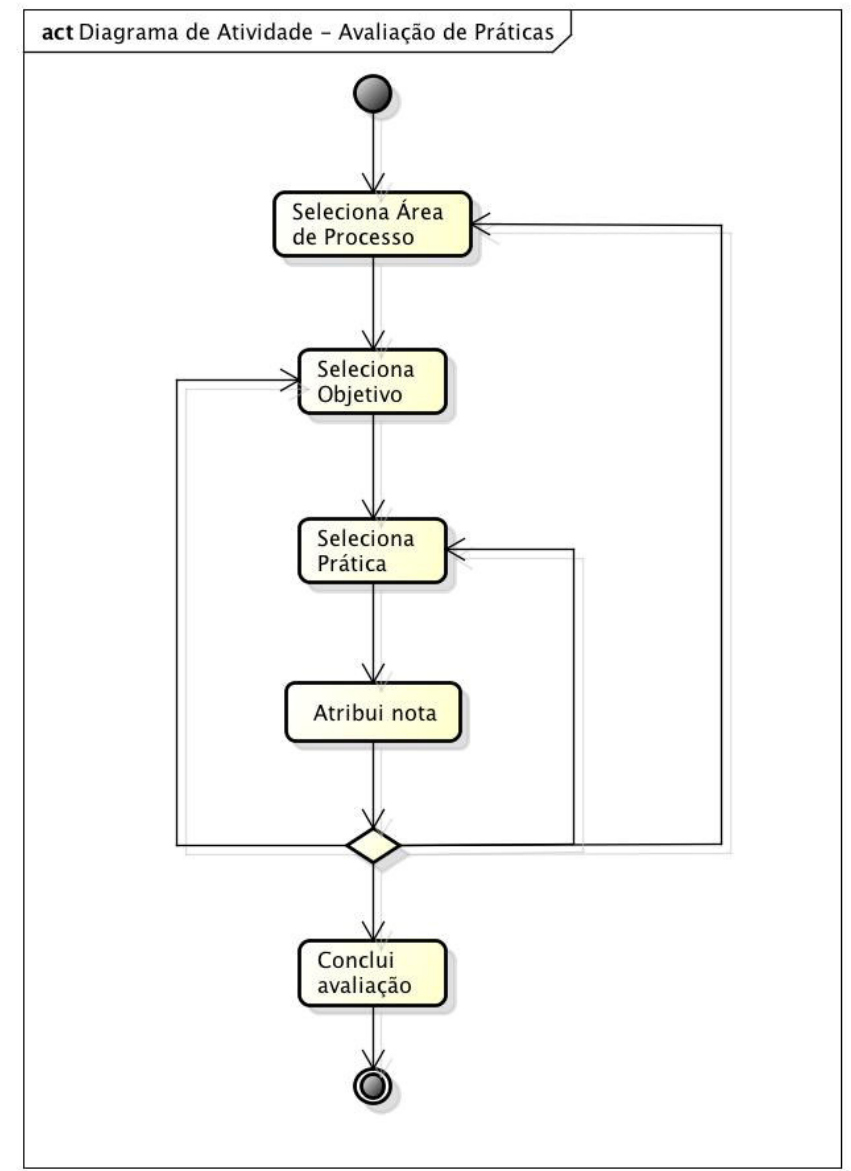

Figura 5.5: Diagrama de atividades: Avaliação por práticas

\subsection{Aspectos relevantes da implementação}

Conforme descrito na Seção 5.2, a ferramenta KITTool foi projetada seguindo a arquitetura MVC (Model Viewer Controller). Como linguagem de desenvolvimento foi escolhida $\mathrm{Java}^{20}$, devido à grande variedade de bibliotecas disponíveis, facilitando a implementação de recursos necessários à natureza da ferramenta, como importação de

${ }^{19}$ Standard CMMI Appraisal Method for Process Improvement (SCAMPI). Software Engineering Institute. www.sei.cmu.edu/library/abstracts/reports/01hb001.cfm

${ }^{20}$ http://www.java.com - último acesso em 04/06/2011. 
arquivos XML, manuseio e apresentação visual de estrutura em árvore, entre outros. $\mathrm{O}$ ambiente de desenvolvimento foi o NetBeans $6.8^{21}$, tendo o PostgreSQL 8.4.3 ${ }^{22}$ como sistema de gerenciamento de banco de dados (SGBD), escolhido por ser um SGBD livre e que atende às necessidades do trabalho.

Algumas bibliotecas adicionais utilizadas foram:

- JFreeChart23 $\rightarrow$ Para a criação dos gráficos nas telas de resultados;

- CheckboxTree24 $\rightarrow$ Utilizado para apresentar a estrutura em árvore com o checkbox.

- JDom25 $\rightarrow$ Essa biblioteca é utilizada na leitura e manipulação dos documentos XML importados.

\subsubsection{Diagrama Entidade-Relacionamento (DER)}

O diagrama de entidade e relacionamento, apresentado na Figura 5.6, descreve o modelo de dados da KITTool. Um projeto é associado a um único mapa (uma versão do KITMap que tenha sido descarregada na máquina do usuário), porém um único mapa pode ser utilizado por vários projetos. Cada mapa possui tópicos, os quais podem possuir hiperlinks e/ou anexos. Os tópicos estão associados entre si, caracterizando uma hierarquia entre eles, ou com associações livres. Nos projetos são conduzidas avaliações, tanto por objetivos quanto por práticas, nas quais notas são atribuídas caracterizando o grau de implantação das áreas de processo, objetivos e práticas no processo sob análise. O resultado dessas avaliações corresponde ao diagnóstico do processo do usuário.

\footnotetext{
21 http://netbeans.org/community/releases/68/ - último acesso em 04/06/2011.

$22 \mathrm{http}$ ///www.postgresql.org/docs/8.4/static/release-8-4-3.html - último acesso em 04/06/2011.

23 http://www.jfree.org/jfreechart

${ }^{24}$ http://www.essi-lab.eu/projectsSites/lablib-checkboxtree

25 http://www.jdom.org
} 


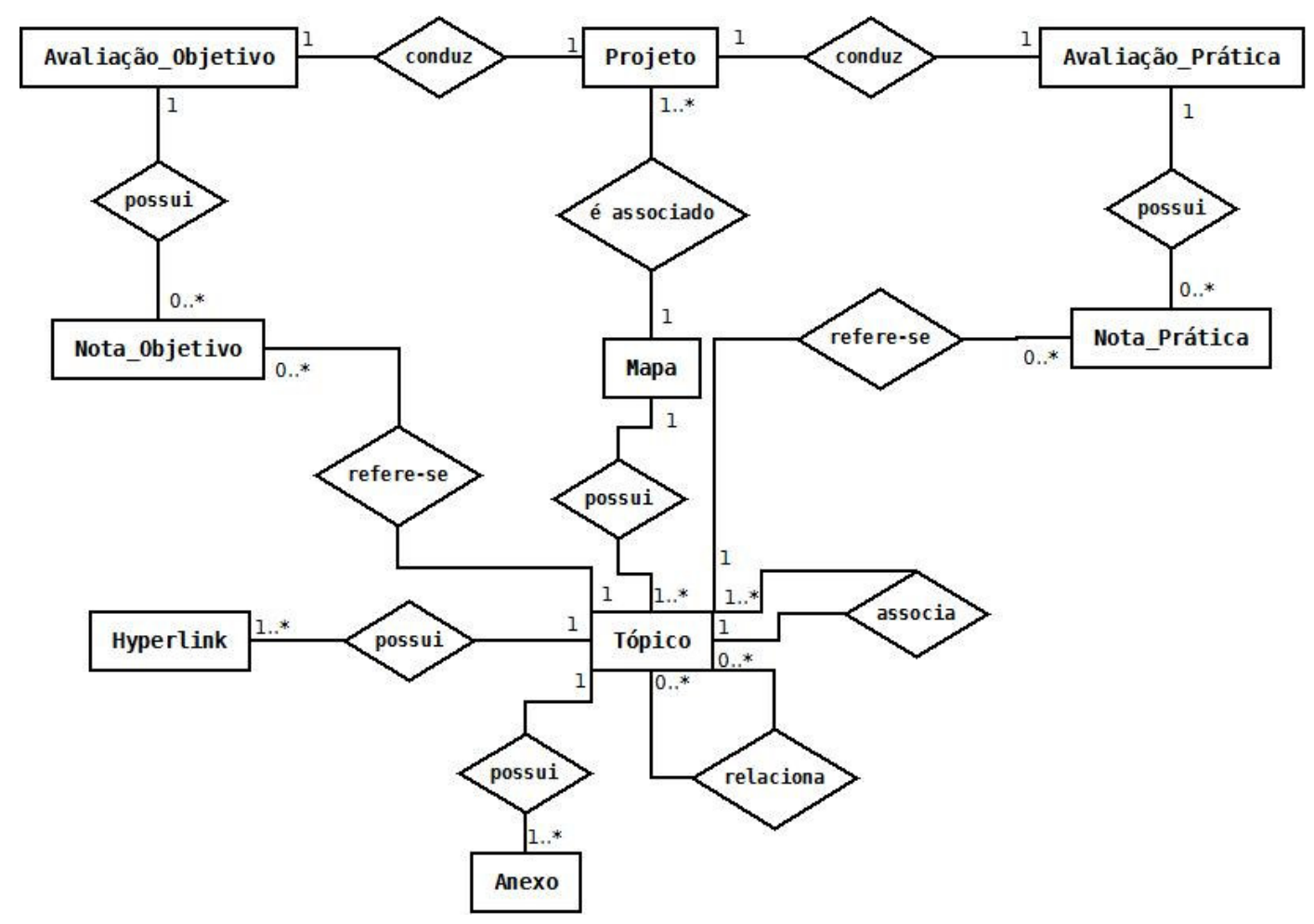

Figura 5.6: Diagrama Entidade-Relacionamento da ferramenta KITTool.

\subsubsection{Análise do documento XML gerado pelo mapa mental KITMap}

Inicialmente, é necessário importar para a ferramenta KITTool o mapa mental disponível na internet - KITMap, que retrata a base de conhecimento em teste em um determinado momento, uma vez que esse mapa deve evoluir com contribuições da comunidade. Essa importação dá-se por meio de documento XML. A biblioteca JDom foi utilizada para auxiliar a manipulação desse documento XML.

De forma recursiva, o arquivo gerado pelo Mindomo é lido, interpretado e inserido no banco de dados da KITTool. As características de hierarquia são mantidas, assim como os relacionamentos entre os tópicos que independem da hierarquia.

\subsubsection{Algoritmos de definição de próximos passos (diretrizes de melhoria)}

As diretrizes de melhoria foram baseadas em dois algoritmos: (1) da área de processo mais atendida na avaliação para a menos atendida; (2) da área de processo menos atendida na avaliação para a mais atendida. Para poder aplicar esses algoritmos, foi realizada uma normalização entre as avaliações por objetivos e por práticas. Essa normalização é necessária porque a nota da avaliação por objetivos possui um intervalo 
de 0 a 10, enquanto a nota da avaliação por prática possui um intervalo de 0 a 100, já que é feita em percentual. Nessa normalização, a nota da avaliação por práticas foi dividida por 10, para deixar ambas as notas na mesma base, podendo assim comparar uma área de processo na qual foi feita uma avaliação por objetivo com uma área de processo que possui uma nota da avaliação por prática.

O usuário pode realizar somente uma avaliação ou as duas. Caso o usuário venha a conduzir as duas avaliações, será considerada somente a nota da avaliação por práticas, por tratar-se de uma avaliação mais detalhada.

Uma vez que o algoritmo de ordenação das áreas de processo tenha sido escolhido, ou seja, algoritmo (1) da área de processo mais atendida na avaliação para a menos atendida ou algoritmo (2) da área de processo menos atendida na avaliação para a mais atendida, as áreas de processo são ordenadas, assim como todos os objetivos e todas as práticas, seguindo o mesmo algoritmo selecionado.

Essa ordenação é realizada da seguinte forma: comparam-se as notas das avaliações das áreas de processo (lembrando-se que se uma área de processo tiver a nota das duas avaliações, será considerada a nota da avaliação por prática), ordenando-as de forma crescente ou decrescente, conforme o algoritmo escolhido pelo usuário. Após a ordenação das áreas de processo, ocorre a ordenação dos objetivos de cada área de processo, seguindo o mesmo algoritmo escolhido. Concluída a ordenação dos objetivos, as práticas de cada objetivo também são ordenadas seguindo a mesma lógica.

Finalizada a ordenação, a KITTool irá buscar na matriz de dependência (explicada na próxima seção) se as práticas que foram apresentadas dependem de alguma outra prática. Caso encontre essa dependência, a KITTool irá colocar as práticas necessárias imediatamente antes da práticas dependentes.

Caso a prática necessária já esteja na árvore de diretrizes de melhoria do processo de teste, a ferramenta verifica se ela deverá ser reposicionada. A mudança de posição só acontece quando a prática necessite ir para uma posição anterior a sua atual. Caso seja para uma posição posterior à que se encontra, a KITTool não altera a posição dessa prática. Dessa forma garante-se que todas as dependências são aplicadas antes das práticas que dependem delas, mantendo ao máximo possível a ordem de execução (conforme algoritmo) escolhida pelo usuário. 


\subsubsection{Elaboração da matriz de dependência das práticas do TMMi}

Para que a KITTool pudesse sugerir diretrizes de melhoria para o processo que foi diagnósticado, foi necessário realizar um estudo sobre as práticas do modelo TMMi e analisar quais possuem dependência entre si. Além disso, foi necessário avaliar o grau de dependência existente entre as práticas. Dois tipos de dependências entre práticas foram definidos para esse fim: necessária e de alinhamento. A dependência necessária ocorre quando alguma prática deve ser implementada somente depois que determinada outra, ou outras, tenham sido implementadas. Geralmente essa dependência ocorre porque a prática dependente utiliza o resultado da antecedente. A dependência de alinhamento ocorre quando os produtos gerados por duas ou mais práticas necessitam ser coerentes e consistentes entre si. Por exemplo, o modelo de referência requer que a estratégia de teste esteja alinhada à política de teste. Tanto a estratégia de teste quanto a política de teste são resultados de duas práticas que, embora estejam em áreas de processo diferentes, devem manter-se alinhadas no sentido de não serem contraditórias nem inconsistentes. Ressalta-se que existem práticas em que os produtos gerados não interferem um no outro e então esse alinhamento não precisa ser avaliado.

Durante a análise das dependências é necessário comparar todas as práticas, aos pares, visando a identificar se há dependência entre elas e, caso haja, deve-se determinar qual tipo de dependência existe. Para agilizar essa comparação foi necessário identificar as práticas que tratavam de um assunto específico (por exemplo, definindo-se termos chave), ou que abordassem esse assunto no seu conteúdo. Conseqüentemente, para analisar as possíveis dependências, foi necessário ler a descrição das práticas.

Para viabilizar a execução da análise foi utilizado um recurso visual por meio da ferramenta SeEd-Visual (Hernandes, 2009), que foi desenvolvida originalmente para apoiar um processo de análise e padronização de um grande volume de dados. Essa ferramenta utiliza o algoritmo de visualização tree-map (Johnson e Shneiderman, 1991) para representar a informação na tela. Considerando que o documento do modelo TMMi tem um texto organizado hierarquicamente, essa forma de visualização tree-map foi ideal para apresentá-lo e para destacar todas as práticas que tratavam de um mesmo assunto, por meio da aplicação da função de busca da ferramenta, o que foi fundamental para o estabelecimento dos tipos de dependência existentes. 
A Figura 5.7 apresenta o modelo TMMi visualizado na ferramenta SeEd-Visual. No destaque está uma Área de Processo (C) composta por três objetivos. O Objetivo (B), por sua vez, é composto de sete práticas e cada uma destas, como a Prática (A), corresponde a uma caixa da metáfora visual.

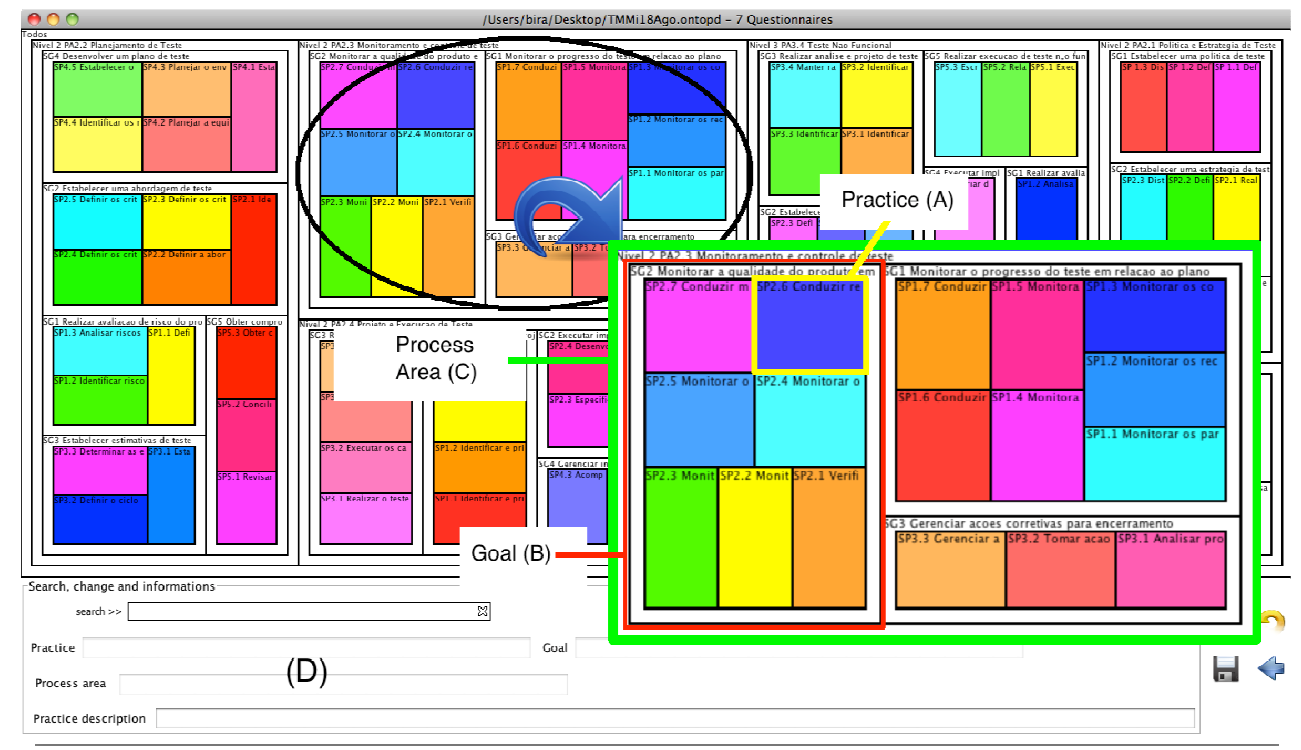

Figura 5.7: TMMi visualizado na ferramenta SeEd-Visual

Como pode ser observado na Figura 5.7, a ferramenta SeEd-Visual possibilita uma visão geral do TMMi. No entanto, para aproveitar esse formato de visualização e poder realizar uma leitura estruturada de seu conteúdo ou mesmo identificar os itens do modelo que se referem a um mesmo assunto, foi necessária uma adaptação na ferramenta. Assim, foi criado um link entre um item da estrutura TMMi, representado por uma caixa na visualização tree-map, e seu respectivo texto no documento TMMi, o qual foi transformado em um arquivo de hipertexto HTML. A partir dessa adaptação, foi possível utilizar a SeEd-Visual para ler o documento do TMMi e identificar as dependências entre as práticas. $\mathrm{O}$ processo baseado em visualização utilizado para a leitura estruturada é apresentado na Figura 5.8. 


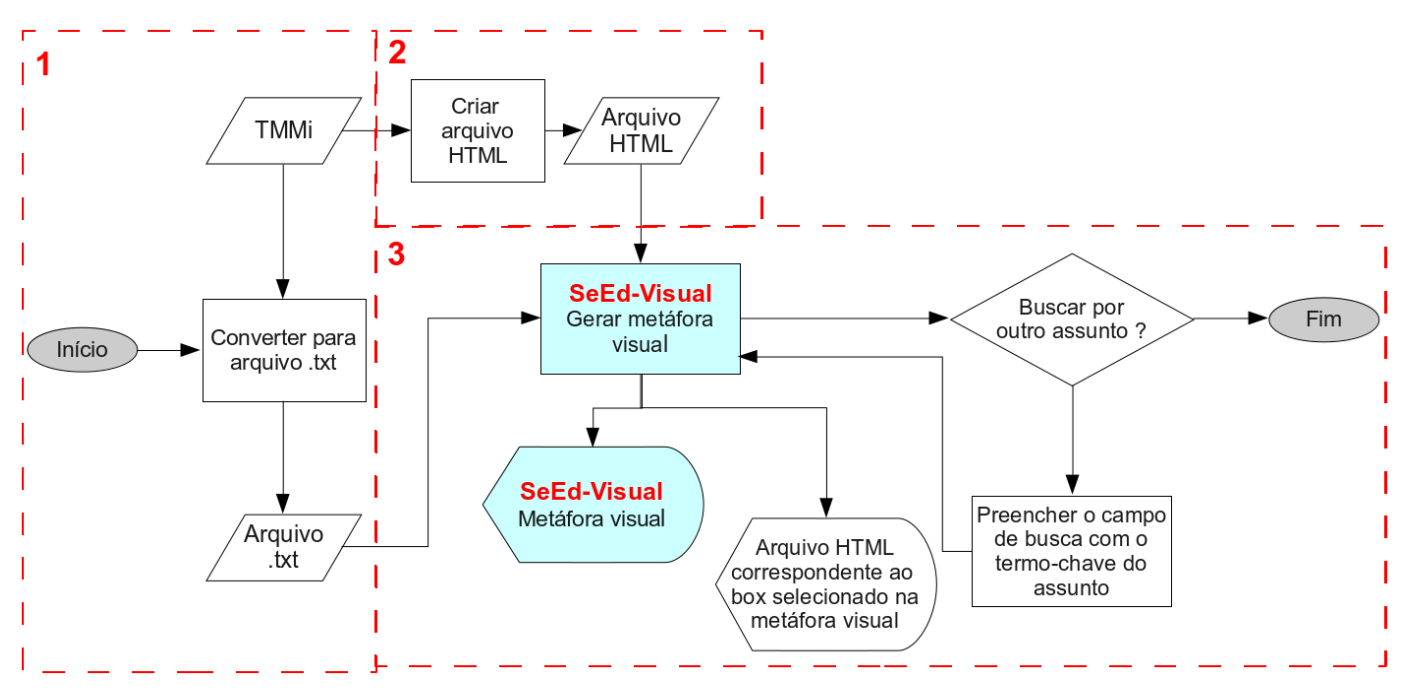

Figura 5.8: Fluxograma do processo baseado em visualização para leitura estruturada de documentos

Primeiramente, dois arquivos são gerados a partir do documento TMMi e carregados na ferramenta SeEd-Visual. Um deles é um arquivo do tipo texto (.txt), o qual contém a estrutura do modelo que se quer visualizar (nesse caso, Área de processo, Objetivo, Prática e Descrição da prática). O outro arquivo é um arquivo HTML, o qual é usado para acessar partes do documento TMMi, dependendo do item do modelo que foi selecionado na visualização pelo usuário.

A ferramenta transforma o arquivo tipo texto em uma metáfora visual, na qual cada prática é representada por uma caixa da visualização tree-map. A partir disso a função de busca pode ser utilizada para identificar as práticas TMMi que tratam do mesmo assunto. Selecionando-se as caixas na metáfora visual, o usuário pode visualizar, em um arquivo HTML, o texto referente às práticas selecionadas. Se as práticas forem consideradas dependentes, devem ser marcadas com o tipo de dependência, podendo ser do tipo necessária ou do tipo alinhamento, conforme foi explicado na Seção 5.4.4.

Cada passo do processo de leitura estruturada, mostrado na Figura 5.8, é detalhado a seguir:

1) Preparar a informação do TMMi que será carregada na ferramenta SeEd-Visual

Criar um arquivo texto que contenha a estrutura do TMMi: Áreas de processo, Objetivos e descrições das Práticas específicas. 


\section{2) Transformar o arquivo do TMMi em um arquivo HTML}

Criar um arquivo HTML correspondente ao documento TMMi, contando hiperlinks nos títulos das estruturas (Áreas de processo, Objetivos e Práticas). Os hiperlinks devem ser iguais aos títulos que estão contidos no arquivo texto que será carregado na ferramenta SeEd-Visual.

\section{3) Carregar o arquivo texto na ferramenta SeEd-Visual}

Os dados são visualizados como mostrado na Figura 5.8, na qual:

a) Cada caixa colorida corresponde a uma prática, mas nesse estudo específico as cores não representam uma informação especial (rótulo "Practice" na Figura 5.7);

b) Caixas brancas agrupando um conjunto de caixas coloridas correspondem a um objetivo (rótulo “Goal” na Figura 5.7);

c) O último nível de agrupamento, isto é, um conjunto de objetivos, corresponde a uma área de processo (rótulo "Process Area" na Figura 5.7); e

d) A informação apresentada na parte inferior, quando uma caixa é marcada, contém: a prática, seu objetivo e área de processo, além do texto descritivo da prática (Figura 5.7, rótulo D).

Assim, uma vez carregado o modelo TMMi na ferramenta, o usuário deverá analisar as práticas para identificar dependências entre elas. Após a seleção das Áreas de processo que abordam o assunto pesquisado, o usuário pode acessar o texto das práticas do TMMi para então analisar se elas apresentam dependência. Um duplo clique na caixa cinza abre o arquivo HTML e apresenta o conteúdo da prática TMMi selecionada. Cada duplo clique abre uma nova ocorrência do arquivo HTML, o que permite mostrar as práticas em paralelo, viabilizando a comparação em pares (Figura 5.8).

A leitura estruturada como foi descrita tornou o manuseio do documento TMMi mais fácil, permitindo uma melhor compreensão do documento e facilitando sua análise para efeito de determinação das dependências entre as práticas, fundamental para dar subsídios à determinação das alternativas de melhoria de um processo de teste diagnosticado pelo usuário. 


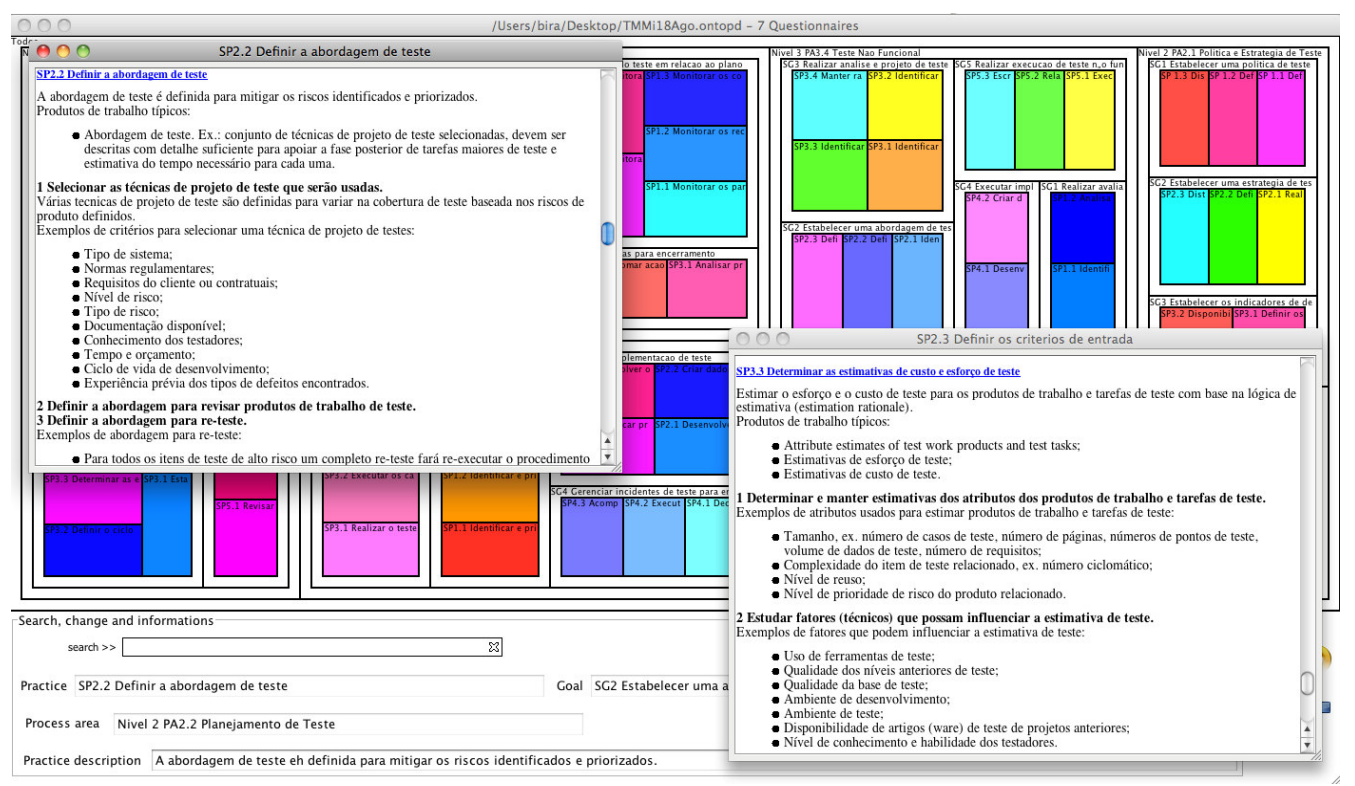

Figura 5.9: O texto de duas práticas selecionadas a partir da visualização tree-map por meio de hiperlinks

\subsection{Aspectos operacionais}

Nesta seção estão descritos os aspectos operacionais da ferramenta KITTool. Salienta-se que na versão atual ainda não estão implementados os perfis de usuários, de forma que todas as funcionalidades estão disponíveis para qualquer tipo de usuário.

A tela inicial é apresentada na Figura 5.10 (a). Nessa tela o usuário pode abrir um projeto existente ou criar um novo projeto com algum dos mapas já importados. $\mathrm{Na}$ Figura 5.10 (b) pode ser visualizado o menu Projeto, pelo qual o usuário tem acesso às opções: Importar do Mindomo, na qual ele pode importar o mapa mental que está disponível na web naquele momento, a partir de um documento XML; criar dependências entre as práticas; ou iniciar um novo projeto.

\section{- Importação do mapa}

A importação do KITMap é imprescindível para o funcionamento da KITTool, pois tanto o diagnóstico de um processo de teste como a geração de melhorias para esse processo ocorrem com base nas informações de um processo genérico de teste e do modelo TMMi, as quais estão modeladas no KITMap. Na ferramenta KITTool esse mapa é importado por meio de um arquivo XML, gerado pela ferramenta Mindomo, pelo gestor desse arcabouço, que o disponibiliza na web para a comunidade. 


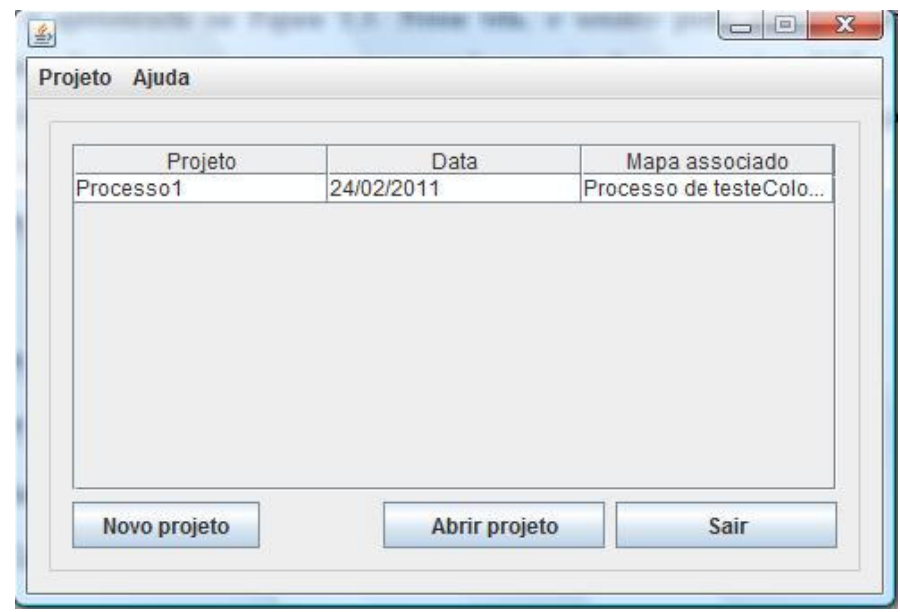

(a) Tela inicial da ferramenta KITTool.

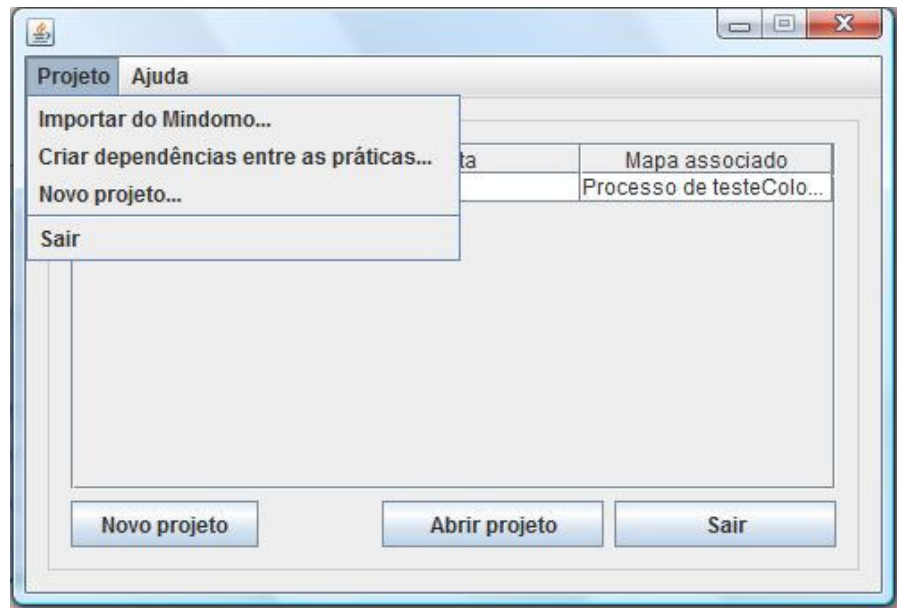

(b) Menu Projeto da tela inicial.

Figura 5.10: Telas iniciais da ferramenta KITTool

Uma vez disponibilizado, o KITMap deve ser importado pelo usuário. Durante a importação é utilizado um parser para fazer a tradução desse documento XML, de forma a capturar tanto os dados quanto os relacionamentos hierárquicos entre eles, montando uma estrutura do tipo árvore, a qual é armazenada no banco de dados da KITTool.

Outras ferramentas de criação de mapas mentais podem ser utilizadas (como $\mathrm{XMind}^{26}$ ou FreeMind ${ }^{27}$ ), sendo necessárias algumas adaptações no parser para ajustálo às características próprias do documento XML de exportação da ferramenta escolhida.

${ }^{26}$ www.xmind.net.

27 freemind.sourceforge.net/ 


\section{- Matriz de dependência entre práticas}

Essa funcionalidade permite que as dependências do modelo que guiarão as melhorias sejam estabelecidas. No caso em questão, as dependências do TMMi foram estabelecidas entre as práticas, foram classificadas como dependência necessária e de alinhamento, e foram identificadas com o auxílio da ferramenta SeEd-Visual, conforme explicado anteriormente. Essa é uma funcionalidade deve ser executada por usuário s que possuam conhecimentos mais profundos em teste de software e em processo de teste.

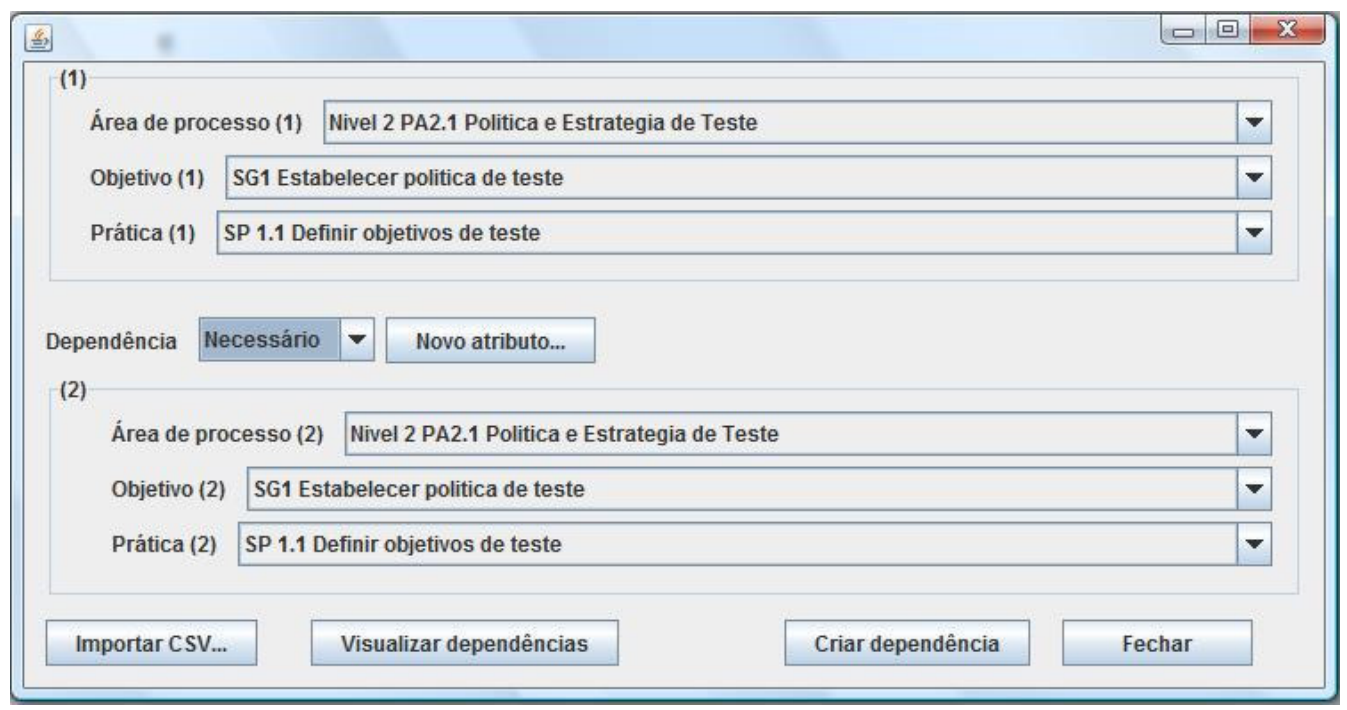

Figura 5.11: Tela para definição das dependências

Dessa forma, no contexto deste trabalho, em que foram estabelecidas as dependências do modelo TMMi, ao mesmo tempo em que esse modelo era explorado com o recurso da leitura estruturada, apoiada pela visualização, utilizava-se a funcionalidade da Figura 5.11 para cadastrar as dependências identificadas, gerando, ao final dessa etapa, a tabela de dependências da Figura 5.12. Ressalta-se que a ferramenta também permite que essa tabela de dependências possa ser construída por meio de outro recurso, por exemplo, uma planilha, e ser importada na ferramenta depois de pronta, no formato "CSV". 


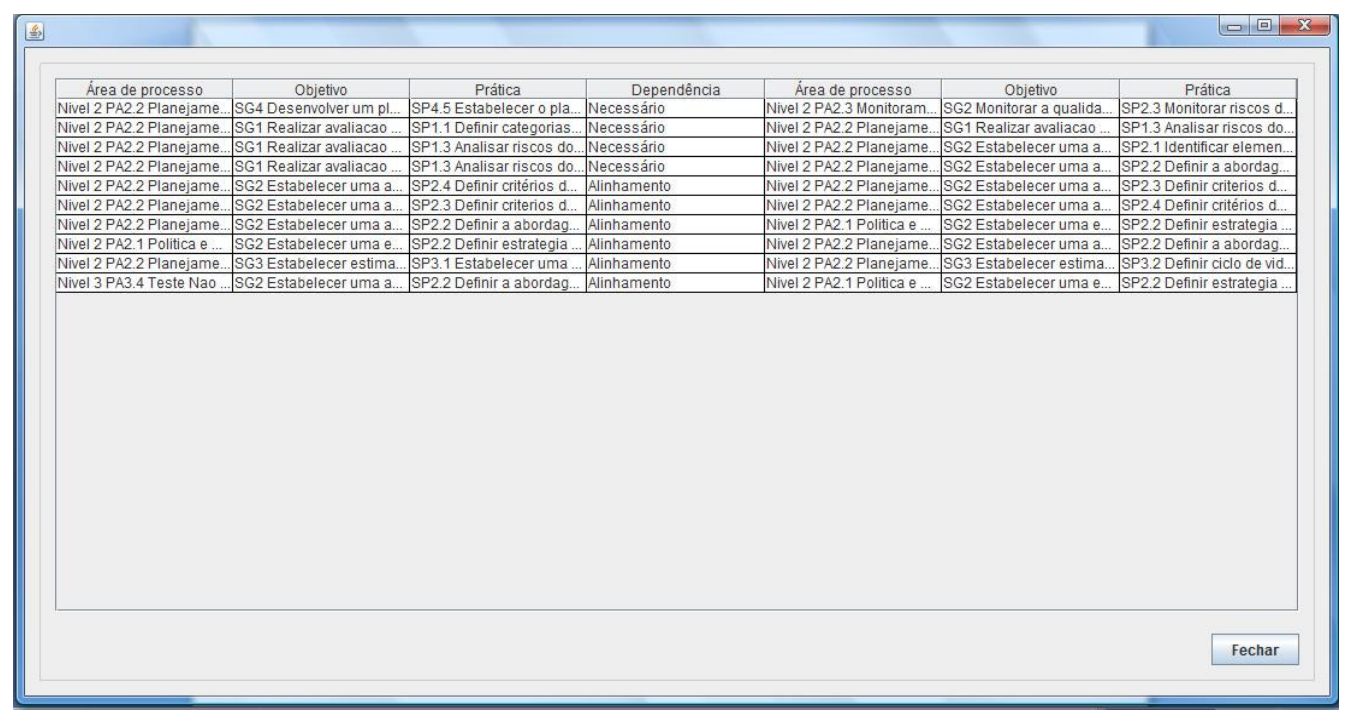

Figura 5.12: Tela de visualização das dependências

\section{- Criação de projeto}

Sempre que um usuário desejar fazer a avaliação de seu processo de teste para depois passar a interagir com os recursos do arcabouço, isso deve ser feito por meio de um projeto criado na KITTool. Esse projeto estará vinculado ao KITMap importado na KITTool. Para criar um novo projeto, o usuário deve escolher um mapa já importado, ou importar outro mapa antes, e fornecer um nome para o projeto. Esse novo projeto usará a estrutura do mapa escolhido, com as informações e dependências referentes a ele. A tela para criação de um novo projeto é apresentada na Figura 5.13.

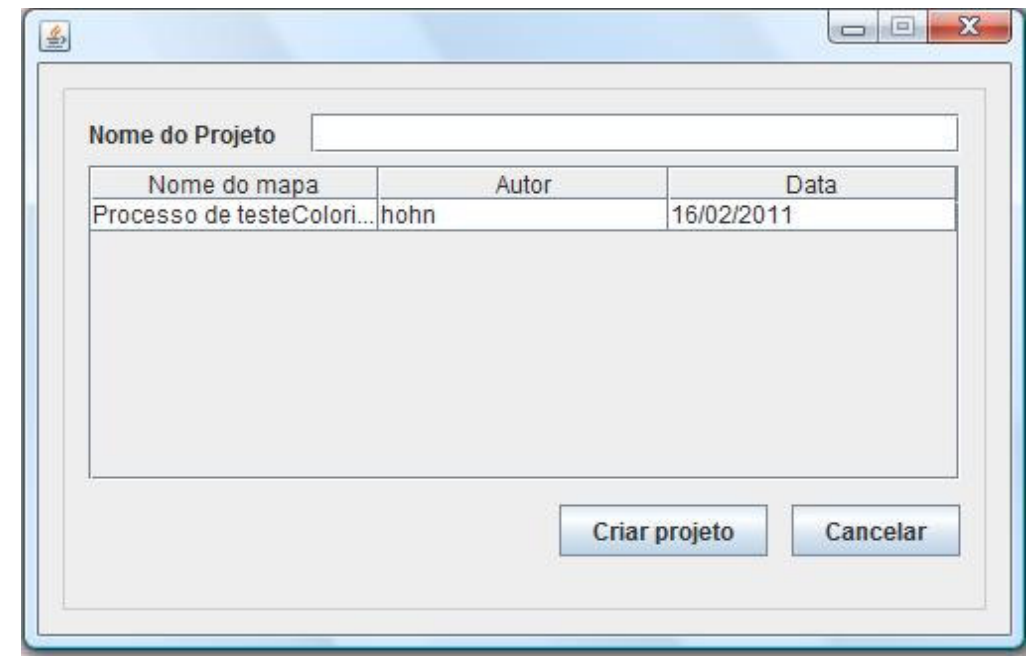

Figura 5.13: Tela de criação de um novo projeto 


\section{- Consulta do mapa de teste}

Uma vez criado um projeto, o mapa de teste fica habilitado para consulta na KITTool, no formato de uma árvore de diretórios, como mostra a Figura 5.14, com a tela principal de um projeto selecionado. Nessa tela o usuário pode visualizar toda a estrutura do mapa, além de detalhes. Ao selecionar um tópico (nó da árvore), detalhes desse tópico aparecem nos campos do lado direito da tela, como: (i) informações adicionais, que geralmente contêm uma breve descrição da prática, objetivo ou área de processo; (ii) a lista de anexos que podem estar vinculadas a esse tópico, como material bibliográfico sobre o assunto, relatos de experiência, etc.; (iii) hiperlinks que podem levar a outros sites relacionados ao assunto; e (iv) a lista dos outros tópicos com os quais ele pode ter relacionamento de forma independente da estrutura hierárquica, ou seja, quando um tópico se relaciona a outro que não seja pai nem filho dele.

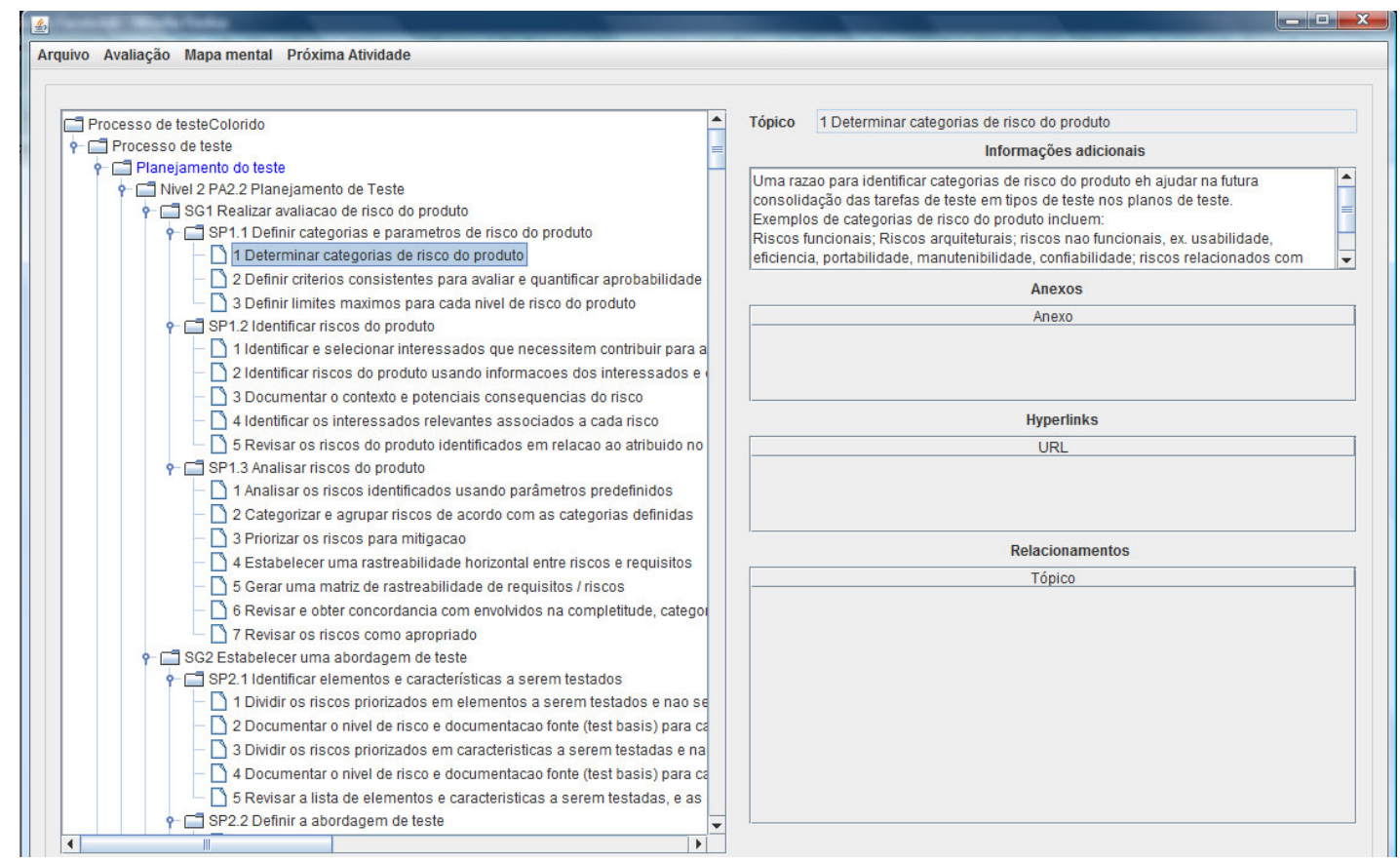

Figura 5.14: Tela principal do projeto

\section{- Condução de avaliações do processo de teste vigente}

Uma das contribuições do arcabouço KITest é prover suporte para que o usuário faça um diagnóstico do processo de teste vigente para que ele tenha conhecimento do grau de aderência de seu processo ao TMMi. Na KITTool estão disponibilizados dois tipos de diagnósticos - um com base nos objetivos do TMMi e outro com base nas práticas. Caso o usuário opte por fazer com base nas práticas, como já foi falado anteriormente, não é necessário que seja feita a avaliação com base nos objetivos. 
Se o diagnóstico for feito com base nos objetivos do TMMi a tela para isso é a apresentada na Figura 5.15. Na parte superior da tela é apresentada uma área de processo e seus objetivos. O usuário deve fornecer notas para cada objetivo, que representem o seu processo de teste, usando a tabela da parte inferior da tela como referência. Devem ser estabelecidas três notas para cada objetivo, as quais correspondem: (i) à abordagem com que o objetivo foi tratado no processo, (ii) à implantação desse objetivo no processo; e (iii) aos resultados obtidos com sua implantação. A média dessas notas representa a nota do objetivo. Utilizando o botão Avançar, o usuário passa para outra área de processo para que possa continuar a avaliação.

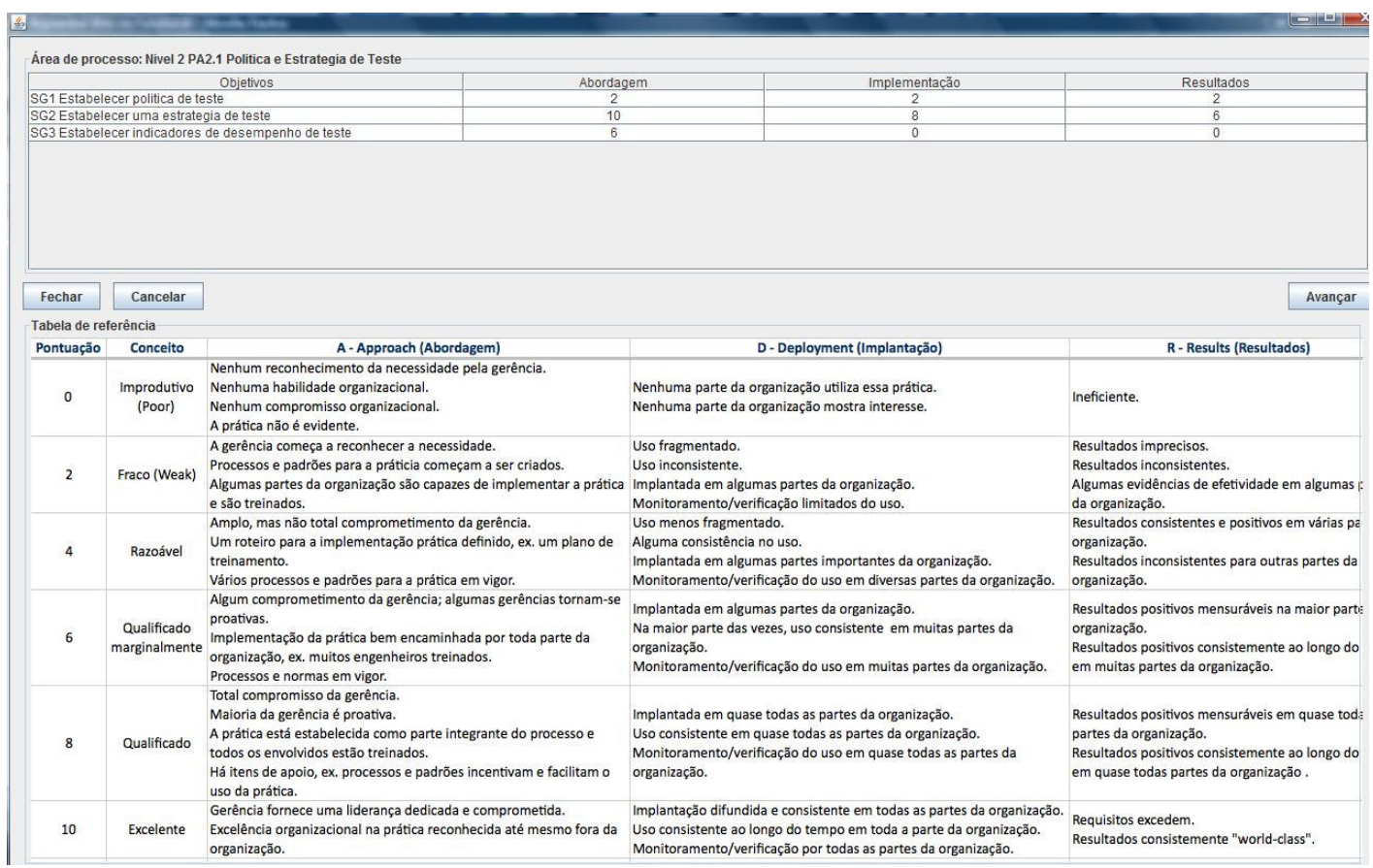

Figura 5.15: Avaliação por Objetivo

Na Figura 5.16 é apresentada a tela para a avaliação por meio das práticas. Essa avaliação é baseada no método de avaliação $\mathrm{SCAMPI}^{28}$. O usuário deve escolher uma área de processo nas abas da parte superior da tela e, uma vez escolhida, os objetivos dessa área de processo são mostrados, um a um, com suas práticas. Para mudar de objetivo, o usuário deve clicar em Avançar e para mudar a área de processo, basta escolher outra aba.

${ }^{28}$ Standard CMMI Appraisal Method for Process Improvement (SCAMPI) http://www.sei.cmu.edu/library/abstracts/reports/01hb001.cfm 


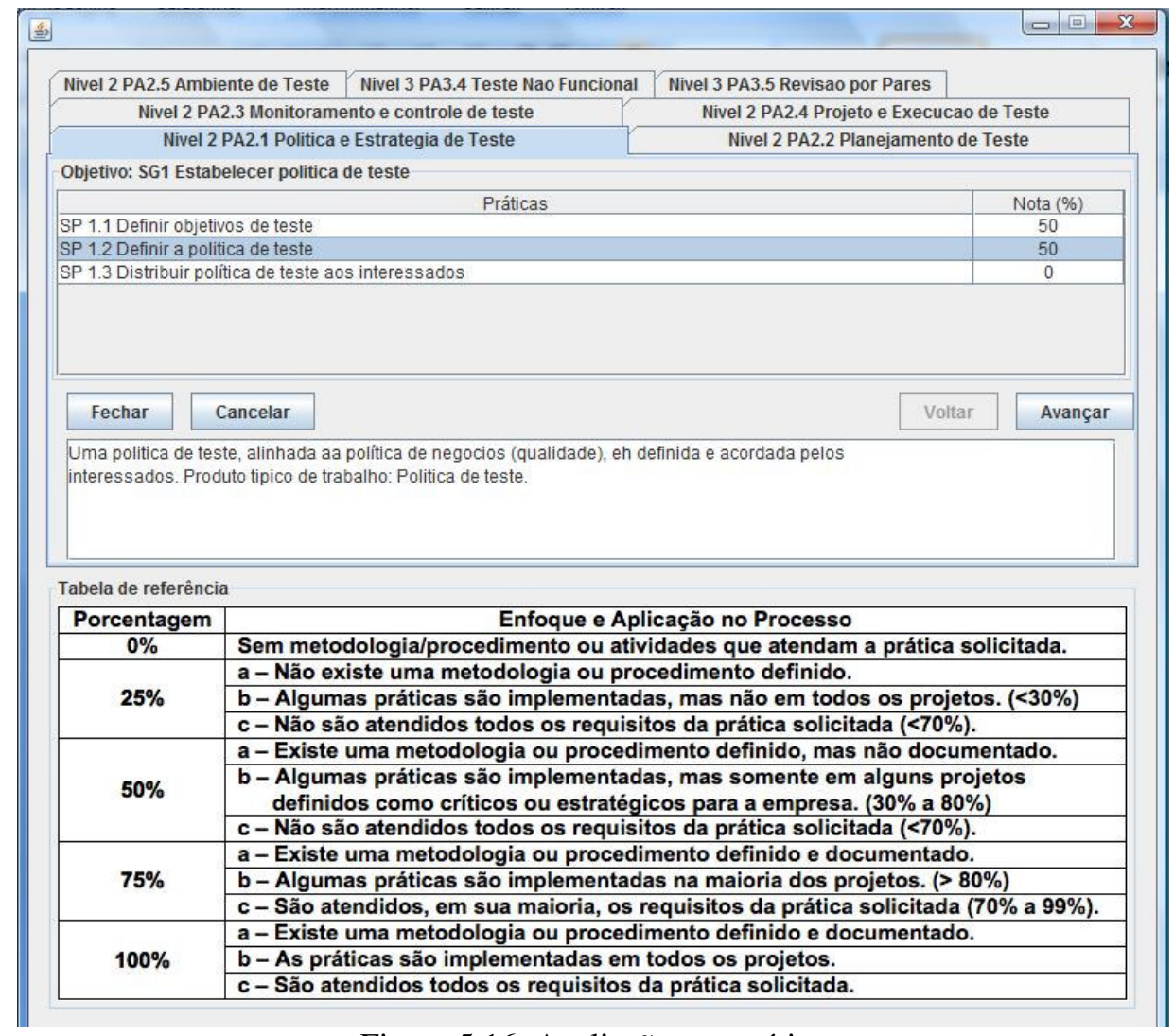

Figura 5.16: Avaliação por prática

O usuário deve atribuir notas às práticas baseando-se na tabela de referência, exibida na parte inferior da tela. As notas consistem de cinco valores percentuais (de 0\% a $100 \%$ ), os quais representam o quanto da prática já foi implantada no processo que está sendo avaliado e em que extensão dos projetos da organização. Para auxiliar o usuário durante a definição das notas, um texto descritivo da prática é apresentado, em um quadro acima da tabela de referência, assim que o usuário clica em uma prática.

\section{- Visualização dos resultados}

Os resultados do diagnóstico do processo vigente são visualizados de acordo com o tipo de avaliação realizada. Em seguida são apresentados exemplos dos resultados, de acordo com as opções de avaliação possíveis.

a) Resultado do diagnóstico por objetivo

Os resultados da avaliação por objetivo são apresentados em uma tabela, conforme exemplificado na Figura 5.17. As cores classificam as notas quanto ao grau de satisfação do objetivo e da área de processo. Se a nota for menor que cinco para um determinado item, a respectiva linha na tabela é destacada em vermelho; se estiver em 
um intervalo entre 5 (cinco) e 7.5 (sete e meio), o item é destacado em amarelo; por fim, se a nota for maior que 7,5 (sete e meio), o item é destacado em verde. O mesmo vale para a nota da área de processo, que é calculada pela média das notas dos seus objetivos.

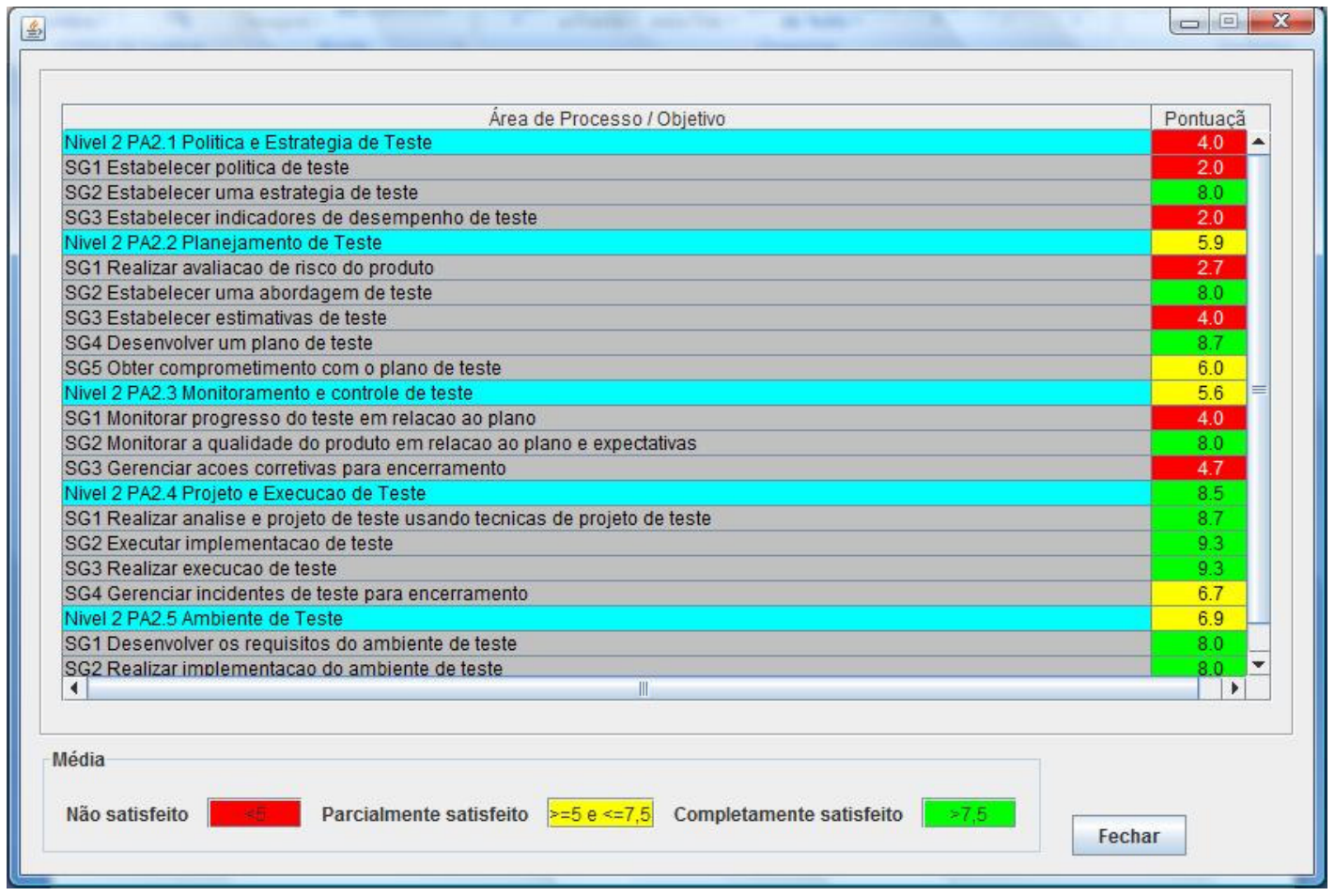

Figura 5.17: Tela de visualização de resultados da avaliação por objetivos

Os resultados também podem ser visualizados no formato de gráfico radar, como apresentado na Figura 5.18. Esse gráfico representa a situação de cada uma das práticas envolvidas no objetivo em questão e permite uma compreensão da situação de cada prática em relação às demais. $\mathrm{O}$ gráfico radar sempre mostra as duas últimas avaliações realizadas, caso haja, para que possa ser observado o progresso do processo de teste do usuário. Exemplo disso será apresentado adiante. 


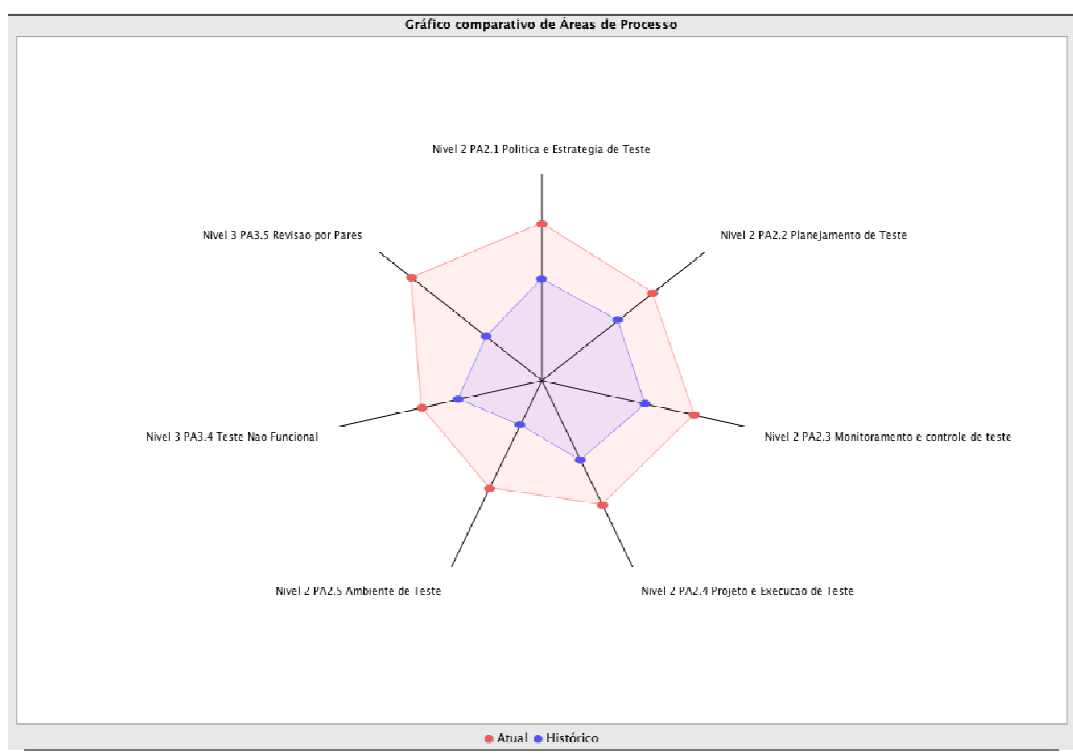

Figura 5.18: Gráfico radar (Spider Web) para visualização, por área de processo, do resultado da avaliação por objetivo

O gráfico radar da Figura 5.19 é similar ao da Figura 5.18 e apresenta a visualização do diagnóstico realizado com base nos objetivos de uma área de processo. $\mathrm{O}$ exemplo mostrado nessa figura refere-se à área de processo Planejamento de Teste. $\mathrm{O}$ usuário escolhe qual área de processo será visualizada. Da mesma forma que o gráfico da Figura 5.18, nesse gráfico podem ser visualizadas as duas últimas avaliações realizadas.

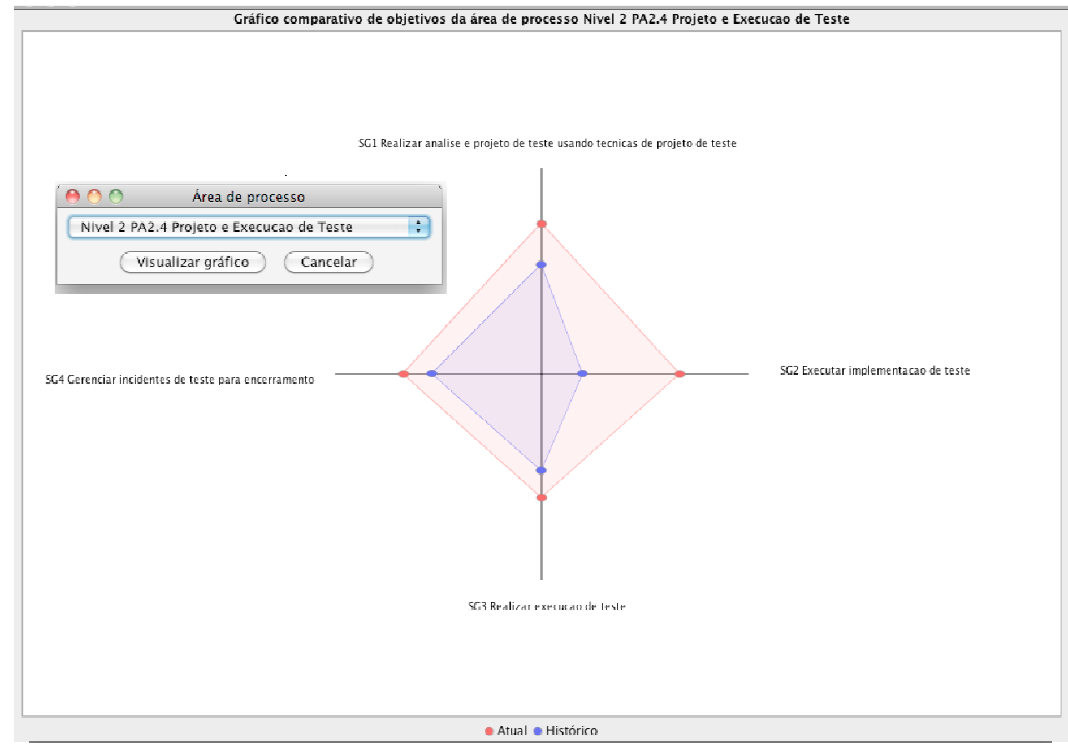

Figura 5.19: Gráfico radar para visualização do resultado da avaliação por objetivo 


\section{b) Resultado do diagnóstico por prática}

De forma similar ao diagnóstico por objetivo, os resultados do diagnóstico por prática são apresentados na tela da Figura 5.20. Nesse caso, as cores estão associadas às notas quanto ao grau de satisfação da prática, do objetivo e da área de processo. Se a nota for menor que 50\%, será destacada em vermelho e é considerada como "não satisfeita"; se estiver em um intervalo entre $50 \%$ e $75 \%$, será destacada em amarelo e significa "parcialmente satisfeita"; e se a nota for maior que $75 \%$, será verde e considerada como "completamente satisfeita". O mesmo vale para a nota do objetivo, que é a média das notas das práticas, e vale também para a área de processo, cuja nota é a média das notas dos seus objetivos.

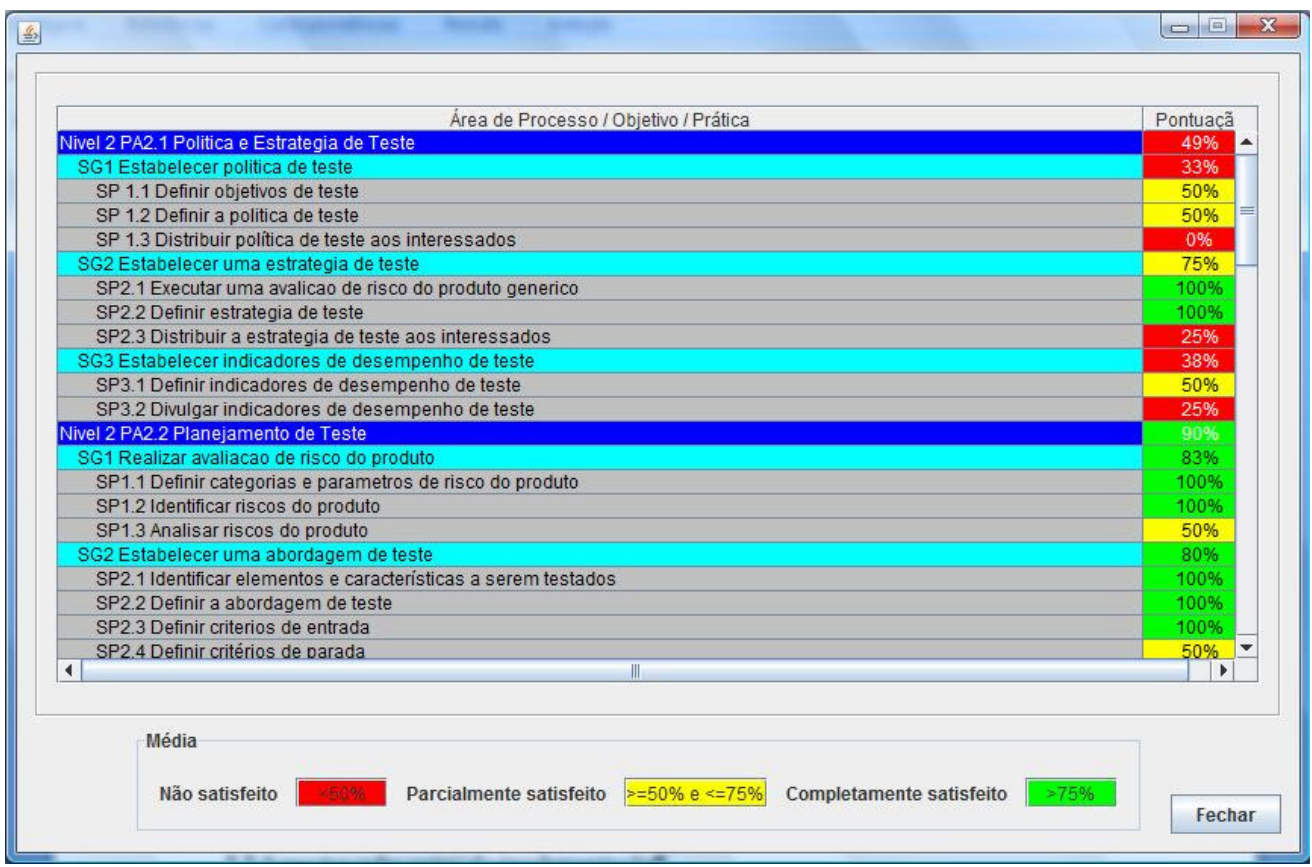

Figura 5.20: Tela de visualização de resultados da avaliação por objetivos

Os resultados do diagnóstico por prática, em gráficos do tipo radar, estão exemplificados na Figura 5.21, que mostra o resultado para cada uma das áreas de processo, e na Figura 5.22, que mostra o resultado por objetivos de uma mesma área de processo. 


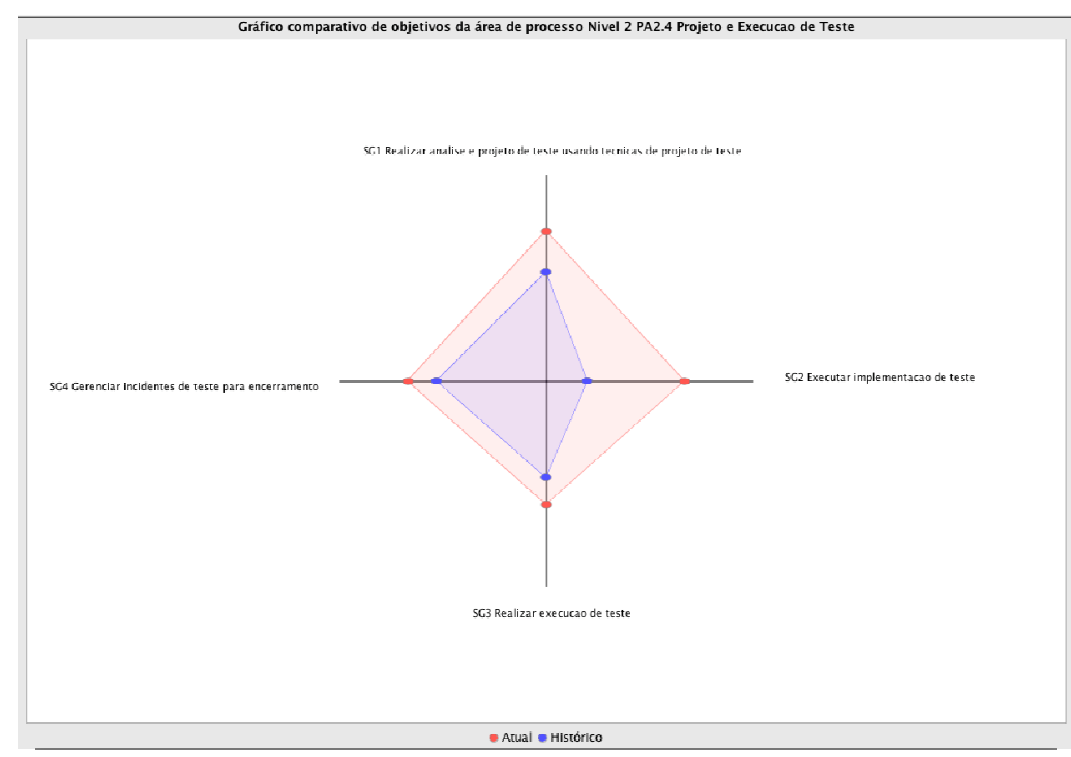

Figura 5.21: Gráfico radar para visualização, por área de processo, do resultado da avaliação por prática

Destacam-se na Figura 5.22 os dois diagnósticos conduzidos para a área de processo Política e Estratégia de Teste. Os pontos azuis representam um diagnóstico histórico e os pontos vermelhos representam o último diagnóstico. Se um novo diagnóstico for conduzido, o que está em rosa na Figura 5.22 passará a ser o histórico, ficando em azul, e os valores do diagnóstico mais novo serão apresentados em rosa. Sempre as duas últimas avaliações são apresentadas.

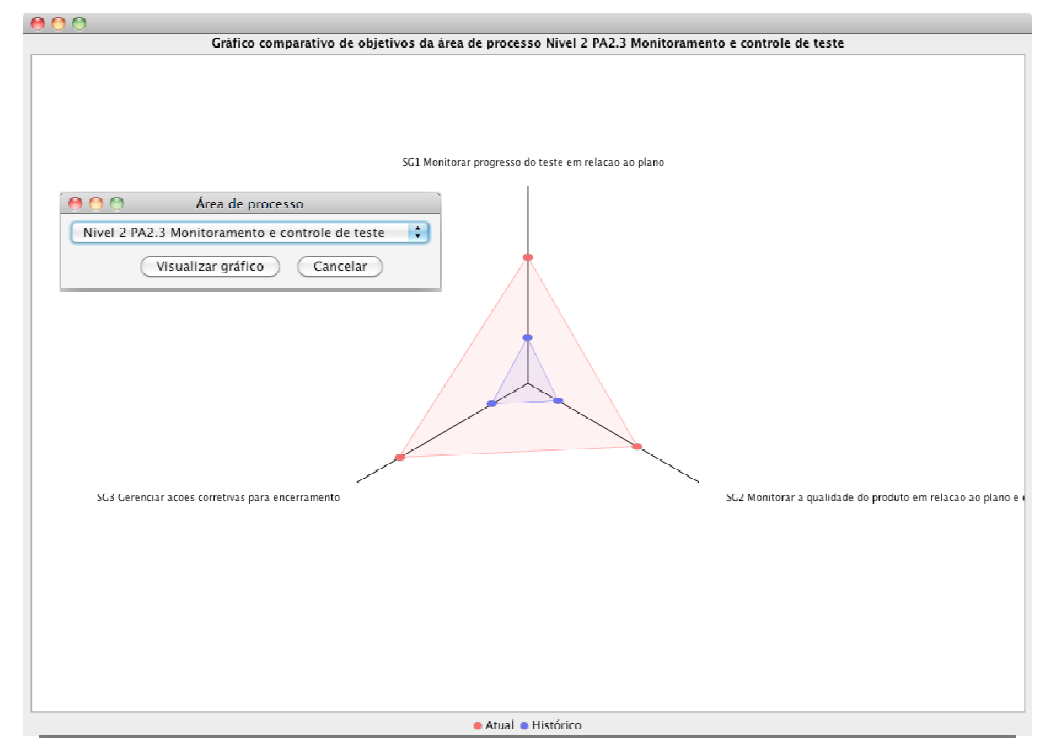

Figura 5.22: Gráfico radar para visualização, por objetivo, do resultado da avaliação por objetivo

Outra opção de visualização dos resultados é o gráfico tipo pilha, como exemplificado na Figura 5.23. Esse gráfico apresenta todas as áreas de processo que 
estão avaliadas, destacando em azul o percentual que foi atendido em relação ao TMMi, e em vermelho o percentual ainda não atendido.

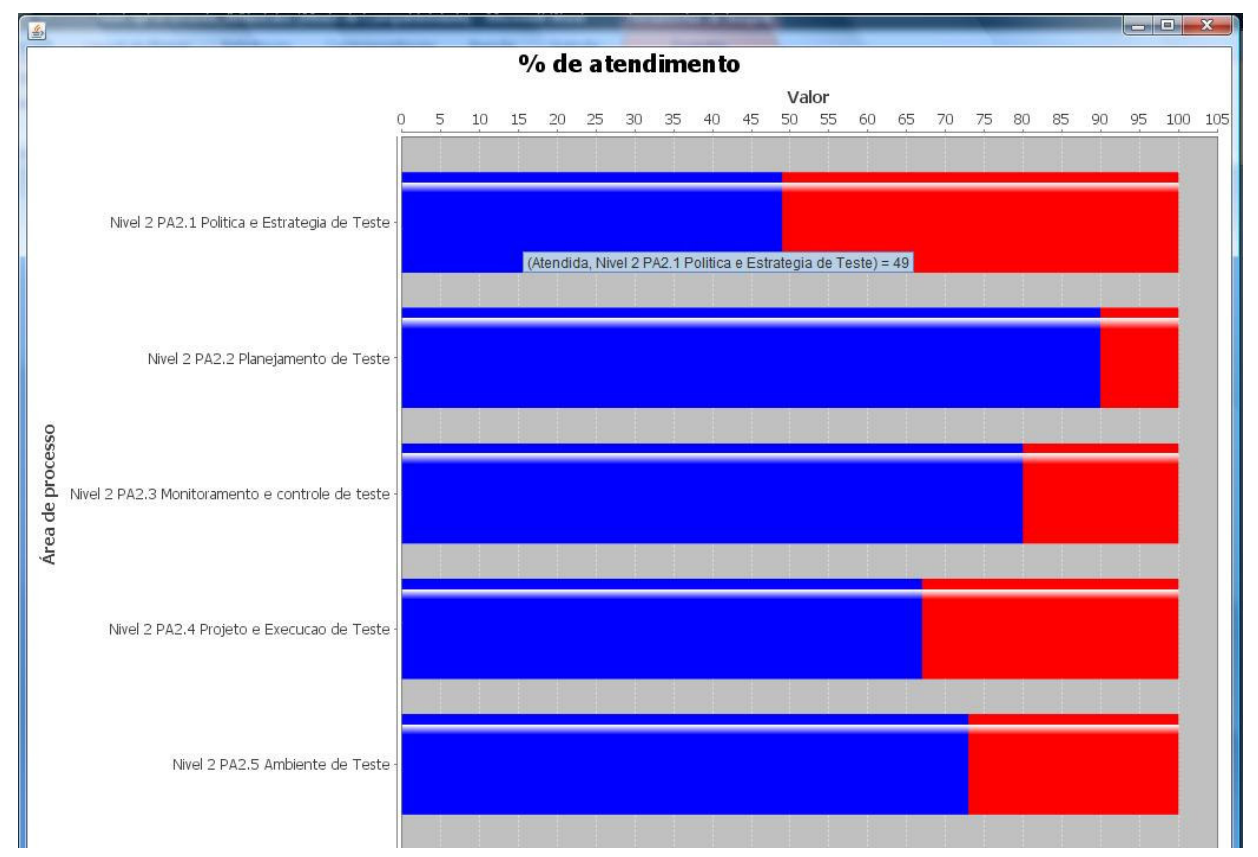

Figura 5.23: Gráfico pilha (Stacked) para visualização das áreas de processo

\section{- Definição de diretrizes de melhoria do processo de teste diagnosticado}

As diretrizes de melhoria também correspondem a uma contribuição do arcabouço KITest, pois auxiliam na indicação de atividades para a melhoria do processo de teste que foi diagnosticado. Isso é feito por meio da opção Diretrizes para Próximas Atividades. O usuário pode escolher se deseja que as atividades sejam indicadas priorizando as áreas de processo em que existem menos atividades cumpridas no processo diagnosticado, ou se prefere trabalhar primeiro nas áreas de processo que estão melhor contempladas para que elas sejam concluídas mais rapidamente. O usuário pode ainda aplicar um filtro por área de processo, caso tenha interesse em atividades específicas do processo de teste. Essas três alternativas são descritas a seguir:

a) Evoluindo da área de processo menos completa para a mais completa.

Na Figura 5.24 é mostrada tela após ter sido escolhida a opção Iniciar com área de processo menos completa, ou seja, trabalhar primeiro com as áreas de processo que têm menos práticas implantadas. Os algoritmos que determinam as diretrizes das próximas atividades, apresentados na Seção 5.5.3, utilizam os resultados dos diagnósticos, apresentados nesta seção, e a matriz de dependência, descrita na Seção 5.5.4. Com base 
neles, as próximas práticas a serem implantadas no processo que foi diagnosticado são definidas.

$\mathrm{Na}$ árvore apresentada nessa tela (Figura 5.24), as práticas estão apresentadas na sequiência sugerida para as atividades de melhoria. Para cada atividade selecionada na árvore da parte esquerda (prática, objetivo ou área de processo) são informadas: informações adicionais (texto descritivo), nota da avaliação por objetivo (menos das práticas) e nota da avaliação por prática. Além disso, também é mostrada uma tabela das dependências de alinhamento, ou seja, quais práticas, daquelas apresentadas, possuem dependência de alinhamento com outra prática. Se o usuário selecionar uma linha na tabela de Dependências de Alinhamento, as duas práticas dependentes serão destacadas em vermelho na árvore da esquerda da tela.

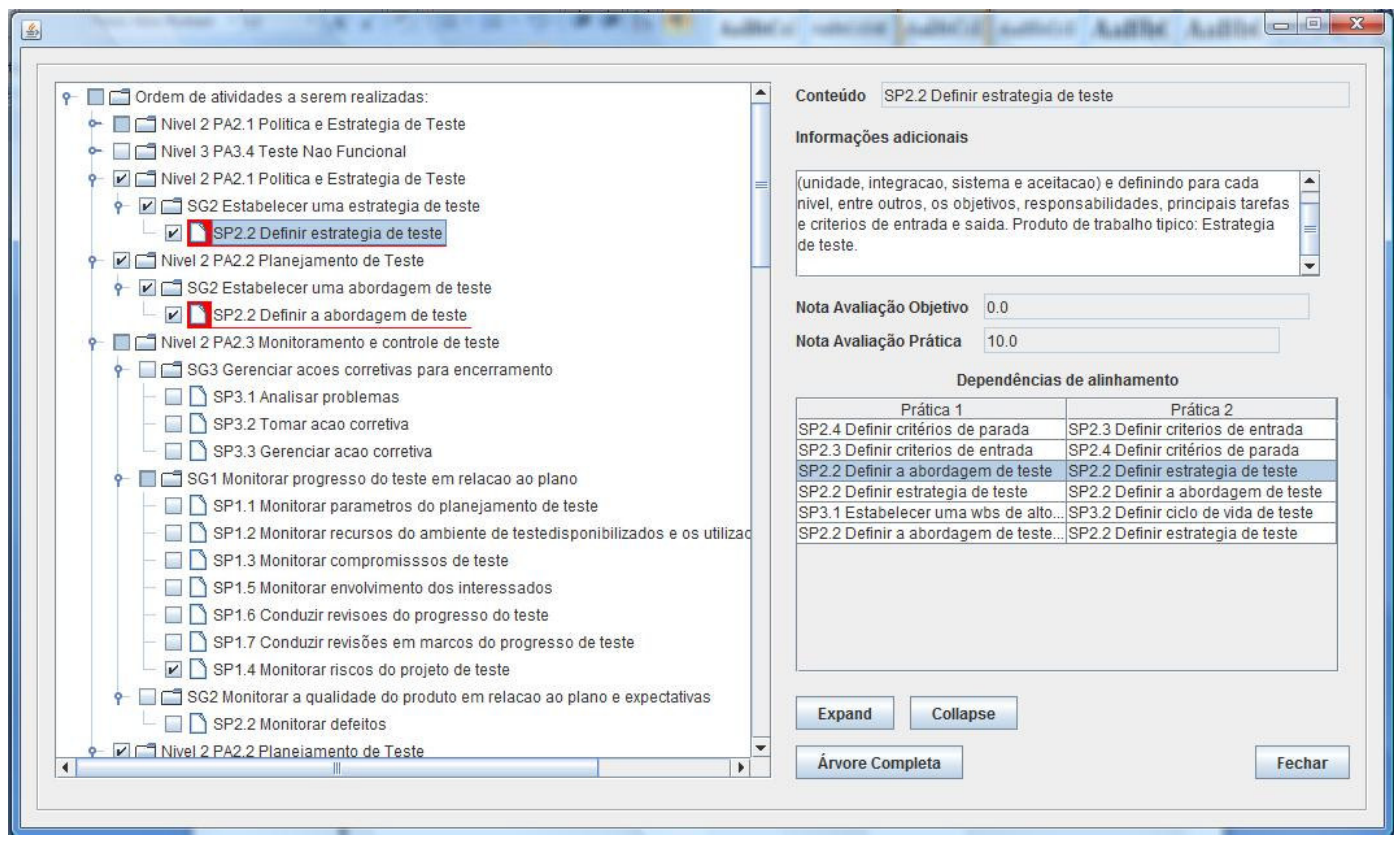

Figura 5.24: Diretrizes para próximas atividades: área de processo menos completa para a mais completa

b) Evoluindo da área de processo mais completa para a menos completa.

O usuário também pode optar por implementar primeiro as atividades das áreas de processo que foram avaliadas com notas maiores e depois evoluir para as que têm menos práticas implementadas. Para isso, o usuário deve optar por Próximas atividades - Iniciar com área de processo mais completa. O resultado, apresentado na Figura 5.25, será uma tela semelhante à figura anterior. 


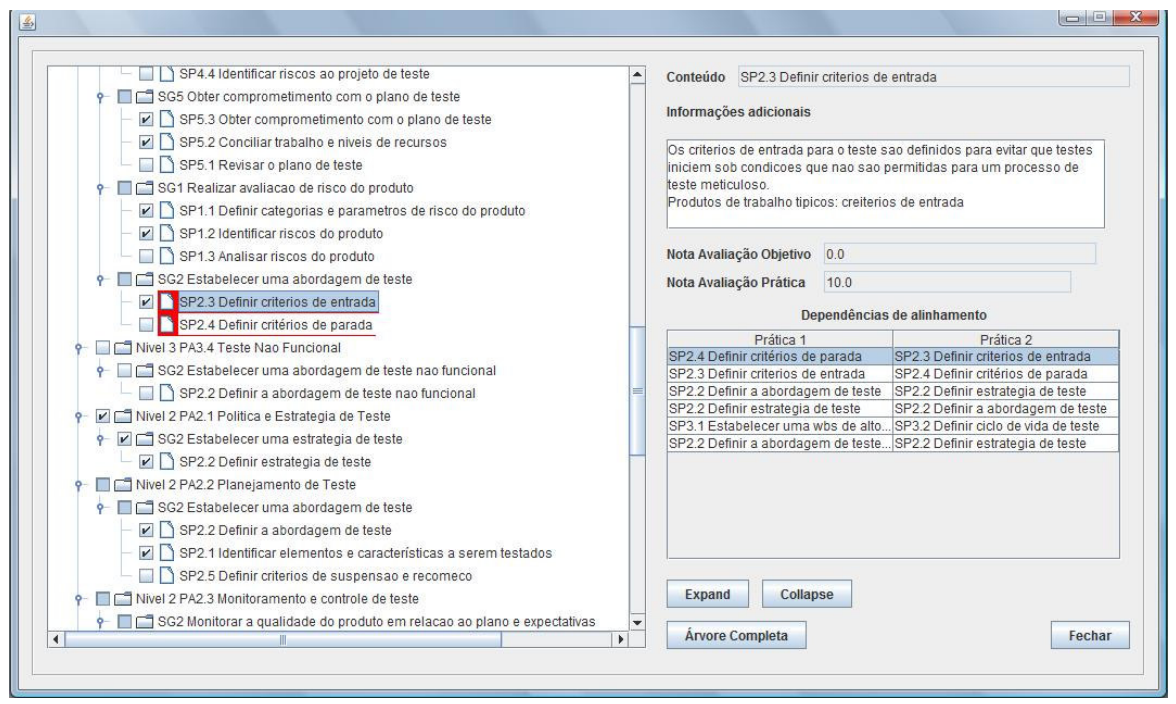

Figura 5.25: Diretrizes para próximas atividades: área de processo mais completa para a menos completa

c) Evoluindo áreas de processos específicas

Caso o usuário necessite diretrizes para implementar atividades relacionadas a uma área de processo específica, ele pode utilizar a opção para próximas atividades com filtro. $\mathrm{Na}$ Figura 5.26 é apresentada a tela na qual o usuário seleciona uma ou mais áreas de processo que deseja trabalhar, além de selecionar que tipo de diretrizes ele prefere, ou seja, iniciar pelas áreas que possuem mais atividades iniciadas (área de processo mais completa para menos completa) ou iniciar com atividades que ainda não foram iniciadas (área de processo menos completa para mais completa).

Após a aplicação do filtro, ou seja, após serem selecionadas as áreas de processo, a ferramenta utiliza o algoritmo de diretrizes das atividades escolhido pelo usuário (área de processo mais completa ou área de processo menos completa), e utiliza a matriz de dependências entre as práticas. Devido às dependências, é possível que apareçam práticas de outras áreas de processo, que não foram escolhidas pelo usuário, dentre a lista das novas atividades sugeridas. Isso ocorre porque para que algumas práticas das áreas de processo escolhidas sejam implantadas, é necessário que outras práticas sejam implantadas antes. 


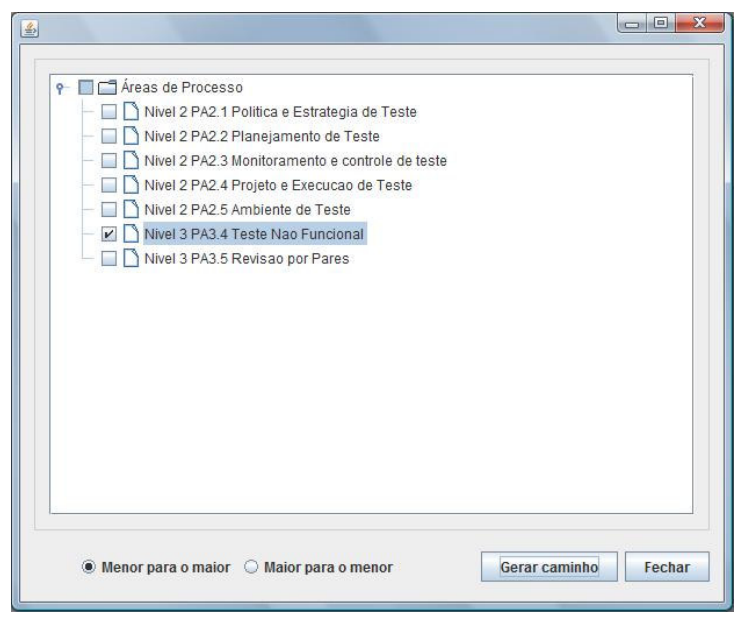

Figura 5.26: Filtro para seleção de áreas de processo

Na Figura 5.27 é apresentada a tela onde as novas diretrizes são apresentadas após a aplicação do filtro. Fora o filtro aplicado, tanto a tela quanto os algoritmos de diretrizes das novas atividades são os mesmos aplicados nas opções apresentadas anteriormente. Destaca-se na Figura 5.27 que algumas atividades apresentadas na árvore estão marcadas. Essa característica também pode ocorrer nas outras opções e significa que aquelas atividades já estão completas, ou seja, receberam nota maior que 7,5 na avaliação por objetivo (com exceção das práticas, pois essa avaliação não é detalhada a esse nível) ou nota maior que $75 \%$, na avaliação por práticas.

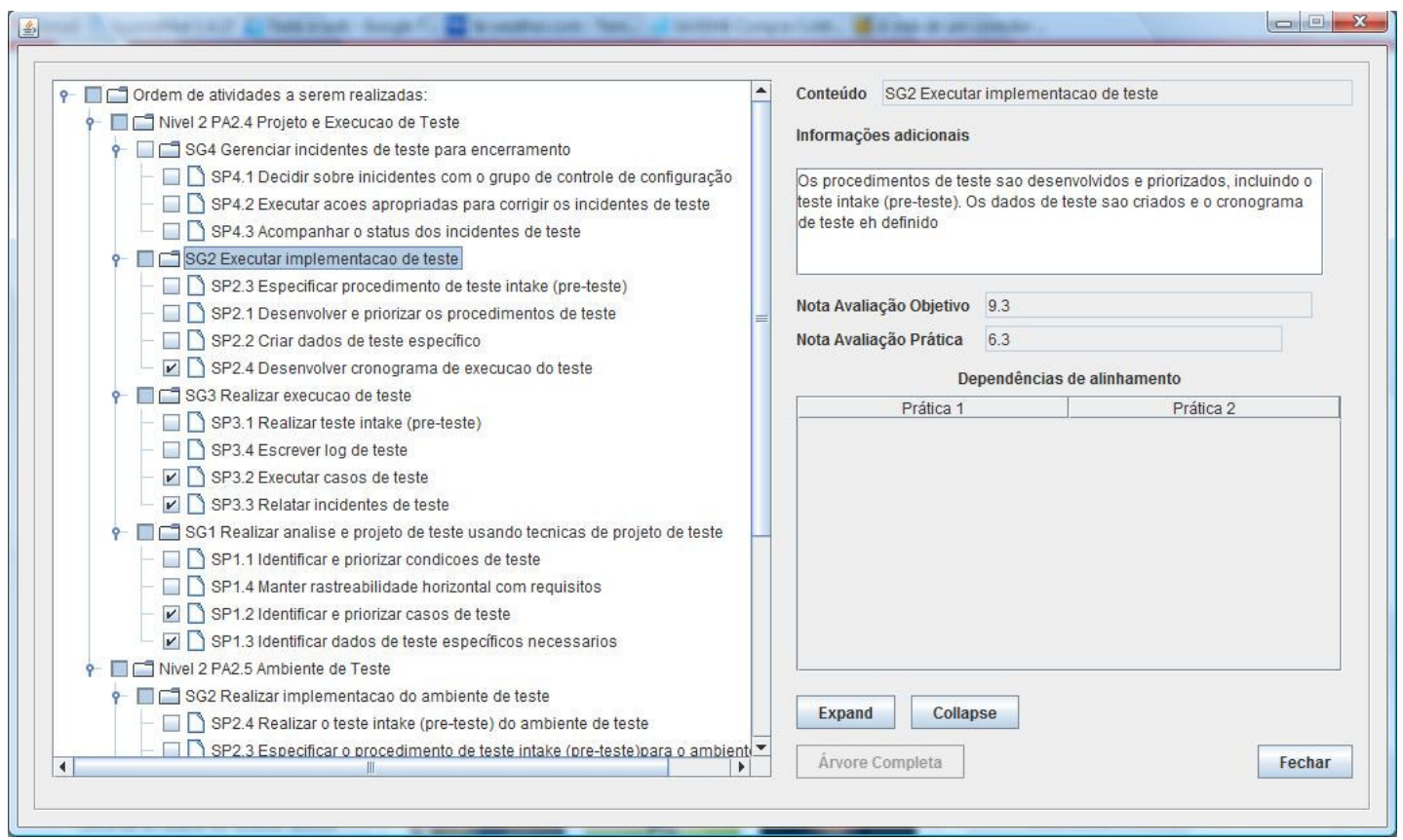

Figura 5.27: Filtro aplicado para áreas de processo escolhidas 


\subsection{Considerações finais}

Neste capítulo foram apresentados a definição, a modelagem, os aspectos de implementação e os aspectos operacionais da KITTool. Essa ferramenta representa o mecanismo que viabiliza a interação da comunidade com as informações da base de conhecimento KITMap, possibilitando aplicar o conhecimento na definição de processos de teste com qualidade, pois segue as melhores práticas contidas no TMMi.

Os três objetivos principais do arcabouço KITest, apresentados no Capítulo 1, foram atendidos com: a representação da base de conhecimento em um mapa mental KITMap, a definição e construção do mecanismo de interação da comunidade com o conhecimento da base, KITTool, apresentado neste capítulo, e a adaptação da estratégia ColabSPI (Malheiros, 2010) para a gestão da evolução da base de conhecimento.

No próximo capítulo apresentaremos as conclusões deste trabalho, as limitações encontradas e trabalhos futuros identificados. 


\section{Capítulo 6 - Conclusões e trabalhos futuros}

\subsection{0 trabalho realizado e suas contribuições}

Considerando-se a hipótese que norteou a condução deste trabalho, desenvolveu-se o arcabouço KITest - Knowledge and Improvement on Test, que estará disponível para uso de toda comunidade.

Esse arcabouço contempla os objetivos de disponibilizar uma base de conhecimento em teste, um mecanismo de utilização dessa base para diagnóstico, definição e melhoria de processos de teste, e uma estratégia de gestão do próprio arcabouço, que trata da atualização da base de conhecimento em teste e de seu mecanismo de utilização pela realimentação da própria comunidade usuária desse arcabouço.

Como mencionado no Capítulo 1, as iniciativas de agregação e caracterização de informações relativas à atividade de teste estão concentradas em dois estudos [Vegas e Basili, 2005] [Juristo et al, 2004] que coletaram e descreveram os resultados de aplicações de técnicas de teste avaliadas por meio de experimentos. Assim, a originalidade deste trabalho é a definição do próprio arcabouço, composto pelos três módulos mencionados (base de conhecimento, mecanismo de interação e estratégia de gestão), na expectativa de que sua disponibilização para a comunidade propicie a definição de processos de teste com maior qualidade, em decorrência da facilidade de acesso às informações sobre a área de teste.

A base de conhecimento em teste, que está modelada por meio de um mapa mental, estrutura e organiza os conceitos sobre o assunto, além agregar material proveniente da literatura e da própria comunidade, quando esta passar a ter relatos de experiência que enriqueçam o conteúdo do mapa inicialmente definido.

Assim, este trabalho produziu as seguintes contribuições:

(i) Definição do KITMap (Knowledge and Improvement Map) - uma base de conhecimento em teste de software que reune as informações da área de teste, de forma organizada e interligada e de forma que possa facilitar a compreensão e aquisição do conhecimento em teste pelo usuário; 
(ii) Definição da KITTool(Knowledge and Improvement on Test - Tool) - um mecanismo que viabiliza a interação da comunidade com a base de conhecimento e possibilita aplicar essas informações para diagnosticar o processo de teste vigente, visualizar os resultados dessa avaliações e gerar diretrizes de melhoria do processo de teste que ajudem a evoluir o processo com base nas premissas de qualidade do TMMi;

(iii) Definição de uma estratégia de gerenciamento do KITMap e da KITTool - uma adaptação da estratégia ColabSPI, que viabiliza a constante evolução desses dois componentes do arcabouço, a qual se torna necessária em decorrência da colaboração da comunidade, por meio de sugestões provenientes do próprio uso do arcabouço.

(iv) Distribuição das práticas do modelo de maturidade em teste - TMMi nas etapas de um processo de teste genérico, o que contribui para o entendimento de como as práticas devem ser aplicadas nas etapas de um processo de teste.

(v) Elaboração de uma matriz de dependência entre as práticas do modelo TMMi, o que contribui para o entendimento de como as práticas estão relacionadas e, consequentemente, qual a ligação entre as áreas de processo desse modelo.

(vi) Definição de algoritmos de melhoria do processo de teste baseados no diagnóstico de um processo de teste, os quais fornecem diretrizes para evolução de um processo de teste em uso (o processo que foi diagnosticado), com base nas premissas de qualidade do modelo TMMi.

(vii)Adaptação da estratégia de melhoria de processo ColabSPI, no que diz respeito à arquitetura de infra-estutura para melhoria de processos. Essa adaptação foi realizada com foco no processo de evolução do próprio arcabouço KITest, mas pode ser utilizada para evolução do processo de teste daqueles que estiverem fazendo uso do arcabouço.

Ressalta-se que o arcabouço proposto pode ser instanciado para outras áreas de conhecimento, desde que mantida a analogia com este contexto, ou seja, esse arcabouço poderia ser facilmente instanciado para apoiar a definição de processos de desenvolvimento com base no modelo CMMi ou MPS-Br

\subsection{Limitações e Trabalhos Futuros}

Devido a restrições de tempo de execução deste trabalho, ainda não se obtiveram evidências sobre a eficácia do arcabouço. No relatório técnico que descreve uma avaliação parcial deste trabalho, são apresentados um exemplo de utilização do KITest 
em uma empresa hipotética e um outro estudo aplicado em uma empresa real que está em processo de certificação MPS-Br, Nível E. Certamente ainda serão necessários outros estudos mais detalhados, com utilização do arcabouço em outras empresas e até grupos de empresas. A realimentação por parte dos usuários do mercado permitirá ajustar e evoluir todos os componentes do arcabouço.

Também deve ser considerado o uso do KITest na academia, na área de engenharia de software, com o objetivo de avaliar a transferência de conhecimento com a utilização do KITMap e da KITTool. Surveys também devem ser conduzidos para obter realimentação dos usuários.

A ferramenta KITTool possui algumas limitações que necessitam ser resolvidas para aumentar sua usabilidade e suas funcionalidades. As seguintes limitações são identificadas:

(a) A KITTool ainda não oferece suporte a diferentes perfis de usuários. Essa característica deve ser implementada para permitir que algumas atividades, próprias do gestor do arcabouço, não estejam disponíveis para um usuário comum. Além disso, essa distinção é importante, pois determinadas atividades dependem do nível de conhecimento em teste, por exemplo, a definição de dependência entre as práticas do modelo de qualidade.

(b) A visualização gráfica do processo de teste na KITTool é disponibilizada atualmente por meio de uma árvore de diretórios, mas a intenção é que essa representação seja similar ao mapa mental do Mindomo.

(c) Os algoritmos para a geração das diretrizes de melhoria do processo de teste vigente foram desenvolvidos especificamente para este contexto e não utilizam, por exemplo, conceitos de inteligência artificial. $O$ uso desses conceitos deve ser investigado com o objetivo de se definirem algoritmos que aprendam juntamente com a evolução do arcabouço e com a realimentação dos usuários. 


\section{Referências Bibliográficas}

Agarwal, B. B; Tayal, S. P. and Gutpa, M. Software engineering and Testing. Jones \& Bartlett Publishers. 2009.

Basili, V. Quantitative Evaluation of Software Methodology. Technical report TR-1519, University of Maryland, 1985.

Biffl, S.; Halling, M. A knowledge management framework to support software inspection planning. Springer-Verlag Berlin Heidelbreg, 2003.

Black, Rex. Critical Testing Process: plan, prepare, perform, perfect. AddisonWesley.2007.

Brinkmann, A. Graphical knowledge display - Mind mapping and concept mapping as efficient tools in mathematics education. Mathematics Education Review, n. 16, p. 3548, 2003.

Burnstein, Ilene. Practical software testing: a process-approach. Springer-Verlag New York. 2002.

Bursntein , Ilene . Practical Software testing - A measurement program to support product and process quality. Ed. Springer. 2003.

Buzan T. e Buzan B., The Mind Map Book, BBC Books, London, 1997

Crespo, A. N.; Jino, M.; Argollo, M.; Bueno, P. M. S. e Barros, C. P. Modelo de Processo Genérico de Teste de Software. Portal do software público brasileiro 5CQualiBr, Dez.2010. Disponível em: http://www.softwarepublico.gov.br/5cqualibr/ xowiki/ Teste-item13.

Cysne, F. P. Transferência de Tecnologia e Desenvolvimento. Revista Ciência da Informação, v. 25, n. 1, 1995.

Davenport, T.; Prusak, L. Conhecimento empresarial: como as organizações gerenciam o seu capital intelectual. Métodos e aplicações práticas. Campus, 1998.

Devinney, T. M. Knowledge, tacit understanding and strategy. In: Twite and O'Keefe, New Directions in Corporate Strategy, Allen \& Unwin, 1999.) Working paper 97-002. October AGSM, UNSW, Sidney, Australia.

Diba, T.; Dingsoyr, T.; Moe, N. B. Proces Improvement in Practice. A handbook for IT Companies. Kluwer Academic Publishers, 2004.

Dumont, Danilo M.; Ribeiro, José A. e Rodrigues, Luiz A. Inteligência pública na era do conhecimento. Ed. Revan. 2006. 
Farrand, P.; Hussain, F.; Hennessy, E. The efficacy of the 'mind map' study technique. Medical Education, n. 36, p. 426\{431, 2002.

Hass, Anne M. J. Testing process. Proceedings of IEEE International Conference on Software Testing Verification and Validation Workshop (ICSTW'08). 2008.

Hernandes, Elis Cristina Montoro. Um processo automatizado para tratamento de dados e conceitualização de ontologias com apoio de visualização. Dissertação de Mestrado. Universidade Federal de São Carlos. 2009.

Höhn, E. N. Técnicas de leitura de especificação de requisitos de software: estudos empíricos e gerência de conhecimento em ambientes acadêmico e industrial. Dissertação de Mestrado, ICMC-USP, São Carlos, SP, 2003.

Jalote, P. An integration approach to software engineering. 3 ed. Springer Science, 2005.

Johnson, Brian e Shneiderman, Ben. Tree-maps: a space-filling approach to the visualization of hierarchical information structures. In proceedings of Conference on Visualization - VIS, 2. San Diego. 1991. IEEE Computer Society, p. 284-291. 1991.

Juristo, Natalia; Moreno, Ana M. e Viegas, Sira. Reviewing 25 years of testing technique experiments. Empirical Software Engineering Journal, 9, 7-44, 2004. Kluwer Academic Publishers.

Lewis, William E. Software testing and continuous quality improvement. 2 ed. Auerbach Publications. 2004.

Liebowitz, Jay e Wilcox, Lyle C. Knowledge management and its integrative elements. CRC Press, 1997.

Linkman, S.; Rombach, H. D. Experimentation as a Vehicle for Software Technology Transfer - A Family of Software Reading Techniques. Information and Software Technology, v. 39, p. 777-780, 1997.

Malheiros, Viviane. Uma contribuição para a melhoria colaborativa e distribuída de processos de software. Tese de doutorado. ICMC-USP. 2010.

Naik, Kshirasagar e Tripathy Priyadarshi. Software testing and quality assurance: theory and practice. Ed. John Wiley.

Nonaka, I.; Takeuchi, H. Criação de conhecimento na empresa. Campus, 376 p. 1997.

Reenskaug, T. Models - Views - Controllers, Technical Note, Xerox PARC, Palo Alto/CA - USA, 1979. Disponível em http://heim.ifi.uio.no/ trygver/1979/mvc-2/197912-MVC.pdf).

Rossatto, Maria Antonieta. Gestão do conhecimento: a busca da humanização, transparência, socialização e valorização do intangível. Ed. Interciência Ltda. 2002. 
Rosemberg, L. Lessons learned in software quality assurance in managing software engineering knowledge. Springer-Verlag Berlin Heidelbreg, 2003.

Royer, Thomas C. Software testing management: life on the critical path. Prentice Hall. 1993.

Sommerville, I. Software engineering. 6 ed. Addison-Wesley, 2007.

Shull, F.; Mendonça, M.; Basili, V. R.; Carver, J.; Maldonado, J. C.; Fabbri, S.; Travassos, G. H.; Ferreira, M. C. Knowledge-sharing issues in experimental software engineering. Empirical Software Engineering: An International Journal, v. 9, n. 1, p. 111-137, 2004.

Tiann, J. Software quality engineering: Testing, quality assurance and quantifiable improvement. Wiley-Interscience, 2005.

TMMi Foundation Test Maturity Model Integration - TMMi Version 2.0. Disponível em http://www.tmmifoundation.org/html/tmmiref.html

Van Veenendaal, Erik e Cannegieter, Jan Jaap. The little TMMi: objective-driven test process improvement. UTN Publishers. TMMi Foundation. 2011

Willis, C. L.; Miertschin, S. L. Mind maps as active learning tools. Journal of Computing Sciences in College-JCSC, v. 21, n. 4, p. 266\{272, 2006. 